\title{
Estudo cinético da hidrólise de betalaínas-modelo
}

\author{
LARISSA CERRATO ESTEVES
}

\author{
Dissertação de Mestrado \\ Programa de Pós-Graduação em Química
}

Versão corrigida da Dissertação defendida

Data do depósito na SPG:

$12 / 02 / 2016$ 
Ficha Catalográfica

Elaborada pela Divisão de Biblioteca e

Documentação do Conjunto das Químicas da USP.

\begin{tabular}{|l} 
E79e \\
Esteves, Larissa Cerrato \\
Estudo cinético da hidrólise de betalaínas-modelo / Larissa \\
Cerrato Esteves. -- São Paulo, 2016. \\
$96 \mathrm{p}$. \\
\\
Dissertação (mestrado) - Instituto de Química da Universidade \\
de São Paulo. Departamento de Química Fundamental. \\
Orientador: Bastos, Erick Leite \\
\\
1. Físico-química orgânica 2. Hidrólise I. T. II. Bastos, Erick \\
Leite, orientador. \\
$\quad 547.13$ \\
CDD
\end{tabular}


LARISSA CERRATO ESTEVES

\title{
Estudo cinético da hidrólise de betalaínas-modelo
}

\author{
Dissertação apresentada ao Instituto de \\ Química da Universidade de São Paulo para \\ obtenção do título de Mestre em Química.
}

Orientador: Prof. Dr. Erick Leite Bastos

São Paulo 



\section{AGRADECIMENTOS}

Erick, pela oportunidade, confiança e por se doar tanto a nós, seus alunos. Pela paciência com as minhas dificuldades e loucuras. Pelo carinho com que sempre me tratou. É um privilégio trabalhar com você!

Vanessa, pela amizade que vai além do que se poderia esperar: um tanto amiga, um tanto irmã, um pouco mãe. Como tantas outras coisas na minha vida, esse trabalho tem muito dela.

Lelaine, por me inspirar com sua força de vontade e suas maluquices. É tanta vida que eu não teria vivido sem ela que não dá nem para começar a escrever. Minha metade otimista, obrigada por tanto!

Carol Rockenbach, Lia, Renata, Ju Carneiro e Amanda, pela amizade que permanece apesar da distância e do tempo.

Colegas do BastosLab e Luiz, pela ajuda e apoio. Esse trabalho não seria possível sem vocês.

Prof. Dr. Cassius V. Stevani, pelas análises no HPLC, e Prof. Dr. Rômulo A. Ando, pelos experimentos no Raman.

Ana Paula, Caroline e Nathana, por deixarem a pós graduação (e a vida!) mais doces, todos os dias. As responsáveis pela minha sanidade, no meio de tanta loucura. Que sorte a minha ter vocês!

Minha família buscapé: tia Lu, madrinha, Luana e Vini. Por tanto amor.

Meus avós, Shirley e Mino, pelo exemplo e pelo apoio.

Nicholas, pelo amor de irmão. 
Meu pai, pelo incentivo, apoio e insistência. E por acreditar mais em mim do que eu mesma.

Minha mãe, por me ensinar sobre as coisas que realmente importam na vida. E por ser a melhor parte de mim. 


\section{RESUMO}

ESTEVES, L. C. Estudo cinético da hidrólise de betalaínas-modelo. 2016. 96 f. Dissertação (Mestrado) - Instituto de Química, Universidade de São Paulo, São Paulo, 2016.

Betanina e indicaxantina foram obtidas e purificadas e a hidrólise térmica de betanina foi investigada em diferentes $\mathrm{pHs,}$, concentrações de tampão, temperaturas e com a adição de sais. Para a decomposição de indicaxantina, foi realizado um estudo em diferentes pHs. Tampões acetato e citrato se mostraram adequados para estudos com betanina, dentro de sua faixa de tamponamento. Os experimentos realizados com tampão fosfato indicaram a ocorrência de catálise geral pelo íon fosfato presente no tampão. $\mathrm{O}$ efeito dos sais sobre a hidrólise de betanina foi investigado em pHs 3 e 6,2, com a adição de sais de sódio, amônio e sais cloretos. $p$-Toluenosulfonato de sódio, cloreto de amônio e cloreto tetrabutilamônio foram os sais que apresentaram maior efeito sobre a constante cinética observada de hidrólise de betanina. A hidrólise das duas betalaínas apresentou um comportamento semelhante com a variação do $\mathrm{pH}$ e o ajuste multiparamétrico dos dados sugere que a catálise básica específica é a principal responsável pela hidrólise de betanina e indicaxantina. Um modelo que sugere a abertura do anel 1,2,3,4-tetrahidropiridínico das betalaínas é proposto para explicar o efeito do pH sobre a constante cinética de decomposição determinada em meio ácido.

Palavras-chave: betalaínas, hidrólise, catálise ácido-base, betanina, indicaxantina. 



\section{ABSTRACT}

ESTEVES, L. C. Kinetic study of the hydrolysis of model betalains. 2016. 96 p.

Dissertation (Master's degree) - Instituto de Química, Universidade de São Paulo, São Paulo, 2016.

Betanin and indicaxanthin were obtained and purified and the thermal hydrolysis of betanin was investigated at different $\mathrm{pH}$, buffer concentration, temperature and in the presence of different salts. For the decomposition of indicaxanthin, a study was conducted at different pHs. Acetate buffer and citrate buffer proved to be suitable for the study of betanin. The experiments carried out with phosphate buffer indicated the occurrence of general base catalysis by phosphate ion present in the buffer. The effect of salts on the betanin hydrolysis was investigated at $\mathrm{pH} 3$ and 6.2 with the addition of sodium salts, ammonium salts and chlorides. Sodium p-toluenesulfonate, ammonium chloride and tetrabutylammonium chloride had the larger effects on the observed rate constant for the hydrolysis of betanin. The variation of $\mathrm{pH}$ resulted in similar hydrolysis profile for both betalains studied and multiparameter fitting of the data suggests that the specific base catalysis is primarily responsible for the hydrolysis of betanin and indicaxanthin. A model that suggests the opening of the 1,2,3,4-tetrahydropyridine ring of betalains is proposed to explain the effect of $\mathrm{pH}$ on the decomposition rate constant under acidic conditions.

Keywords: betalains, hydrolysis, acid-base catalysis, betanin, indicaxanthin . 



\section{LISTA DE ABREVIATURAS E SIGLAS}

$\varepsilon$

Coeficiente de atenuação molar

$\lambda^{\text {máx }}$

Comprimento de onda de máxima absorção no espectro UV-Vis

$\mathrm{Bt}$

Betalaína

DAD

Diode array detector, detector de arranjo de diodos

ESI+

Electrospray ionization, ionização por elétron-spray em modo positivo

${ }^{1} \mathrm{H}-\mathrm{RMN} \quad$ Espectroscopia de ressonância magnética nuclear de hidrogênio

$\mathrm{HBt}$

Ácido betalâmico

HPLC

High performance liquid chromatography, cromatografia líquida de alta eficiência

HPLC-MS Cromatografia líquida de alta eficiência acoplada a espectrometria de massas

$m / z$

Razão massa/carga na espectrometria de massas

TPi

Tampão fosfato 



\section{LISTA DE ESTRUTURAS}

\begin{tabular}{lll}
\hline Sigla Nome & Betanina \\
Bn & Indicaxantina & \\
HBt & Ácido betalâmico
\end{tabular}





\section{SUMÁRIO}

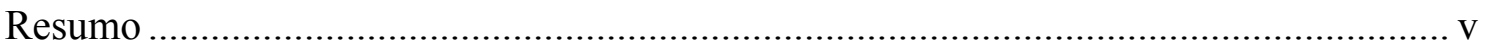

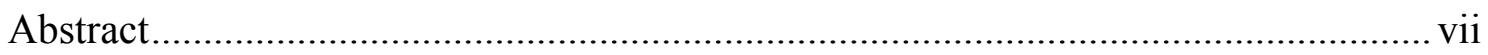

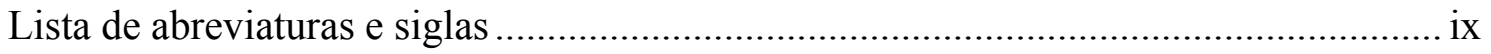

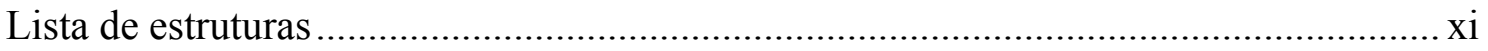

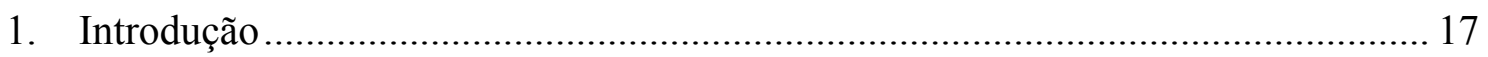

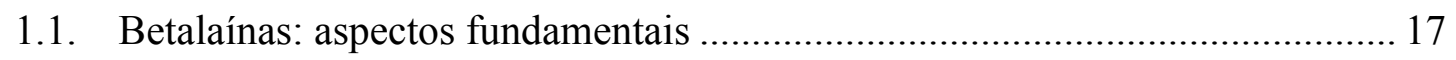

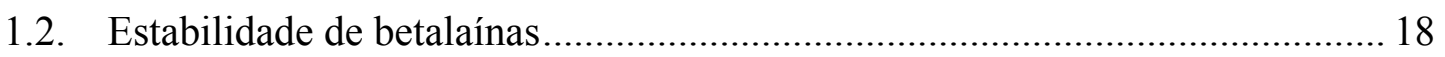

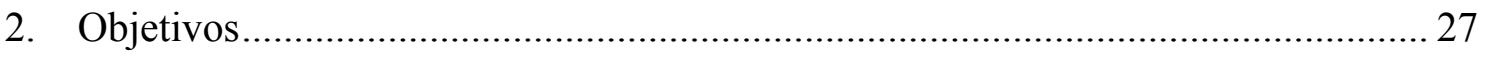

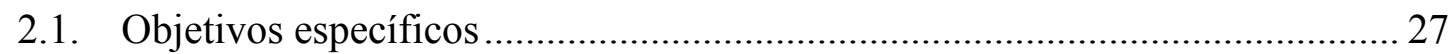

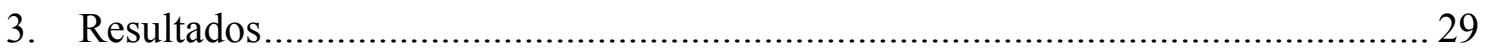

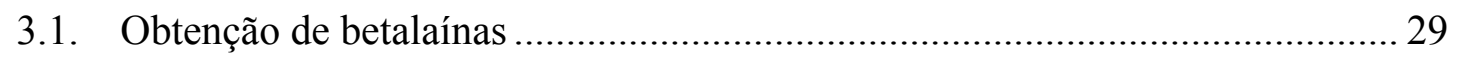

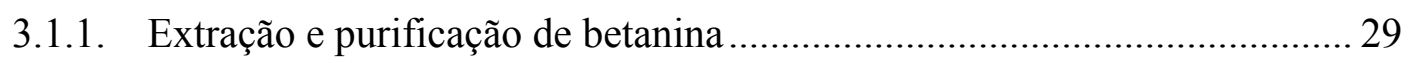

3.1.2. Semissíntese e purificação de indicaxantina …........................................ 30

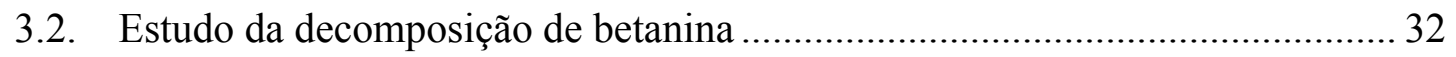

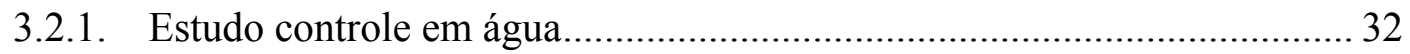

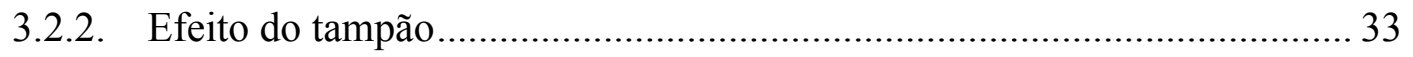

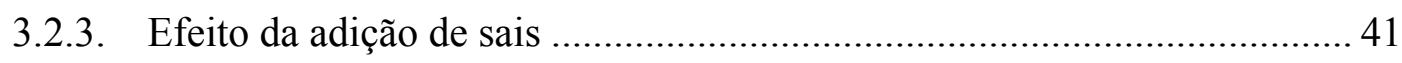

3.3. Efeito do $\mathrm{pH}$ sobre a hidrólise de betanina e indicaxantina ............................ 46

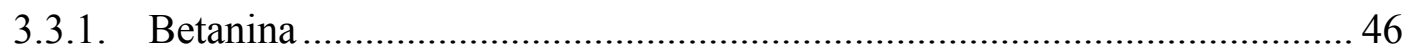

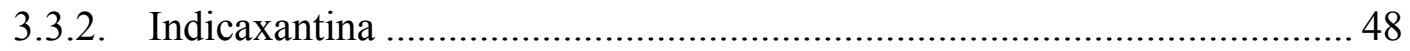

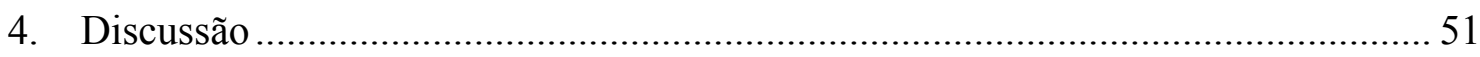

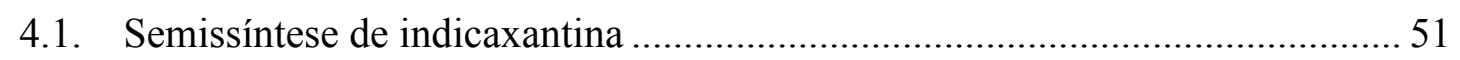

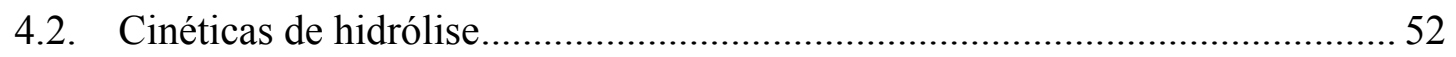




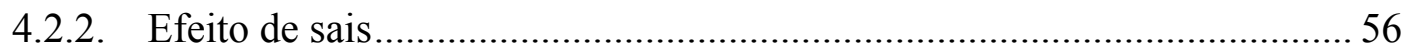

4.2.3. Efeito do $\mathrm{pH}$ sobre a hidrólise de betalaínas ........................................... 59

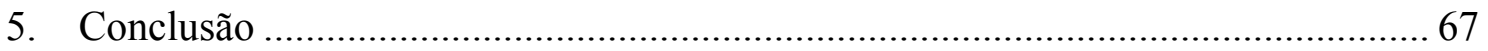

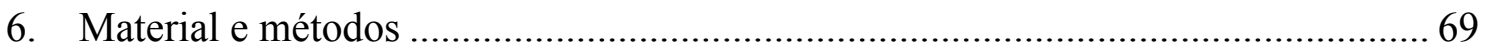

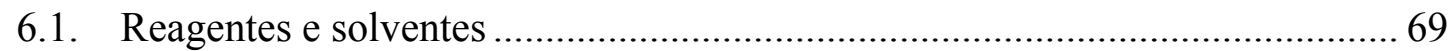

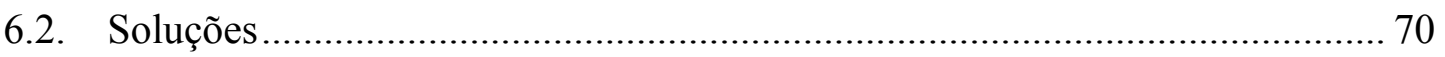

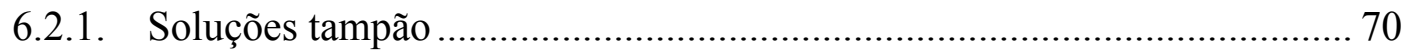

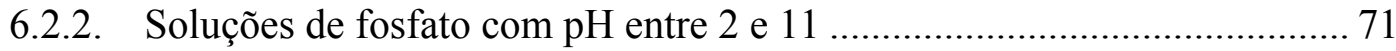

6.2.3. Soluções de sais em meio tamponado ................................................. 71

6.3. Obtenção de betanina a partir de suco de beterraba ........................................ 71

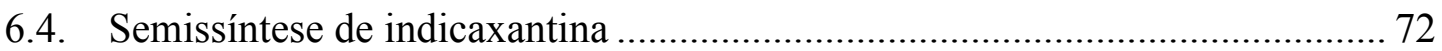

6.4.1. Obtenção de ácido betalâmico em acetato de etila ................................... 72

6.4.2. Semissíntese e purificação de indicaxantina ............................................ 73

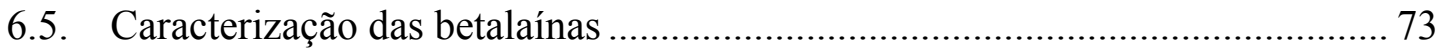

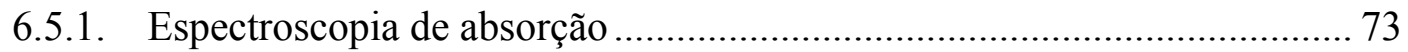

6.5.2. Cromatografia líquida de alta eficiência................................................. 74

6.6. Estudo cinético da decomposição de betalaínas .............................................. 74

6.6.1. Efeito da concentração do tampão............................................................. 74

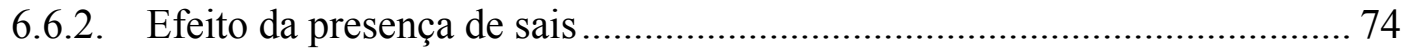

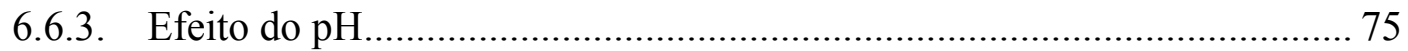

6.7. Determinação das constantes cinéticas observadas $\left(\mathrm{k}_{\mathrm{obs}}\right)$............................. 75

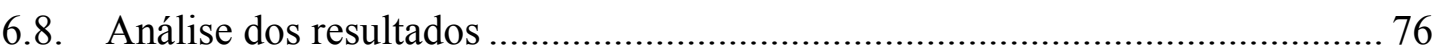

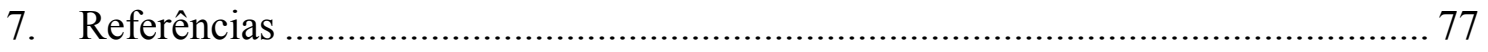


8.1. Curvas cinéticas de hidrólise de Bn nos tampões acetato e citrato ................. 81

8.2. Curvas cinéticas de hidrólise de Bn em tampão fosfato .................................. 83

8.3. Curvas cinéticas de hidrólise de $\mathrm{Bn}$ em tampão fosfato $100 \mathrm{mmol} \mathrm{L}^{-1}$, na

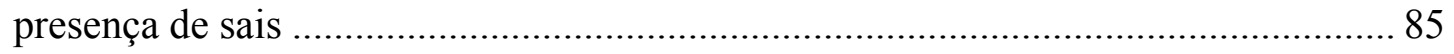

8.4. Curvas cinéticas de hidrólise de Bn em tampão fosfato $10 \mathrm{mmol} \mathrm{L}^{-1}$, em função

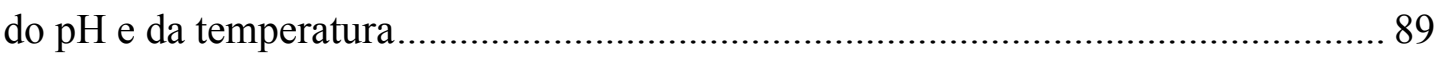

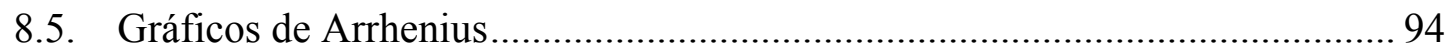

8.6. Curvas cinéticas de hidrólise de BtP em tampão fosfato $10 \mathrm{mmol} \mathrm{L}^{-1}$, em

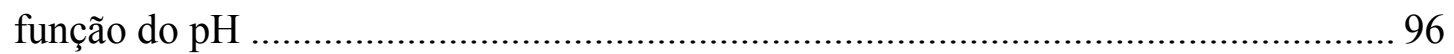





\section{INTRODUÇÃO}

\subsection{Betalaínas: aspectos fundamentais}

Betalaínas são pigmentos vegetais cuja biossíntese envolve o ácido betalâmico (HBt), um aldeído $\alpha, \beta$-insaturado instável e fracamente fluorescente (Esquema 1). ${ }^{1,2}$ Nas células vegetais, betalaínas são formadas por meio de um acoplamento aldimínico espontâneo entre aminoácidos e o ácido betalâmico e armazenadas no vacúolo. ${ }^{3}$

As betalaínas substituem as antocianinas em algumas famílias de plantas da ordem Caryophyllales (e.g., Bougainvillea spp. (primavera) e Beta vulgaris (beterraba) $)^{4}$, e em alguns fungos basidiomicetos dos gêneros Amanita e Hygrophorus, como o ágario-das-moscas (A. muscaria $)^{5}$.

As betalaínas naturais são dividas em duas classes, dependendo do aminoácido da qual se originam, sendo classificadas como betacianinas ou betaxantinas (Esquema 1). As betalaínas que se derivam da ciclo-DOPA pertencem à classe das betacianinas $($ kyaneos $=$ azul $)$, devido à sua intensa coloração violeta. As demais betalaínas são classificadas como betaxantinas (xanthos $=$ amarelo) ${ }^{6}$

Betanina (Bn, betanidina-5-O-glicosídeo), é uma betacianina natural encontrada na beterraba vermelha (Beta vulgaris) que é responsável pela cor característica da planta (Esquema 1). ${ }^{7}$ A betanina tem máximo de absorção $\left(\lambda^{\text {abs }}\right)$ em 536 nm, não é fluorescente e é a única betalaína aprovada para uso como corante em alimentos (código E-162). ${ }^{7}$

A indicaxantina $\left(\right.$ BtP; $\left.\lambda^{\text {abs }}=485 \mathrm{~nm}\right)$ é uma betaxantina derivada da L-prolina (Esquema 1) encontrada em abundância nas frutas da opuntia (Opuntia ssp. $)^{6}$. A BtP também está presente na beterraba e nas variedades amarelas de flores com pétalas fluorescentes, como a maravilha e a onze-horas, ${ }^{8}$ apesar de ser fracamente fluorescente 
(rendimento quântico de fluorescência $\left(\Phi_{\mathrm{Fl}}\right)$ de $4 \times 10^{-3}$ em água) ${ }^{9}$. A fluorescência das flores pode estar relacionada com o processo de polinização, devido aos padrões de contrastes formados. ${ }^{8}$
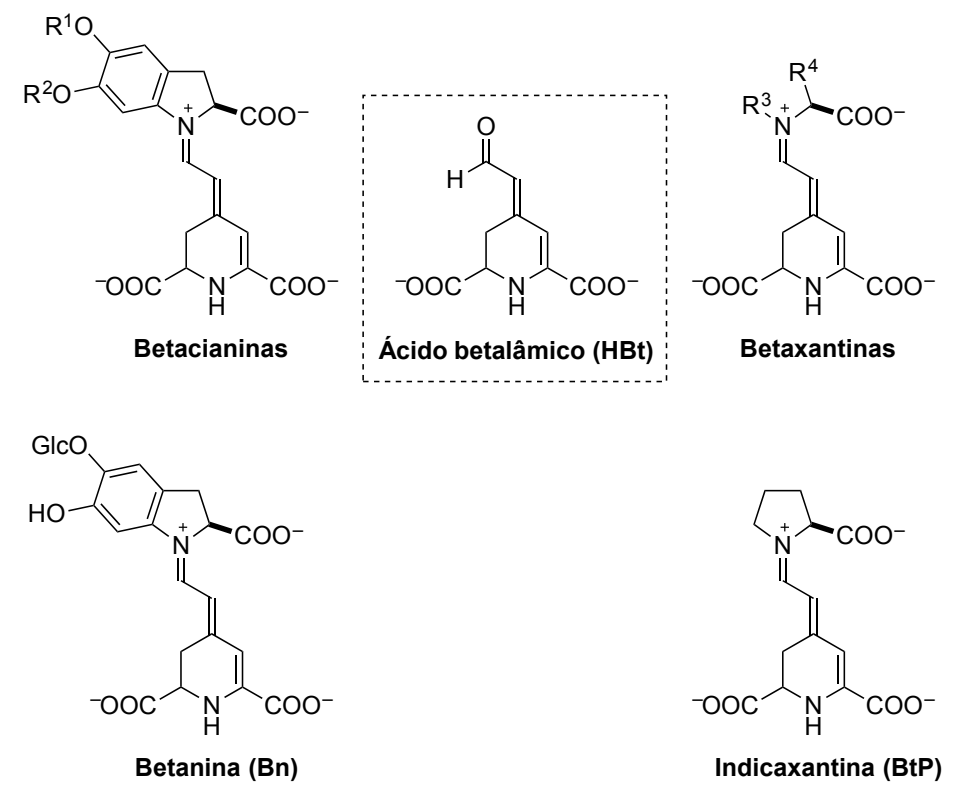

Esquema 1. Estruturas químicas do ácido betalâmico (HBt), das duas classes de betalaínas naturais que se originam dele (betacianinas vermelhas e betaxantinas amarelas) e de betalaínas que pertencem a cada uma delas: betanina (Bn) e indicaxantina (BtP). $R^{1}$ e $R^{2}=H$, glc; $R^{3}=H$, alquil e $R^{4}=$ cadeia lateral de aminoácidos.

\subsection{Estabilidade de betalaínas}

A modificação química de alimentos está geralmente associada a mudanças na coloração, o que pode comprometer o apelo comercial, os benefícios à saúde e a segurança. ${ }^{10}$ A fim de se garantir a retenção de cor nos alimentos em que betalaínas são utilizadas como corantes, o manuseio, processamento e estocagem devem ser feitos em condições controladas. A estabilidade de betalaínas é influenciada por fatores intrínsecos, como a composição e a estrutura ${ }^{1}$, e extrínsecos, como temperatura, $\mathrm{pH}$, oxigênio, presença de luz ${ }^{6,11}$, atividade de água ${ }^{12,13}$, e atividades enzimáticas, sendo a temperatura fator decisivo para a decomposição de betalaínas ${ }^{11}$. 
A temperatura pode ser considerada o fator mais importante na degradação de betalaínas. Como a conservação de alimentos geralmente inclui tratamento térmico das matérias-primas para garantir a segurança alimentar, vários estudos foram realizados para obter informação sobre a degradação térmica betalaínas presentes no suco de beterrabas e de cactus fruits. ${ }^{14,15,16,17,18,19}$ A estabilidade térmica de betalaínas depende tanto da temperatura quanto do tempo de aquecimento. Além disso, fatores como estrutura do pigmento, presença de luz, oxigênio, $\mathrm{pH}$, também influenciam a velocidade de degradação térmica destes compostos. De forma geral, betacianinas tem sido consideradas mais estáveis que betaxantinas. ${ }^{18,20}$ Entretanto, a hidrólise de BtP, uma betaxantina, em água pura $\left(k_{\mathrm{obs}}=6,9 \times 10^{-4} \mathrm{~h}, \mathrm{t}_{1 / 2}=996 \mathrm{~h}\right)$ é muito mais lenta que a de $\operatorname{Bn}\left(k_{\text {obs }}=5,3 \times 10^{-3} \mathrm{~h}, \mathrm{t}_{1 / 2}=130 \mathrm{~h}\right)$, nas mesmas condições experimentais. ${ }^{9}$

Betalaínas são relativamente estáveis entre os pHs 3 e $7 .{ }^{21}$ Abaixo de $\mathrm{pH} 3,5$, o máximo de absorção é deslocado para comprimentos de onda menores e, acima de pH 7, para comprimentos de onda maiores. $\mathrm{O}$ pH ótimo para a estabilidade de $\mathrm{Bn}$ foi reportado entre 5,5 e 6, na presença de oxigênio, enquanto condições anaeróbicas favorecem a estabilidade de $\mathrm{Bn}$ em pHs mais baixo (entre 4 e 5). ${ }^{22}$ Betaxantinas são mais estáveis entre $\mathrm{pH} 4$ e 7 e o $\mathrm{pH}$ ótimo para o máximo de estabilidade de betaxantinas também é $5,5 .^{23}$ Em condições alcalinas, ocorre a hidrólise da ligação aldimínica, e a acidificação induz a recondensação do ácido betalâmico tanto com aminoácidos (betaxantinas) quanto com derivados da ciclo-DOPA (betacianinas). ${ }^{24}$ Em temperatura ambiente, a hidrólise de Bn ocorre instantaneamente em $\mathrm{pH}=14 .^{25}$

Embora a maioria das betalaínas seja solúvel somente em água ou solventes orgânicos polares próticos (e.g., metanol, etanol, 2,2,2-trifluoroetanol (TFE)), estes pigmentos são muito sensíveis a hidrólise, já que são formalmente iminas ou sais de 
imínio. 2, 6, 26 Entretanto, a degradação destes pigmentos pode ocorrer por diferentes mecanismos. Foram caracterizados diversos produtos de degradação desidrogenados, descarboxilados e de hidrólise obtidos com o tratamento térmico de Bn. ${ }^{17,27,18,10,28}$

Nas plantas, betalaínas existem como misturas de diastereoisômeros. Quando o carbono $s p^{3}$ do sistema 2,6-dicarboxi-1,2,3,4-tetrapiridínico está na configuração $S$, os compostos recebem seus nomes convencionais, nomes que muitas vezes são usados para se referirem ao conjunto de isômeros presentes. Os isômeros $R$ recebem o prefixo iso. Assim, betanina é $(2 S / 15 S)$ betanidina 5-O-glicosídeo e o seu epímero $(2 S / 15 R)$ é chamado de isobetanina (Esquema 2). A proporção entre os dois isômeros depende da fonte de onde a betalaína foi obtida. ${ }^{6} \mathrm{~A}$ isobetanina e a betanina têm propriedades de absorção e fluorescência idênticas, mas podem ser separadas por cromatografia em condições de fase reversa. ${ }^{7,}{ }^{24}$ A epimerização de betacianinas para suas respectivas formas iso ocorre em meio ácido, sob aquecimento, ${ }^{6}$ assim como de iminas em geral. ${ }^{29}$

A clivagem da ligação aldimínica de betalaínas foi reportada em $\mathrm{pH}$ maior que 6 e também durante tratamento térmico. ${ }^{24}$ A quebra da ligação aldimínica resulta no ácido betalâmico, de coloração amarelo-brilhante. Assim, é observada tanto a perda de cor da solução de betalaína quanto uma mudança de cor para o amarelo. Além disso, a hidrólise da ligação aldimínica de betacianinas é mais pronunciada durante o tratamento térmico de soluções purificadas do que nos sucos de beterraba e pitaya roxa. ${ }^{28}$ 

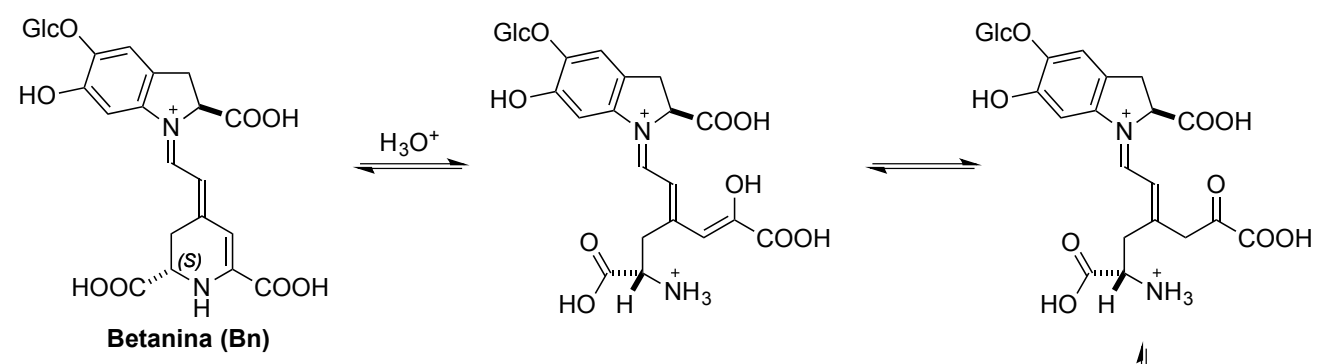

Betanina (Bn)
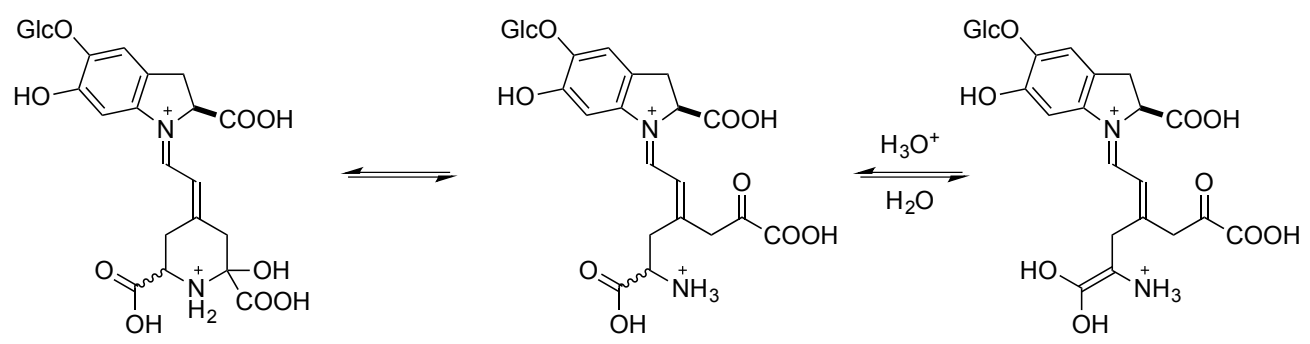

$$
\mathrm{H}_{2} \mathrm{O}
$$
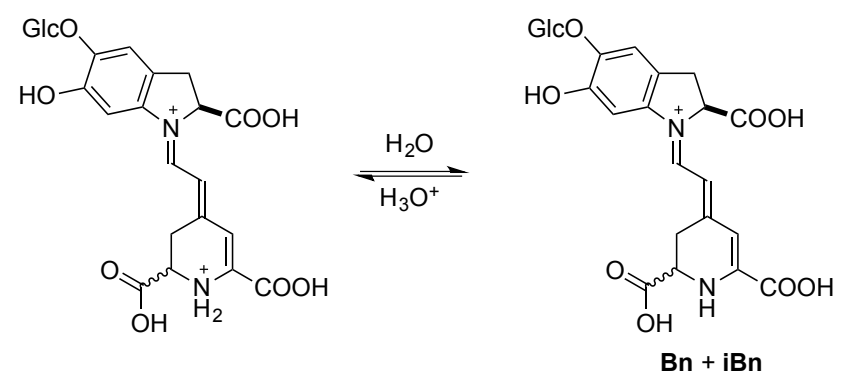

Esquema 2. Epimerização de betanina ((2S/15S)-betanidina 5-O-glicosídeo) para a isobetanina ((2S/15R)betanidina 5-O-glicosídeo) em meio aquoso ácido.

Por se tratar de um equilíbrio, a hidrólise da ligação aldimínica de betalaínas é reversível com a acidificação do meio, seguindo o mecanismo inverso da condensação aldimínica (Esquema 3). Assim, a mudança do pH do meio e da concentração dos reagentes alteram a constante de equilíbrio. Ainda, a reação se torna mais exergônica com o aumento da temperatura. Assim, a hidrólise mediada pelo aumento da basicidade do meio é revertida pela adição de ácido, i.e., HBt e aminoácidos formam betalaínas quando ácido é adicionado ao meio. $\mathrm{O}$ aquecimento leva à decomposição tanto do HBt quanto de alguns aminoácidos, em especial de derivados de ciclo-DOPA. ${ }^{6}{ }^{23} \mathrm{O}$ 
resultado deste efeito de concentração é uma dependência da diminuição gradual da concentração de betalaínas com a temperatura. Sabe-se que o resfriamento de soluções de betalaínas resulta na regeneração destes pigmentos; este resultado está relacionado ao deslocamento do equilíbrio por conta do efeito positivo do resfriamento sobre a etapa de desidratação e pelo aumento da energia de Gibbs para a hidrólise com a diminuição da temperatura.
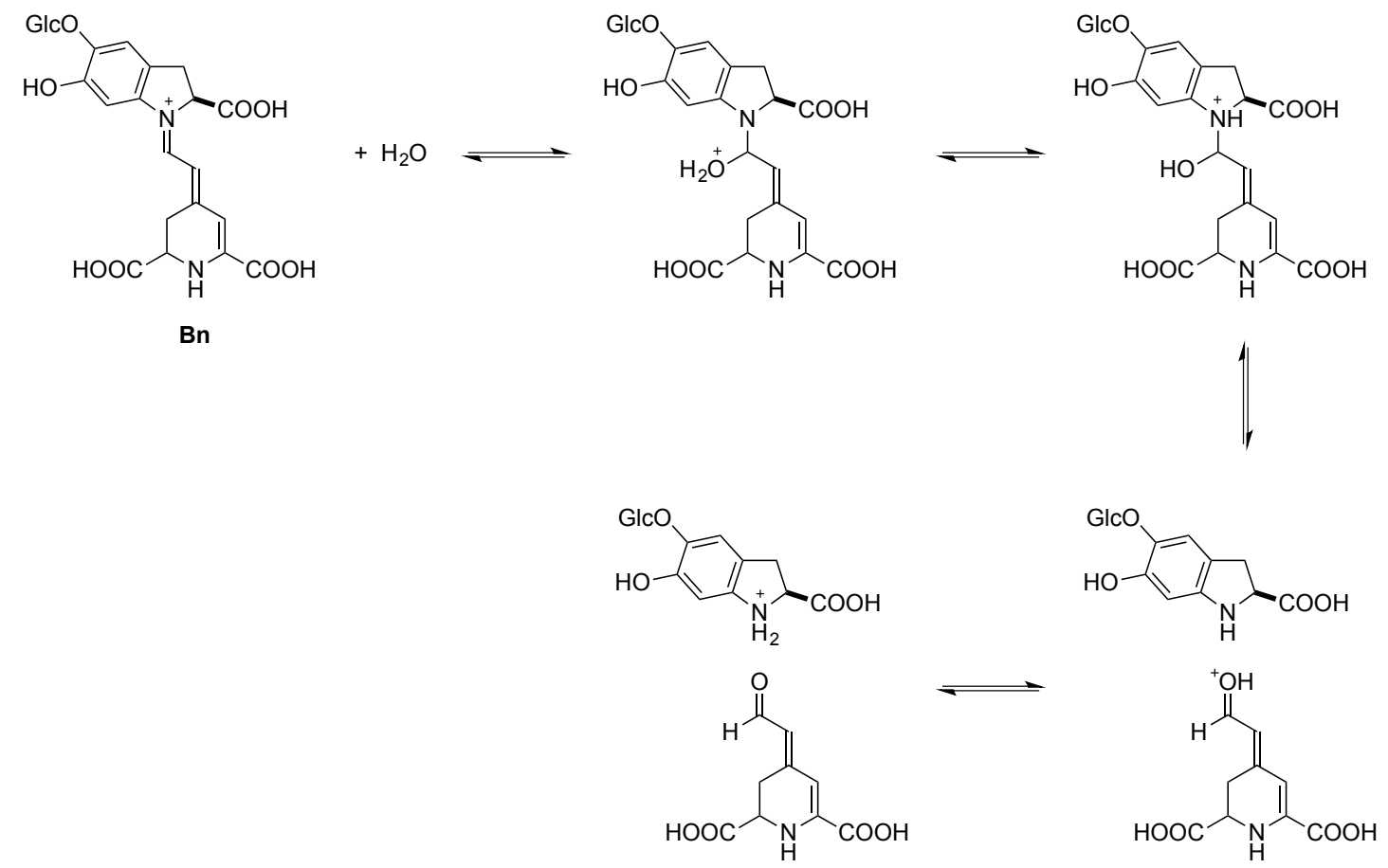

Esquema 3. Mecanismo de hidrólise de betanina a ácido betalâmico e ciclo-DOPA 5-O-glicosilada.

Betacianinas ${ }^{16}$ e betaxantinas ${ }^{30,23}$ são mais estáveis in natura em suas matrizes naturais do que puras em solução. Biomoléculas constituintes das plantas, em especial açúcares, e.g., pectinas: polissacarídeo ramificado; um dos principais componentes da parede celular das células vegetais, diminuem a atividade da água $\left(a_{\mathrm{w}}\right)$ o que resulta em uma diminuição da velocidade de hidrólise. ${ }^{6}$ Atividade de água é uma medida obtida da pressão de vapor da água na presença de diferentes solutos. Quanto maior o valor de $\mathrm{a}_{\mathrm{W}}$, menos associadas estão as moléculas de água e, portanto, mais disponíveis para o ataque 
nucleofílico. Além disso, a interação intermolecular de solutos que diminuem a aw, por exemplo açucares ramificados, com betalaínas cria um ambiente mais hidrofóbico nas imediações do pigmento, o que desfavorece a hidrólise. ${ }^{12-13,31}$

O aumento da temperatura favorece também reações de descarboxilação, que podem ocorrer nos carbonos C-2, C-15 e C-17 das betacianinas e nos carbonos C-11 e C-13 das betaxantinas. ${ }^{6}$ Os produtos descarboxilados apresentam máximo de absorção deslocado para o azul, quando comparados com seus compostos originais devido à concentração de carga no sistema conjugado 1,7-diazaheptametínico. ${ }^{6}$ Betanina pode sofrer descarboxilação nos carbonos C-2, C-15 e C-17, embora a susceptibilidade frente a descarboxilação de cada grupo seja diferente dependendo das condições experimentais (Esquema 4). ${ }^{28}$ Por exemplo, a descarboxilação inicial depende do solvente: em etanol, observa-se a formação de betacianinas descarboxiladas na posição C-17 e, em meio aquoso, a descarboxilação na posição C-2 é mais rápida. ${ }^{27}$ Após um prolongado período de aquecimento, todos os grupos carboxílicos são eliminados. ${ }^{27}$ Sob aquecimento, observa-se também a formação de produtos de oxidação desidrogenados ${ }^{6}$ (Esquema 4).

Comparando-se a estabilidade de diferentes betacianinas, foi reportado que as estruturas glicosiladas são mais estáveis que as agliconas (derivados não glicosilados) quando submetidas a degradação por espécies de oxigênio ativo ${ }^{6,32}$. Isto foi atribuído ao maior potencial de oxidação dos compostos glicolisados. ${ }^{32} \mathrm{O}$ tempo de meia-vida de Bn na presença de espécies reativas de oxigênio $\left(t_{1 / 2}=21 \pm 2 \mathrm{~h}\right)$ é dezessete vezes maior que a de betanidina, sua forma não glicosilada. ${ }^{32}$ Contudo, o aumento do número de resíduos de açúcar não proporciona aumento de estabilidade; por exemplo, a amarantina (betanidina 5-O- $\beta$-glucuronoglicosídeo) é tão estável quanto betanina na presença de oxigênio. ${ }^{33}$ A desglicosilação de betanina ocorre em meio fortemente ácido, sob alta 
temperatura e na presença da enzima $\beta$-glicosidase. ${ }^{6}$ Este processo é acompanhado de um deslocamento batocrômico (cerca de $4 \mathrm{~nm}$ ) e, novamente, leva a agliconas que são mais susceptíveis a oxidação do que o material de partida. ${ }^{6}$ Betanina e betanidina também são oxidadas por oxigênio. ${ }^{6,34}$ O tempo de vida de betalaínas aumenta sensivelmente em atmosfera de nitrogênio ou baixas concentrações de ácido ascórbico ou isoascórbico. ${ }^{6,14,35}$ Entretanto, altas concentrações de ácido ascórbico aumentam a degradação de betanina, devido ao efeito pró-oxidante do radical ascorbila, que é formado nessas condições. ${ }^{34}$
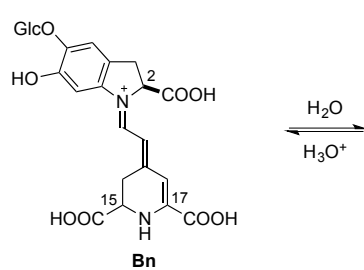

$\mathrm{Bn}$<smiles>C1CCCCC1</smiles>

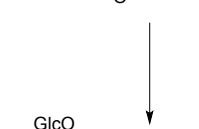$$
\mathrm{GlcO}
$$<smiles></smiles>

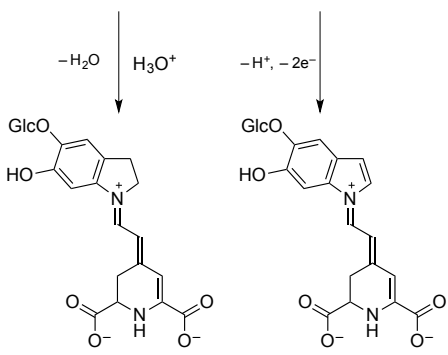

$\mathrm{GlcO}$

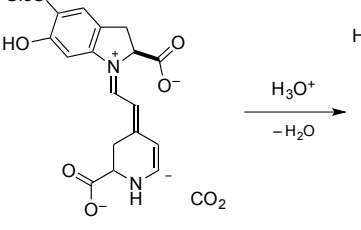

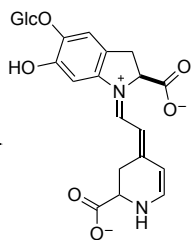

$\mathrm{GlcO}$<smiles>COc1cc2c(cc1O)N(CC=C1C=C(C(=O)[O-])NCC1)C(C(=O)[O-])C2</smiles>

$\mathrm{GlcO}$

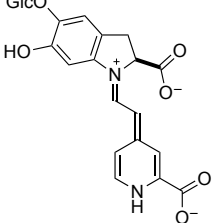

Esquema 4. Reação de descarboxilação de betanina e a formação de produtos descarboxilados e oxidados.

A presença de grupos ionizáveis torna as betalaínas sensíveis à presença de espécies iônicas. A presença dos cátions metálicos $\mathrm{Fe}^{2+}, \mathrm{Fe}^{3+}, \mathrm{Sn}^{2+}, \mathrm{Al}^{3+}, \mathrm{Cr}^{3+} \mathrm{e} \mathrm{Cu}^{2+}$, 


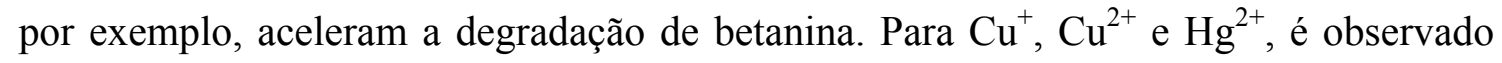
um deslocamento batocrômico da banda de absorção da betanina, indicando, possivelmente, a formação de complexos, ${ }^{36}$ que são dissociados com adição de ácido e/ou EDTA. ${ }^{36}$ 



\section{OBJETIVOS}

Entender como ocorre a decomposição de betalaínas em meio aquoso tamponado na ausência e na presença de sais.

\subsection{Objetivos específicos}

- Determinar os efeitos do $\mathrm{pH}$ do meio e da temperatura sobre a cinética de hidrólise de betanina e indicaxantina;

- Determinar como diferentes tampões e sais afetam a cinética de decomposição de betanina. 



\section{RESULTADOS}

O estudo cinético da hidrólise de betalaínas foi realizado com betanina (Bn) e indicaxantina (BtP), que foram obtidas a partir das metodologias estabelecidas anteriormente no grupo de pesquisa, ${ }^{7,37}$ com algumas modificações. Neste texto serão apresentados e discutidos inicialmente os detalhes da obtenção destas betalaínas. Em seguida, são apresentados os resultados obtidos com a variação da concentração de diferentes soluções tampão, do $\mathrm{pH}$ e da temperatura e com a adição de diferentes sais sobre a hidrólise de Bn. Também são apresentados os resultados obtidos com a variação do $\mathrm{pH}$ sobre a hidrólise de BtP.

\subsection{Obtenção de betalaínas}

\subsubsection{Extração e purificação de betanina}

Betanina foi obtida a partir do suco de beterraba conforme método estabelecido anteriormente no grupo. ${ }^{7}$ A betanina presente em suco de beterrada é purificada por cromatografia em coluna em condições de fase reversa (sílica C-18 como fase estacionária e água como eluente). ${ }^{7}$ As frações magenta obtidas foram analisadas por cromatografia líquida de alta eficiência (HPLC), reunidas e submetidas a análise por espectrofotometria UV-Vis (Figura 1). Os dados de cromatografia analítica indicam que Bn foi obtida com um excelente grau de pureza $\left(+98 \%{ }^{\mathrm{HPLC}, 254} \mathrm{~nm}\right)$. Estes resultados foram comparados os dados obtidos com betanina padrão caracterizada anteriormente no grupo por espectrometria de ressonância magnética nuclear (RMN), cromatografia líquida acoplada a detectores de grade de diodo e espectrometria de massas em modo positivo de ionização electrospray (HPLC-DAD-MS(ESI+)). ${ }^{7,25}$ Embora eficiente na obtenção de Bn pura, este método tem limitações quanto à quantidade de composto que 
pode ser purificado por hora pois depende de coluna cromatográfica. Por esse método, foi possível purificar $5 \mathrm{mg}$ de $\mathrm{Bn}$ a partir de $5 \mathrm{~mL}$ de suco de beterraba em, aproximadamente, 4 horas (uma coluna). Além disso, cromatografia de coluna em condições de fase reversa é uma técnica cromatográfica muito cara comparada ao uso de outras fases estacionárias como a sílica gel 60 , celulose ou algumas resinas de troca iônica.
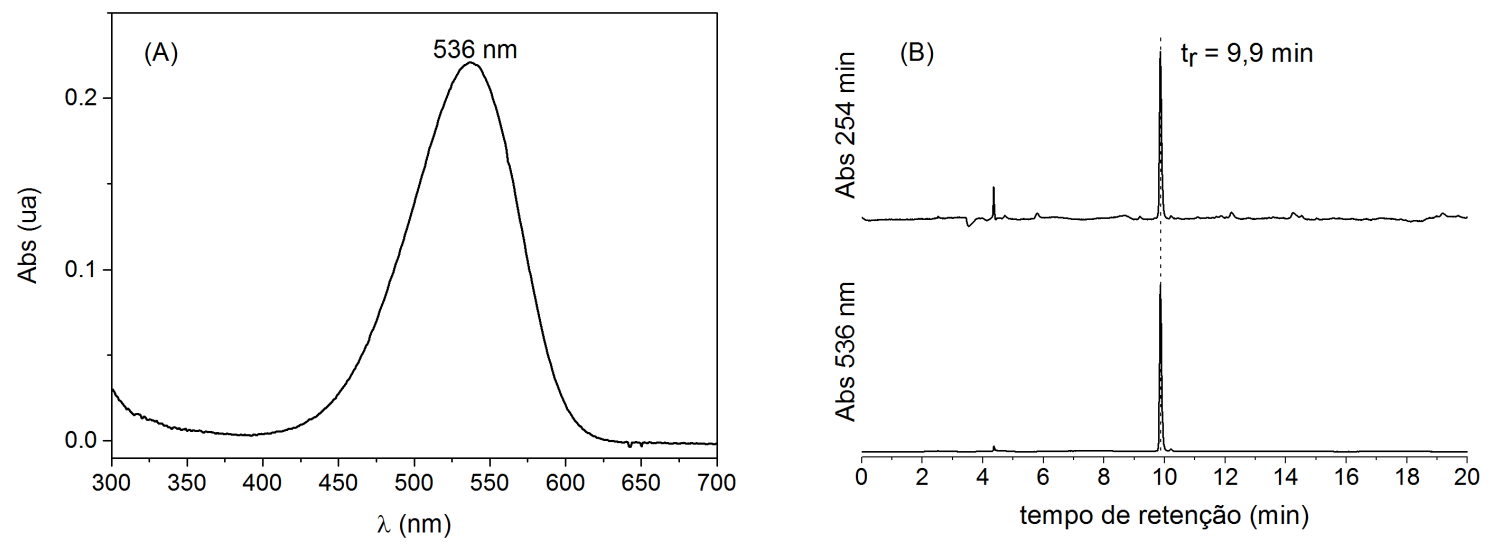

Figura 1. (A) Espectro de absorção de betanina obtida por cromatografia de coluna em C18. (B) Cromatograma de Bn acompanhado por UV-vis em 254 nm e 536 nm (coluna de fase reversa C18, $250 \times$ 4,6 mm; sistema cromatográfico: 5-95\% B em 20 min, sendo o solvente A: 0,1\% TFA/água e solvente B: $0,1 \%$ TFA/60\% MeCN/água com fluxo de $1 \mathrm{~mL} \mathrm{~min}^{-1}$ ).

\subsubsection{Semissíntese e purificação de indicaxantina}

Para a semissíntese de betalaínas, é necessário primeiramente obter ácido betalâmico (HBt) e purificá-lo. No método empregado pelo nosso grupo para obtenção de indicaxantina, o HBt é obtido a partir da hidrólise alcalina do suco de beterraba e purificado em uma coluna de troca iônica com Amberlite XAD 16 como fase estacionária. $^{25,} 37$ L-prolina é, então, adicionada ao HBt em meio aquoso alcalino $\mathrm{pH}=11$, e após 30 min sob agitação, o meio é acidificado com ácido acético glacial até $\mathrm{pH}=5$. 
Infelizmente, a BtP obtida por esse método contém grandes quantidades de ânion acetato, o que dificulta a realização de estudos posteriores do efeito do $\mathrm{pH}$. Assim, foi utilizado um método alternativo para a semissíntese de indicaxantina, no qual HBt foi extraído em acetato de etila. O método utilizado para extração de HBt está descrito na literatura ${ }^{3}$; entretanto, foram feitas algumas modificações pelo nosso grupo para aumentar sua escala e diminuir as etapas de processamento. Suco de beterraba foi hidrolisado com $\mathrm{NH}_{4} \mathrm{OH}(\mathrm{pH}=11,4)$, em seguida acidificado com $\mathrm{HCl}$ concentrado até $\mathrm{pH}=2$ e então, o HBt foi extraído com acetato de etila. O HBt foi obtido em concentração média próxima a $0,5 \mathrm{mmol} \mathrm{L}^{-1}$, com um rendimento médio de, aproximadamente, $10 \%$, em relação ao conteúdo de Bn presente no suco de beterraba $\left(\varepsilon^{536 \mathrm{~nm}}=6,5 \times 10^{4} \mathrm{~L} \mathrm{~mol}^{-1} \mathrm{~cm}^{-1}\right)$. A concentração de HBt foi calculada considerando-se $\varepsilon^{424 \mathrm{~nm}}=2,4 \times 10^{4} \mathrm{~L} \mathrm{~mol}^{-1} \mathrm{~cm}^{-1} .38$

A reação de semissíntese foi realizada adicionando-se um excesso de L-prolina (10 equivalentes), a temperatura ambiente. Como a L-prolina não é solúvel em acetato de etila, a reação de formação de BtP ocorre de maneira heterogênea na superfície do sólido. A reação é quase instantânea, e pode ser constatada pela mudança da coloração do sólido, de branco para alaranjado. O sólido é então filtrado a vácuo, com o auxílio de um funil de Büchner, e solubilizado em água. O composto foi purificado por cromatografia em coluna de fase reversa $\left(\mathrm{SiO}_{2}-\mathrm{C} 18\right)$, utilizando-se água como eluente.

A análise por espectrofotometria UV-vis e por cromatografia líquida de alta eficiência (Figura 2) indicam que o composto obtido é a BtP e que esta foi obtida com alto grau de pureza. A caracterização é feita por comparação com os espectros e cromatogramas de BtP padrão já caracterizada pelo grupo. 

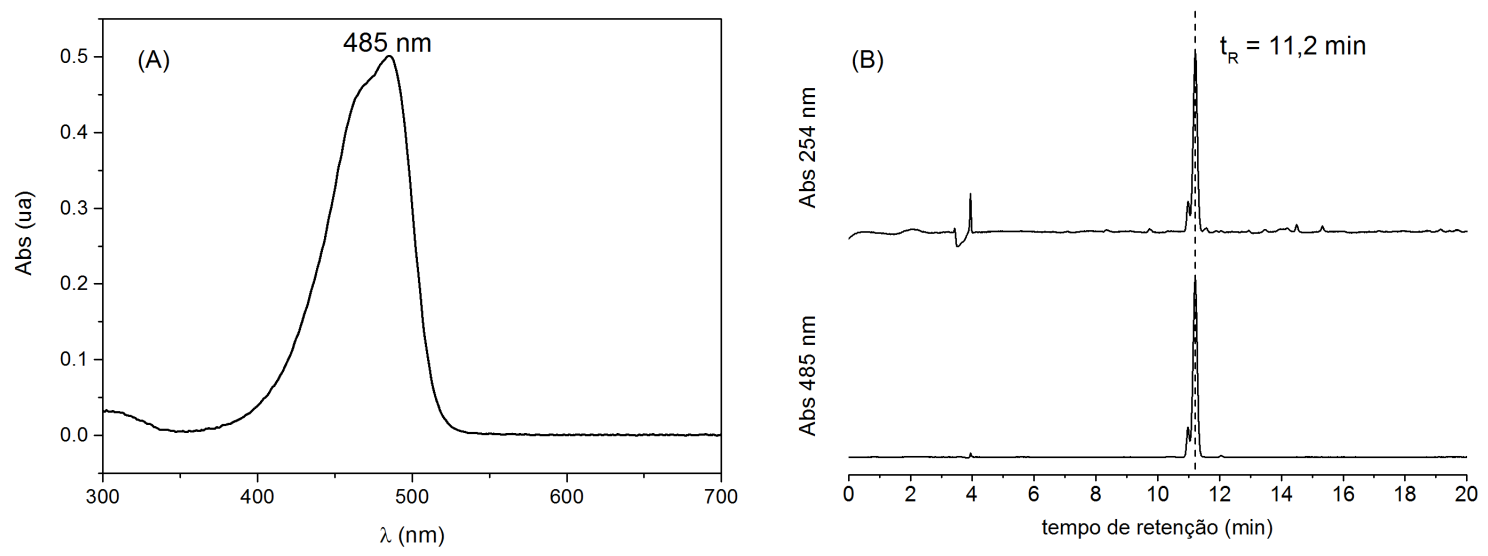

Figura 2. (A) Espectro de absorção de indicaxantina. (B) Cromatograma de BtP acompanhado por UV-vis em $254 \mathrm{~nm}$ e $485 \mathrm{~nm}$ (coluna de fase reversa C18, $250 \times 4,6 \mathrm{~mm}$; sistema cromatográfico: 5 - 95\% B em 20 min, sendo o solvente A: 0,1\% TFA/água e solvente B: 0,1\% TFA/60\% MeCN/água com fluxo de $1 \mathrm{~mL} \mathrm{~min}{ }^{-1}$ ).

\subsection{Estudo da decomposição de betanina}

\subsubsection{Estudo controle em água}

O valor da constante cinética observada $\left(k_{\text {obs }}\right)$ para a decomposição de $\mathrm{Bn}$ em água a $85^{\circ} \mathrm{C}$ foi determinado a partir da variação do máximo de absorção em função do tempo. Os espectros foram adquiridos a cada 2,5 min durante 150 min (Figura 3). Dada a baixíssima condutividade de água deionizada, estima-se que o $\mathrm{pH}$ da água era 7 dada a sua resistividade de $18,2 \mathrm{M} \Omega \cdot \mathrm{cm}$ e uma medição semiquantitativa com fita indicadora de $\mathrm{pH}$.
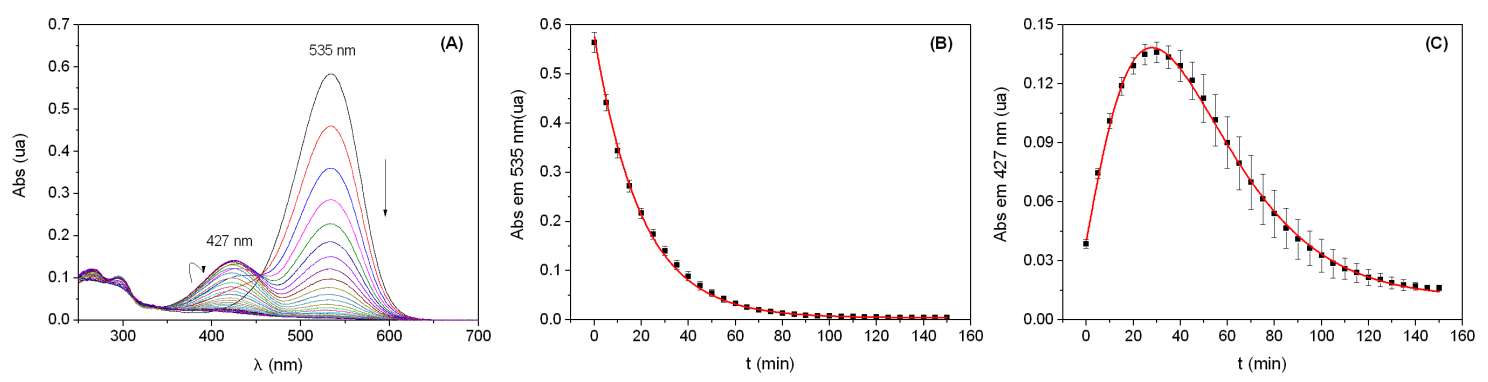

Figura 3. (A) Espectros de absorção de Bn em água ( $\left.[\mathrm{Bn}]=9 \mu \mathrm{mol} \mathrm{L}{ }^{-1}\right)$, em função do tempo, a $85^{\circ} \mathrm{C}$. (B) Cinética de decaimento da absorção de Bn em $\lambda=535 \mathrm{~nm} ; k_{\mathrm{obs}}=(5,0 \pm 0,2) \times 10^{-2} \mathrm{~min}^{-1} ; \mathrm{t}_{1 / 2}=14,5 \pm 0,6$ min. (C) Cinética de formação e posterior decaimento de $\mathrm{HBt}$ em $\lambda=427 \mathrm{~nm} ; k_{\mathrm{obs}, 1}=(3,60 \pm 0,42) \times 10^{-2}$ $\min ^{-1} ; t_{1 / 2,1}=19,4 \pm 2,1 \min$ e $k_{\mathrm{obs}, 2}=(3,57 \pm 0,42) \times 10^{-2} \min ^{-1} ; \mathrm{t}_{1 / 2,2}=19,6 \pm 2,2 \mathrm{~min}$. 
A análise do perfil de absorção de Bn em água indica a diminuição da banda de absorção com máximo em $535 \mathrm{~nm}$ (correspondente a Bn) em função do tempo, e o aparecimento, seguido de diminuição, de uma banda com máximo em $427 \mathrm{~nm}$, que corresponde ao máximo de absorção do ácido betalâmico, um dos produtos de hidrólise da $\mathrm{Bn}$. Os dados para a degradação de $\mathrm{Bn}\left(\lambda_{\text {máx }}=535 \mathrm{~nm}\right)$ foram ajustados utilizando-se uma função monoexponencial e a constante cinética observada $\left(k_{\mathrm{obs}}\right)$ foi calculada em $(5,0 \pm 0,2) \times 10^{-2} \mathrm{~min}^{-1}$, correspondendo a um tempo de meia-vida $\left(\mathrm{t}_{1 / 2}\right)$ de $14,5 \pm 0,6$ min. Os dados correspondentes a formação, e posterior decomposição, de HBt foram ajustados utilizando-se uma função biexponencial. A constante cinética observada de formação de $\operatorname{HBt}\left(k_{\mathrm{obs}, 1}\right)$ foi calculada em $(3,60 \pm 0,42) \times 10^{-2} \mathrm{~min}^{-1}$ e o tempo de meiavida, $\mathrm{t}_{1 / 2,1}=19 \pm 2 \min$, e a constante cinética observada para a sua degradação $\left(k_{\mathrm{obs}, 2}\right)$ foi calculada em $(3,57 \pm 0,42) \times 10^{-2} \mathrm{~min}^{-1}$ com tempo de meia-vida, $\mathrm{t}_{1 / 2,2}=19,6 \pm 2,2$ $\min$.

\subsubsection{Efeito do tampão}

Para o estudo do efeito do tampão sobre a constante cinética observada $\left(k_{\mathrm{obs}}\right)$ de hidrólise de $\mathrm{Bn}$ a $85^{\circ} \mathrm{C}$, foram escolhidos três diferentes tampões: acetato ( $\left.\mathrm{p} K_{\mathrm{a}}=4,8\right)$, citrato $\left(\mathrm{p} K_{\mathrm{a}} \mathrm{s}=3,1,4,8,6,4\right)$ e fosfato $\left(\mathrm{p} K_{\mathrm{a}} \mathrm{s}=2,1,7,2,12,3\right),{ }^{39}$ nas concentrações 10,50 , $100,250,500 \mathrm{mmol} \mathrm{L}^{-1}$.

\subsubsection{Tampões acetato e citrato}

O efeito dos tampões acetato e citrato sobre as constantes cinéticas observadas ( $\left.k_{\text {obs }}\right)$ para a decomposição de Bn foi determinado em tampão acetato pH 4,8 e 5,8, e em tampão citrato $\mathrm{pH} 4,8$. Cada um dos tampões foi preparado em cinco concentrações (10, $50,100,250$ e $500 \mathrm{mmol} \mathrm{L}{ }^{-1}$ ). Os valores de $k_{\mathrm{obs}}$ foram obtidos por meio do ajuste 
monoexponencial dos dados de máximos de absorção versus tempo. Os espectros de absorção de Bn em função do tempo estão apresentados na Figura 4.
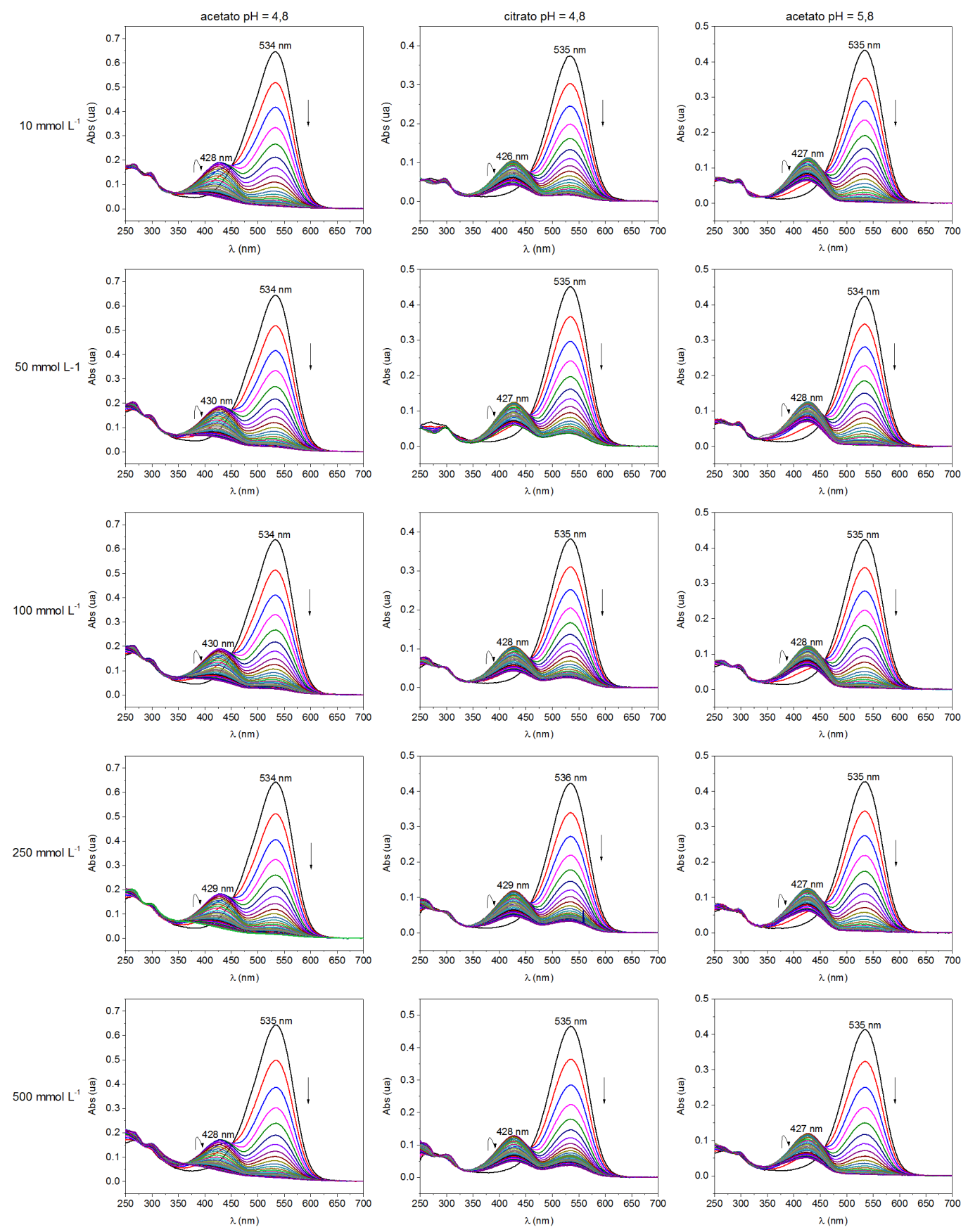

Figura 4. Espectros de absorção de Bn em função do tempo em tampão acetato e citrato. Na horizontal, tampão acetato $\mathrm{pH}=4,8$, tampão citrato $\mathrm{pH}=4,8$ e tampão acetato $\mathrm{pH}=5,8$, e a [Bn] é 10,7 e 6,5 $\mu \mathrm{mol}$ $\mathrm{L}^{-1}$; na vertical, a concentração do tampão é $10,50,100,250,500 \mathrm{mmol} \mathrm{L}^{-1}$. Os espectros foram obtidos a cada 5 min durante $150 \mathrm{~min}$. 
A Tabela 1 apresenta os valores de $k_{\text {obs }}$ e $\mathrm{t}_{1 / 2}$ determinados para a decomposição de $\mathrm{Bn}$ em tampão acetato $\mathrm{pH}=4,8$ e em tampão citrato $\mathrm{pHs}=4,8$ e 5,8. Observa-se que tampão acetato $\mathrm{pH} 4,8$ não interfere no valor do $k_{\mathrm{obs}}$, mesmo com o aumento de sua concentração. Nos demais tampões, o aumento da concentração provoca um pequeno aumento do $k_{\text {obs }}$. Entretanto, os valores médios calculados a partir das diferentes concentrações dos tampões $\left((4,7 \pm 0,2) \times 10^{-2} \min ^{-1},(4,9 \pm 0,5) \times 10^{-2} \mathrm{~min}^{-1}\right.$ e $(4,5 \pm$ $0,4) \times 10^{-2} \mathrm{~min}^{-1}$, respectivamente) são comparáveis com o $k_{\mathrm{obs}}$ do experimento controle em água $\left((5,0 \pm 0,2) \times 10^{-2} \mathrm{~min}^{-1}\right)$.

A cinética de degradação de Bn também pode ser acompanhada pela formação de HBt. Observa-se, na Figura 4, o aparecimento de uma banda entre 426 e $430 \mathrm{~nm}$, correspondente a formação do HBt. Entretanto, o HBt também sofre degradação após determinado tempo de aquecimento. Os dados correspondentes à formação e degradação do $\mathrm{HBt}$ versus tempo foram ajustados utilizando-se uma função biexponencial. A constante cinética observada, $k_{\mathrm{obs}, 1}$, corresponde a formação de HBt, enquanto $k_{\mathrm{obs}, 2}$, corresponde a constante cinética observada para sua degradação (Tabela 2).

Os valores médios calculados a partir das diferentes concentrações dos tampões considerando a formação de $\mathrm{HBt}$ em tampão acetato $\mathrm{pH}=4,8$, citrato $\mathrm{pH}=4,8$ e acetato $\mathrm{pH}=5,8\left(\left(4,5 \pm 0,6 \times 10^{-2}\right) \min ^{-1},\left(4,3 \pm 0,7 \times 10^{-2}\right) \min ^{-1}\right.$ e $\left(4,0 \pm 0,7 \times 10^{-2}\right) \mathrm{min}^{-1}$, respectivamente) estão muito próximos dos calculados acompanhando-se a degradação de Bn, o que confirma os resultados obtidos.

A velocidade de degradação de HBt é menor em meio tamponado do que em água. Comparando-se os valores médio calculados a partir das diferentes concentrações dos tampões $\left((2,5 \pm 0,6) \times 10^{-2} \min ^{-1},(1,4 \pm 0,2) \times 10^{-2} \min ^{-1} \mathrm{e}\right.$ 
$(1,3 \pm 0,3) \times 10^{-2} \mathrm{~min}^{-1}$, respectivamente) com o valor obtido com a degradação de HBt em água $\left((3,57 \pm 0,42) \times 10^{-2} \mathrm{~min}^{-1}\right)$, na mesma temperatura, observa-se que o HBt é mais persistente no meio tamponado do que em água deionizada. Além disso, observase que a degradação ocorre mais rápido em tampão acetato $\mathrm{pH} \mathrm{4,8} \mathrm{do} \mathrm{que} \mathrm{nos} \mathrm{demais}$ tampões.

Tabela 1. Valores de $k_{\text {obs }}$ e de tempo de meia-vida para a degradação da Bn em tampão acetato, citrato e no controle (água deionizada).

\section{Tampão pH Conc. $\left(\mathrm{mmol} \mathrm{L}^{-1}\right) \quad k_{\text {obs }}\left(\mathrm{min}^{-1}\right) \quad \mathbf{t}_{1 / 2}\left(\mathrm{~min}^{-1}\right)$}

\begin{tabular}{|c|c|c|c|c|}
\hline Controle & & & 0,050 & 14,5 \\
\hline \multirow{5}{*}{ Acetato } & \multirow{5}{*}{4,8} & 10 & 0,046 & 15 \\
\hline & & 50 & 0,046 & 15 \\
\hline & & 100 & 0,046 & 15 \\
\hline & & 250 & 0,047 & 15 \\
\hline & & 500 & 0,051 & 14 \\
\hline \multirow{5}{*}{ Citrato } & \multirow{5}{*}{4,8} & 10 & 0,044 & 16 \\
\hline & & 50 & 0,047 & 15 \\
\hline & & 100 & 0,047 & 15 \\
\hline & & 250 & 0,050 & 14 \\
\hline & & 500 & 0,056 & 12 \\
\hline \multirow{5}{*}{ Acetato } & \multirow{5}{*}{5,8} & 10 & 0,041 & 17 \\
\hline & & 50 & 0,042 & 16 \\
\hline & & 100 & 0,043 & 16 \\
\hline & & 250 & 0,046 & 15 \\
\hline & & 500 & 0,052 & 13 \\
\hline
\end{tabular}


Tabela 2. Valores de $k_{\mathrm{obs}}$ de formação $\left(k_{1}\right)$ e degradação $\left(k_{2}\right)$ e de tempo de meia-vida para a formação e degradação de HBt em tampão acetato e citrato.

Tampão pH Conc. $\left(\mathrm{mmol} \mathrm{L}^{-1}\right) \quad k_{\text {obs, } 1}\left(\mathrm{~min}^{-1}\right) \quad t_{1 / 2,1}(\min ) \quad k_{\text {obs,2 }}\left(\mathrm{min}^{-1}\right) \quad \mathbf{t}_{1 / 2,2}(\mathrm{~min})$

\begin{tabular}{|c|c|c|c|c|c|c|}
\hline \multirow{5}{*}{ Acetato } & \multirow{5}{*}{4,8} & 10 & 0,035 & 20 & 0,035 & 20 \\
\hline & & 50 & 0,045 & 15 & 0,022 & 32 \\
\hline & & 100 & 0,046 & 15 & 0,020 & 34 \\
\hline & & 250 & 0,048 & 14 & 0,022 & 31 \\
\hline & & 500 & 0,052 & 13 & 0,027 & 25 \\
\hline \multirow{5}{*}{ Citrato } & \multirow{5}{*}{4,8} & 10 & 0,041 & 17 & 0,011 & 60 \\
\hline & & 50 & 0,036 & 19 & 0,016 & 42 \\
\hline & & 100 & 0,038 & 18 & 0,015 & 45 \\
\hline & & 250 & 0,046 & 15 & 0,014 & 48 \\
\hline & & 500 & 0,053 & 13 & 0,014 & 48 \\
\hline \multirow{5}{*}{ Acetato } & \multirow{5}{*}{5,8} & 10 & 0,032 & 21 & 0,017 & 42 \\
\hline & & 50 & 0,034 & 20 & 0,015 & 45 \\
\hline & & 100 & 0,042 & 17 & 0,011 & 63 \\
\hline & & 250 & 0,046 & 15 & 0,0092 & 75 \\
\hline & & 500 & 0,048 & 14 & 0,013 & 54 \\
\hline
\end{tabular}

\subsubsection{Tampão fosfato}

Foram preparadas quinze soluções de Bn em tampão fosfato, i.e., três pHs $(2,1$, 6,2 e 8,2) em cinco concentrações $\left(10,50,100,250\right.$ e $\left.500 \mathrm{mmol} \mathrm{L}^{-1}\right)$ cada. Os espectros de absorção em função do tempo em todas as condições são apresentados na Figura 5. 

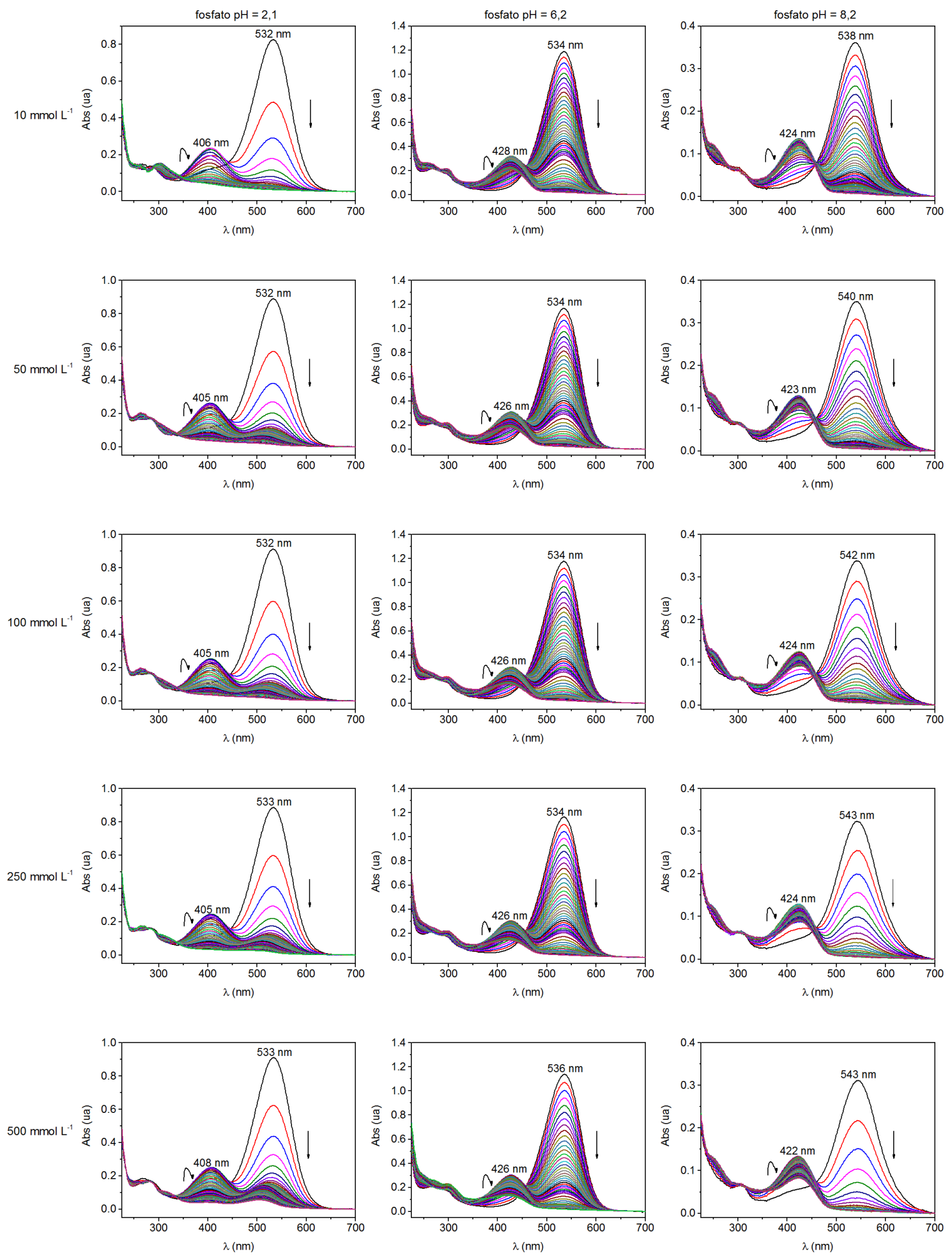

Figura 5. Espectros de absorção de Bn em função do tempo em tampão fosfato. Na horizontal, o pH é 2,1, 6,2 e 8,2 e a [Bn] é 13, 18 e 5,5 $\mu \mathrm{mol} \mathrm{L}^{-1}$; na vertical, a concentração do tampão é 10, 50, 100, 250,

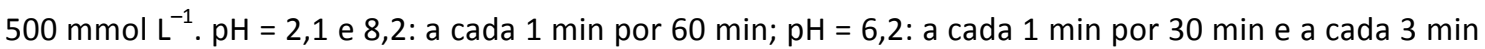
por $90 \mathrm{~min}$ (tempo total de $120 \mathrm{~min}$ ). 
Assim como para a hidrólise de Bn em água, a análise do perfil de absorção de Bn em tampão fosfato, indica uma diminuição do máximo de absorção ( $\lambda_{\text {máx }}$ entre 532 e $543 \mathrm{~nm}$ ) em função do tempo, e a formação, seguida de diminuição, de uma banda com máximo de absorção referente ao ácido betalâmico. O meio ácido provoca um pequeno deslocamento hipsocrômico do máximo de absorção da $\mathrm{Bn}$, em relação à água, e o aumento da basicidade provoca um deslocamento batocrômico.

Os dados de máximo de absorção versus tempo foram ajustados com uma função monoexponencial de forma a determinar os valores de constante cinética observada $\left(k_{\text {obs }}\right)$ em cada uma das condições estudadas. Quando o ajuste biexponencial foi necessário, utilizou-se o valor da maior constante. Os valores de $k_{\mathrm{obs}}$ e tempo de meia-vida estão apresentados na Tabela 3 . Observou-se que o $k_{\text {obs }}$ aumenta com o aumento da concentração nos tampões pHs 6,2 e 8,2, sendo mais evidenciado em meio básico. Em $\mathrm{pH}=2,1$, apesar de pequeno (quando comparado aos demais pHs), observa-

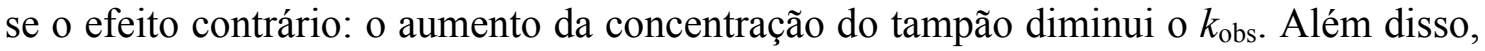
em $\mathrm{pH}=6,2$, nas concentrações mais baixas, o tampão interfere pouco no valor do $k_{\mathrm{obs}}$, sendo este próximo ao valor obtido em água $\left((5,0 \pm 0,2) \times 10^{-2} \mathrm{~min}^{-1}\right)$.

A cinética da reação de formação do $\mathrm{HBt}$, para os $\mathrm{pHs} 6,2$ e 8,2, e para sua decomposição também foram investigadas. Os valores de $k_{\mathrm{obs}, 1}$ (formação de $\mathrm{HBt}$ ) e $k_{\text {obs,2 }}$ (degradação de HBt) e seus respectivos tempos de meia-vida estão apresentados na Tabela 4. Em pH = 2,1, observa-se o contrário do que é observado acompanhando-se a reação pela degradação de $\mathrm{Bn}$ : o aumento do valor de $k_{\mathrm{obs}}$ com o aumento da concentração do tampão. Entretanto, a variação continua sendo muito pequena (diferença entre o $t_{1 / 2}$ do tampão menos concentrado e do mais concentrado é menor que $1 \mathrm{~min})$. 
Tabela 3. Valores de $k_{\mathrm{obs}}$ e de tempo de meia-vida para a degradação da $\mathrm{Bn}$ em tampão fosfato e no controle (água deionizada).

Tampão pH Conc. $\left(\mathrm{mmol} \mathrm{L}^{-1}\right) \quad k_{\text {obs }}\left(\min ^{-1}\right) \quad t_{1 / 2}(\min )$

\begin{tabular}{|c|c|c|c|c|}
\hline Controle & & & 0,050 & 14,5 \\
\hline \multirow{5}{*}{ Fosfato } & \multirow{5}{*}{2,1} & 10 & 0,60 & 1,1 \\
\hline & & 50 & 0,57 & 1,2 \\
\hline & & 100 & 0,55 & 1,3 \\
\hline & & 250 & 0,52 & 1,3 \\
\hline & & 500 & 0,51 & 1,4 \\
\hline \multirow{5}{*}{ Fosfato } & \multirow{5}{*}{6,2} & 10 & 0,043 & 16 \\
\hline & & 50 & 0,047 & 15 \\
\hline & & 100 & 0,052 & 13 \\
\hline & & 250 & 0,060 & 11 \\
\hline & & 500 & 0,070 & 10 \\
\hline \multirow{5}{*}{ Fosfato } & \multirow{5}{*}{8,2} & 10 & 0,083 & 8 \\
\hline & & 50 & 0,13 & 5 \\
\hline & & 100 & 0,16 & 4 \\
\hline & & 250 & 0,25 & 3 \\
\hline & & 500 & 0,38 & 2 \\
\hline
\end{tabular}


Tabela 4. Valores de $k_{\mathrm{obs}}$ de formação $\left(k_{1}\right)$ e degradação $\left(k_{2}\right)$ e de tempo de meia-vida para a formação e degradação de HBt em tampão fosfato.

Tampão $\quad$ pH Conc. $\left(\operatorname{mmol~L}^{-1}\right) \quad k_{0 b s, 1}\left(\min ^{-1}\right) \quad t_{1 / 2,1}(\min ) \quad k_{0 b s, 2}\left(\min ^{-1}\right) \quad t_{1 / 2,2}(\min )$

\begin{tabular}{|c|c|c|c|c|c|c|}
\hline \multirow{5}{*}{ Fosfato } & \multirow{5}{*}{2,1} & 10 & 0,28 & 2,4 & 0,28 & 2,4 \\
\hline & & 50 & 0,28 & 2,4 & 0,10 & 6,7 \\
\hline & & 100 & 0,32 & 2,1 & 0,11 & 6,5 \\
\hline & & 250 & 0,36 & 2 & 0,095 & 7,3 \\
\hline & & 500 & 0,40 & 1,7 & 0,060 & 11 \\
\hline \multirow{5}{*}{ Fosfato } & \multirow{5}{*}{6,2} & 10 & 0,042 & 16 & 0,017 & 41 \\
\hline & & 50 & 0,047 & 15 & 0,014 & 49 \\
\hline & & 100 & 0,050 & 14 & 0,016 & 44 \\
\hline & & 250 & 0,057 & 12 & 0,016 & 44 \\
\hline & & 500 & 0,063 & 11 & 0,018 & 39 \\
\hline \multirow{5}{*}{ Fosfato } & \multirow{5}{*}{8,2} & 10 & 0,088 & 8 & 0,0081 & 85 \\
\hline & & 50 & 0,14 & 5 & 0,016 & 44 \\
\hline & & 100 & 0,17 & 4 & 0,015 & 46 \\
\hline & & 250 & 0,28 & 2 & 0,014 & 49 \\
\hline & & 500 & 0,46 & 1,5 & 0,014 & 49 \\
\hline
\end{tabular}

\subsubsection{Efeito da adição de sais}

O efeito de adição de diferentes sais sobre a constante cinética de decomposição de betanina foi estudado, inicialmente, empregando-se diferentes sais de sódio. Foram preparadas soluções aquosas concentradas $\left(500 \mathrm{mmol} \mathrm{L}^{-1}\right)$ dos sais apresentados na Tabela 5 e o pH das soluções foi aferido. Observou-se uma variação do pH do meio 
entre 3,5 e 8,4 (Tabela 5). Por esse motivo, o efeito da adição de sais sobre a cinética decomposição de $\mathrm{Bn}$ foi estudado em tampão fosfato $100 \mathrm{mmol} \mathrm{L}^{-1}$ (pK $K_{\mathrm{a} 1}=2,1 \mathrm{e}$ $\left.\mathrm{p} K_{\mathrm{a} 2}=7,2\right)$ nos $\mathrm{pHs} 3$ e $6,2$.

Tabela 5. pH de soluções aquosas de diferentes sais de sódio $\left(500 \mathrm{mmol} \mathrm{L}^{-1}\right)$, ácido precursor do sal e seu valor de $\mathrm{p} K_{\mathrm{a}}$.

\begin{tabular}{lclc}
\hline Sal & $\mathbf{p H}$ & Ácido precursor & $\mathbf{p} \boldsymbol{K}_{\mathbf{a}}$ \\
\hline $\mathrm{NaCl}$ & 5,1 & $\mathrm{HCl}$ & -7 \\
$\mathrm{NaBr}$ & 5,1 & $\mathrm{HBr}$ & -9 \\
$\mathrm{NaF}$ & 8,4 & $\mathrm{HF}$ & 3,2 \\
$\mathrm{NaI}$ & 5,3 & $\mathrm{HI}$ & -10 \\
$\mathrm{Na}_{2} \mathrm{SO}_{4}$ & 6,8 & $\mathrm{H}_{2} \mathrm{SO}_{4}$ & $-3 ; 1,9$ \\
$\mathrm{NaOAc}$ & 8,2 & $\mathrm{CH}_{3} \mathrm{COOH}(\mathrm{HOAc})$ & 4,8 \\
$\mathrm{NaBF}_{4}$ & 3,5 & $\mathrm{HBF}_{4}$ & $-0,4$ \\
\hline
\end{tabular}

$\mathrm{O}$ uso de tampão fosfato evitou a variação do pH com a adição de sal na maioria dos casos. Contudo, em alguns casos o tampão não foi suficiente para manter o $\mathrm{pH}$ da solução constante. Nesses casos, adicionou-se um volume mínimo de solução de $\mathrm{NaOH}$ ou $\mathrm{HCl}\left(1,0 \mathrm{~mol} \mathrm{~L}^{-1}\right)$ até o $\mathrm{pH}$ atingir o valor adequado. Os espectros e curvas cinéticas correspondentes a cada sal são apresentados no Anexo 8.3. Como descrito anteriormente, a hidrólise é mais rápida em $\mathrm{pH}=3$ do que em $\mathrm{pH}=6,2$, independente do sal adicionado. A cinética de degradação de Bn foi acompanhada a $60{ }^{\circ} \mathrm{C}$.

\subsubsection{Cátion sódio}

Exceto para sulfato de sódio e p-toluenosulfonato de sódio, observa-se uma variação discreta do valor de $k_{\mathrm{obs}}$ com a adição de sais $\left(500 \mathrm{mmol} \mathrm{L} \mathrm{L}^{-1}\right)$ nos dois $\mathrm{pHs}$ estudados (Tabela 6 e Figura 6). A adição de acetato de sódio ao tampão em $\mathrm{pH}=3$ 
alterou o pH do meio e a adição de um volume mínimo de $\mathrm{HCl}\left(1,0 \mathrm{~mol} \mathrm{~L}^{-1}\right)$ não foi suficiente para corrigi-lo. Como a mudança da concentração da solução aquosa poderia interferir no resultado do experimento, o efeito da adição de acetato de sódio sobre a cinética de decomposição de $\mathrm{Bn}$ em $\mathrm{pH}=3$ não foi investigado.

Tabela 6. Valores de constante cinética observada $\left(k_{\text {obs }}\right)$ e tempo de meia-vida $\left(t_{1 / 2}\right)$ para a decomposição de $\mathrm{Bn}$ em meio aquoso tamponado (tampão fosfato $100 \mathrm{mmol}$ L-1 pH = 3 ou 6,2) na presença de diferentes sais de sódio.

\begin{tabular}{lll|lll}
\hline $\mathbf{p H}=\mathbf{3 , 0}$ & $\boldsymbol{k}_{\mathbf{o b s}}\left(\mathbf{m i n}^{-\mathbf{1}}\right)$ & $\mathbf{t}_{\mathbf{1 / 2}} \mathbf{( m i n )}$ & $\mathbf{p H}=\mathbf{6 , 2}$ & $\boldsymbol{k}_{\mathbf{o b s}}\left(\mathbf{m i n}^{-\mathbf{1}}\right)$ & $\mathbf{t}_{\mathbf{1} / \mathbf{2}}(\mathbf{m i n})$ \\
\hline $\mathrm{TPi}$ & $0,025 \pm 0,001$ & $28 \pm 1$ & $\mathrm{TPi}$ & $0,0042 \pm 0,0001$ & $165 \pm 2$ \\
$\mathrm{NaCl}$ & $0,028 \pm 0,001$ & $24,9 \pm 0,4$ & $\mathrm{NaCl}$ & $0,0048 \pm 0,0001$ & $145 \pm 4$ \\
$\mathrm{NaBr}$ & $0,030 \pm 0,001$ & $23,1 \pm 0,4$ & $\mathrm{NaBr}$ & $0,0046 \pm 0,0001$ & $150 \pm 2$ \\
$\mathrm{NaI}$ & $0,022 \pm 0,001$ & $31 \pm 2$ & $\mathrm{NaI}$ & $0,0058 \pm 0,0001$ & $120 \pm 2$ \\
$\mathrm{Na}_{2} \mathrm{SO}_{4}$ & $0,043 \pm 0,001$ & $16 \pm 0,3$ & $\mathrm{Na}_{2} \mathrm{SO}_{4}$ & $0,0057 \pm 0,0000$ & $123 \pm 1$ \\
$p_{-\mathrm{TsONa}}$ & $0,040 \pm 0,001$ & $17,3 \pm 0,5$ & $p-\mathrm{TsONa}_{2} 0,0061 \pm 0,0001$ & $113 \pm 1$ \\
& & & $\mathrm{AcONa}$ & $0,0060 \pm 0,0000$ & $115 \pm 1$ \\
\hline
\end{tabular}
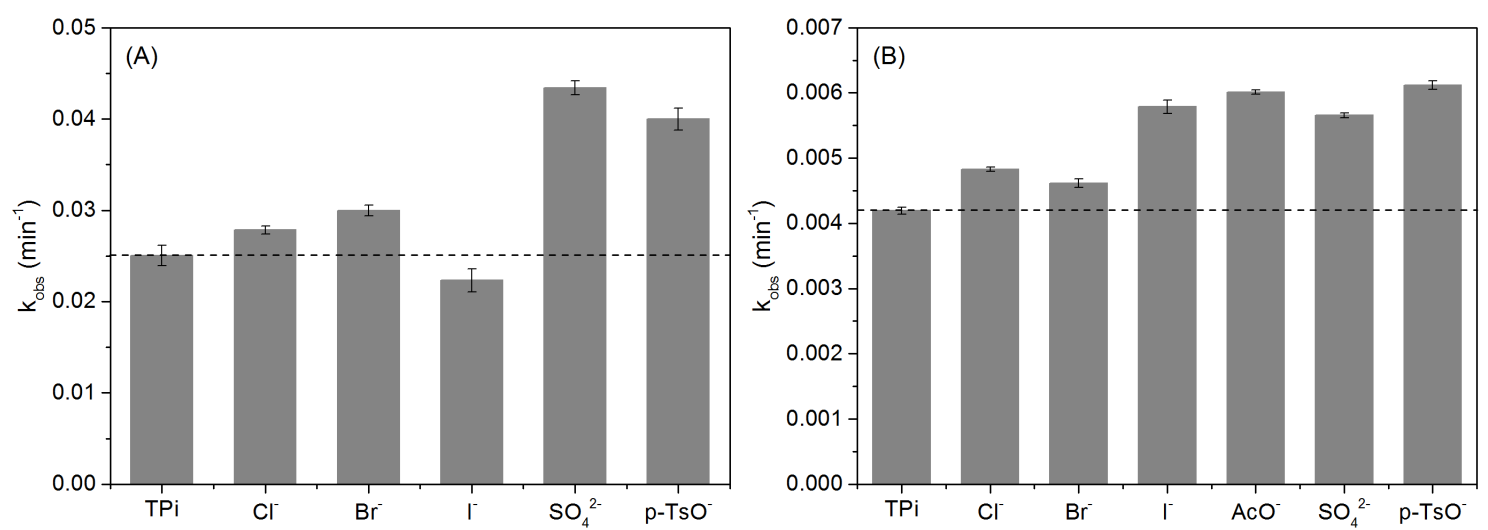

Figura 6. Efeito de diferentes sais de sódio sobre a constante cinética de hidrólise de $\mathrm{Bn}$ em tampão fosfato $100 \mathrm{mmol} \mathrm{L}^{-1} \mathrm{em} \mathrm{(A)} \mathrm{pH} 3$ e (B) pH 6,2. 


\subsubsection{Cátion amônio}

A adição de cátions amônio ao meio tamponado aumentou a velocidade de degradação de $\mathrm{Bn}$ em todos os casos em $\mathrm{pH}=6,2$ e em apenas uma das condições estudadas em $\mathrm{pH}=3$ (Tabela 7 e Figura 7). O tempo de meia-vida de Bn diminuiu cerca de duas vezes com a adição dos sais ao meio em pH $=6$,2. $\mathrm{Em} \mathrm{pH} \mathrm{3,} \mathrm{a} \mathrm{adição} \mathrm{de} \mathrm{NH}_{4} \mathrm{Cl}$ ao meio aumenta em quase três vezes o valor do $k_{\mathrm{obs}}$ de degradação de $\mathrm{Bn}$, enquanto para $\mathrm{NH}_{4} \mathrm{I}$ e $\left(\mathrm{NH}_{4}\right)_{2} \mathrm{SO}_{4}$ observa-se nenhum ou um efeito muito discreto sobre o $k_{\text {obs. }} \mathrm{O}$ efeito da adição de fluoreto de amônio e acetato de amônio sobre a cinética de decomposição de $\mathrm{Bn}$ em $\mathrm{pH}=3$ não foi investigado. A adição destes sais ao tampão alterou o pH do meio e a adição de quantidades mínimas de $\mathrm{HCl} / \mathrm{NaOH}\left(1,0 \mathrm{~mol} \mathrm{~L}{ }^{-1}\right)$ não foi suficiente para corrigi-los.

Tabela 7. Valores de constante cinética observada $\left(k_{\text {obs }}\right)$ e tempo de meia-vida $\left(t_{1 / 2}\right)$ para a decomposição de $\mathrm{Bn}$ em meio aquoso tamponado (tampão fosfato $100 \mathrm{mmol} \mathrm{L}-1 \mathrm{pH}=3$ ou 6,2) na presença de diferentes sais de amônio.

\begin{tabular}{lll|lcl}
\hline $\mathbf{p H}=\mathbf{3 , 0}$ & $\boldsymbol{k}_{\mathbf{o b s}}\left(\mathbf{m i n}^{-\mathbf{1}}\right)$ & $\mathbf{t}_{\mathbf{1 / 2}}(\mathbf{m i n})$ & $\mathbf{p H}=\mathbf{6 , 2}$ & $\boldsymbol{k}_{\mathbf{o b s}}\left(\mathbf{m i n}^{-\mathbf{1}}\right)$ & $\left.\mathbf{t}_{\mathbf{1 / 2}} \mathbf{( m i n}\right)$ \\
\hline $\mathrm{TPi}$ & $0,025 \pm 0,001$ & $28 \pm 1$ & $\mathrm{TPi}$ & $0,0042 \pm 0,0001$ & $165 \pm 2$ \\
$\mathrm{NH}_{4} \mathrm{Cl}$ & $0,072 \pm 0,014$ & $10 \pm 2$ & $\mathrm{NH}_{4} \mathrm{Cl}$ & $0,0074 \pm 0,0001$ & $93 \pm 2$ \\
$\mathrm{NH}_{4} \mathrm{I}$ & $0,026 \pm 0,002$ & $27 \pm 2$ & $\mathrm{NH}_{4} \mathrm{I}$ & $0,0080 \pm 0,0001$ & $86 \pm 1$ \\
$\left(\mathrm{NH}_{4}\right)_{2} \mathrm{SO}_{4}$ & $0,029 \pm 0,001$ & $23,8 \pm 0,3$ & $\left(\mathrm{NH}_{4}\right)_{2} \mathrm{SO}_{4}$ & $0,0084 \pm 0,0001$ & $83 \pm 1$ \\
& & & $\mathrm{NH}_{4} \mathrm{~F}$ & $0,0087 \pm 0,0003$ & $80 \pm 2$ \\
& & & $\mathrm{AcONH}_{4}$ & $0,0088 \pm 0,0001$ & $79,0 \pm 0,2$ \\
& & & & & \\
\hline
\end{tabular}



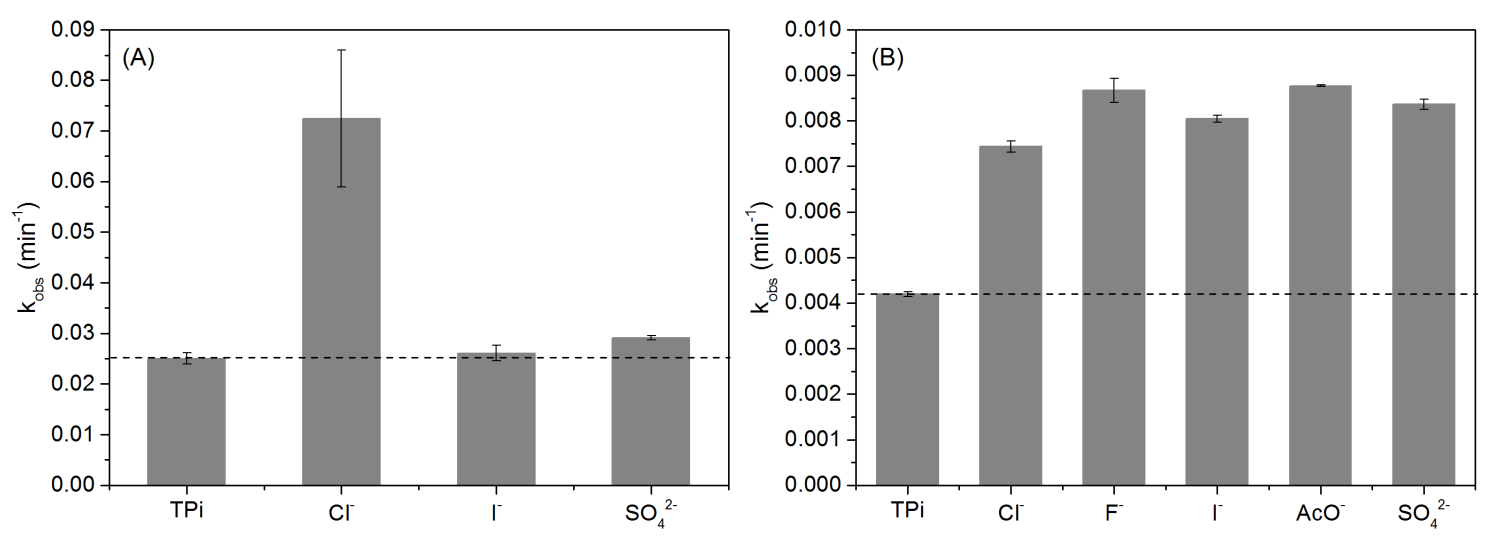

Figura 7. Efeito de diferentes sais de amônio sobre a constante cinética observada $\left(k_{\mathrm{obs}}\right)$ de hidrólise de Bn em tampão fosfato $100 \mathrm{mmol} \mathrm{L}^{-1} \mathrm{em}(\mathrm{A}) \mathrm{pH}=3$ e (B) $\mathrm{pH}=6,2$.

\subsubsection{3 Ânion cloreto}

Em $\mathrm{pH}=3$, além do efeito da adição de $\mathrm{NH}_{4} \mathrm{Cl}$, descrito no item anterior, o efeito da adição dos sais cloretos sobre o $k_{\mathrm{obs}}$ de degradação de Bn é discreto. Em pH = 6,2, a adição de $\mathrm{Bu}_{4} \mathrm{NCl}$ diminuiu em pouco mais de três vezes o tempo de meia-vida para a degradação de Bn (Tabela 8 e Figura 8).

Tabela 8. Valores de constante cinética observada $\left(k_{\mathrm{obs}}\right)$ e tempo de meia-vida $\left(\mathrm{t}_{1 / 2}\right)$ para a decomposição de $\mathrm{Bn}$ em meio aquoso tamponado (tampão fosfato $100 \mathrm{mmol} \mathrm{L}^{-1} \mathrm{pH}=3$ ou 6,2 ) na presença de diferentes sais cloretos.

\begin{tabular}{lll|lll}
\hline $\mathbf{p H}=\mathbf{3 , 0}$ & $\boldsymbol{k}_{\mathbf{o b s}}\left(\mathbf{m i n}^{-\mathbf{1}}\right)$ & $\mathbf{t}_{\mathbf{1 / 2}} \mathbf{( m i n )}$ & $\mathbf{p H ~ 6 , 2}$ & $\boldsymbol{k}_{\mathbf{o b s}}\left(\mathbf{m i n}^{-\mathbf{1}}\right)$ & $\mathbf{t}_{\mathbf{1} / \mathbf{2}}(\mathbf{m i n})$ \\
\hline $\mathrm{TPi}$ & $0,025 \pm 0,001$ & $28 \pm 1$ & $\mathrm{TPi}$ & $0,0042 \pm 0,0001$ & $165 \pm 2$ \\
$\mathrm{LiCl}$ & $0,026 \pm 0,001$ & $27 \pm 1$ & $\mathrm{LiCl}$ & $0,0048 \pm 0,0001$ & $143 \pm 4$ \\
$\mathrm{NaCl}$ & $0,028 \pm 0,001$ & $24,9 \pm 0,4$ & $\mathrm{NaCl}$ & $0,0048 \pm 0,0001$ & $145 \pm 4$ \\
$\mathrm{KCl}$ & $0,017 \pm 0,001$ & $40 \pm 1$ & $\mathrm{KCl}$ & $0,0045 \pm 0,0001$ & $153 \pm 5$ \\
$\mathrm{NH}_{4} \mathrm{Cl}$ & $0,072 \pm 0,014$ & $10 \pm 2$ & $\mathrm{NH}_{4} \mathrm{Cl}$ & $0,0074 \pm 0,0001$ & $93 \pm 2$ \\
$\mathrm{Bu}_{4} \mathrm{NCl}$ & $0,042 \pm 0,001$ & $16,4 \pm 0,2$ & $\mathrm{Bu}_{4} \mathrm{NCl}$ & $0,014 \pm 0,001$ & $50,9 \pm 0,2$ \\
$\mathrm{MgCl}_{2}$ & $0,039 \pm 0,001$ & $17,6 \pm 0,5$ & & & \\
\hline
\end{tabular}



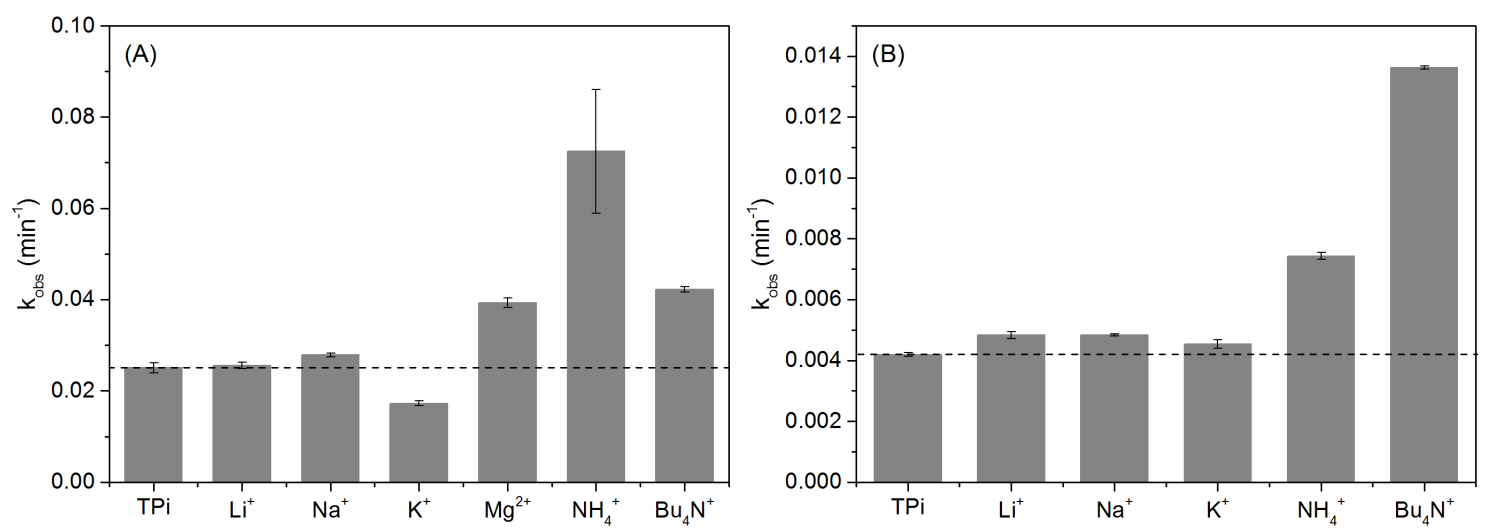

Figura 8. Efeito de diferentes sais cloretos sobre a constante cinética observada ( $\left.k_{\mathrm{obs}}\right)$ de hidrólise de $\mathrm{Bn}$ em tampão fosfato $100 \mathrm{mmol} \mathrm{L}^{-1} \mathrm{em}(\mathrm{A}) \mathrm{pH}=3$ e (B) $\mathrm{pH}=6,2$.

A adição de cloreto de magnésio ao tampão fosfato $\mathrm{pH}=6,2$ alterou $\mathrm{o} \mathrm{pH}$ do tampão de modo que a adição de quantidades mínimas de $\mathrm{HCl}$ ou $\mathrm{NaOH}\left(1,0 \mathrm{~mol} \mathrm{~L}^{-1}\right)$ não foi suficiente para corrigi-lo.

\subsection{Efeito do pH sobre a hidrólise de betanina e indicaxantina}

Para o estudo da decomposição de Bn e BtP em diferentes pHs, foi utilizado tampão fosfato $10 \mathrm{mmol} \mathrm{L}^{-1} \mathrm{com} \mathrm{pH}$ entre 2 e 11 . Os espectros de absorção foram registrados ao longo de duas meias-vidas, quando possível. Os máximos de absorção versus tempo foram ajustados com uma função monoexponencial para determinar os valores de $k_{\text {obs. }}$ Quando apropriado, foi feito um ajuste com uma função biexponencial e o valor da constante mais alta é apresentado. Com a Bn, o efeito do $\mathrm{pH}$ foi estudado em cinco temperaturas $\left(65,70,75,80\right.$ e $\left.85^{\circ} \mathrm{C}\right)$; com a BtP apenas a $60^{\circ} \mathrm{C}$.

\subsubsection{Betanina}

A constante cinética observada $\left(k_{\text {obs }}\right)$ para a decomposição de $\mathrm{Bn}$ em meio aquoso tamponado (tampão fosfato $10 \mathrm{mmol} \mathrm{L}^{-1}$ ) foi determinada em função da temperatura em diferentes pHs. Os valores de $k_{\text {obs }}$ obtidos estão apresentados na 
Tabela 9 e a dependência de $k_{\mathrm{obs}}$ com o pH em diferentes temperaturas é apresentada na Figura 9.

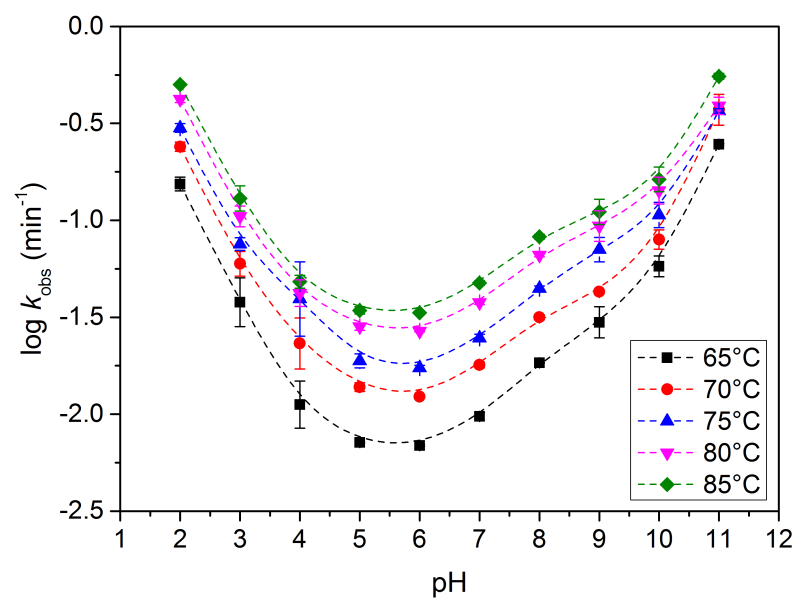

Figura 9. Logaritmo das constantes de decaimento exponencial de absorção de $\mathrm{Bn}$ em diferentes temperaturas, em função do $\mathrm{pH}$.

Tabela 9. Valores de constante cinética observada $\left(k_{\mathrm{obs}}\right)$ e tempo de meia-vida $\left(\mathrm{t}_{1 / 2}\right)$ para a decomposição de $\mathrm{Bn}$ em meio aquoso tamponado em função do $\mathrm{pH}$ e da temperatura.

\begin{tabular}{cccccc}
\hline \multicolumn{5}{c}{$\boldsymbol{k}_{\text {obs }}\left(\mathbf{m i n}^{-1}\right)$} \\
\hline $\mathbf{p H}$ & $\mathbf{6 5}^{\circ} \mathbf{C}$ & $\mathbf{7 0}^{\circ} \mathbf{C}$ & $\mathbf{7 5}^{\circ} \mathbf{C}$ & $\mathbf{8 0}{ }^{\circ} \mathbf{C}$ & $\mathbf{8 5}^{\circ} \mathbf{C}$ \\
\hline 2 & $0,15 \pm 0,01$ & $0,24 \pm 0,01$ & $0,30 \pm 0,02$ & $0,42 \pm 0,02$ & $0,50 \pm 0,01$ \\
3 & $0,039 \pm 0,012$ & $0,060 \pm 0,008$ & $0,075 \pm 0,006$ & $0,11 \pm 0,01$ & $0,13 \pm 0,02$ \\
4 & $0,012 \pm 0,003$ & $0,024 \pm 0,008$ & $0,042 \pm 0,017$ & $0,042 \pm 0,007$ & $0,048 \pm 0,004$ \\
5 & $0,0071 \pm 0,0001$ & $0,014 \pm 0,001$ & $0,019 \pm 0,002$ & $0,028 \pm 0,001$ & $0,034 \pm 0,001$ \\
\hline 6 & $0,0069 \pm 0,0001$ & $0,012 \pm 0,001$ & $0,017 \pm 0,001$ & $0,027 \pm 0,001$ & $0,033 \pm 0,001$ \\
7 & $0,0098 \pm 0,0004$ & $0,018 \pm 0,001$ & $0,025 \pm 0,001$ & $0,038 \pm 0,001$ & $0,048 \pm 0,001$ \\
\hline 8 & $0,018 \pm 0,000$ & $0,032 \pm 0,001$ & $0,044 \pm 0,001$ & $0,066 \pm 0,001$ & $0,082 \pm 0,002$ \\
9 & $0,030 \pm 0,006$ & $0,043 \pm 0,001$ & $0,071 \pm 0,011$ & $0,095 \pm 0,018$ & $0,11 \pm 0,02$ \\
\hline 10 & $0,058 \pm 0,007$ & $0,080 \pm 0,009$ & $0,11 \pm 0,02$ & $0,14 \pm 0,02$ & $0,16 \pm 0,02$ \\
\hline 11 & $0,25 \pm 0,00$ & $0,38 \pm 0,07$ & $0,37 \pm 0,01$ & $0,39 \pm 0,04$ & $0,55 \pm 0,02$ \\
\hline
\end{tabular}


Observou-se que a curva de $k_{\text {obs }}$ de hidrólise em função do $\mathrm{pH}$ segue o mesmo perfil para todas as temperaturas: concavidade para cima, com mínimo entre pHs 5 e 6 . Além disso, nas extremidades, meio muito ácido e muito básico, os valores de $k_{\mathrm{obs}}$ são mais próximos do que nos $\mathrm{pHs}$ intermediários.

\subsubsection{Indicaxantina}

\subsubsection{Estudo controle em água}

O valor da constante cinética observada $\left(k_{\text {obs }}\right)$ para a decomposição de BtP em água a $60^{\circ} \mathrm{C}$ foi determinado a partir da variação do máximo de absorção em função do tempo. Os espectros foram adquiridos a cada 2 ou 5 min durante 480 min (Figura 10). Dada a baixíssima condutividade de água deionizada, estima-se que o $\mathrm{pH}$ da água era 7 dada a sua resistividade de $18,2 \mathrm{M} \Omega \cdot \mathrm{cm}$ e uma medição semiquantitativa com fita indicadora de $\mathrm{pH}$.
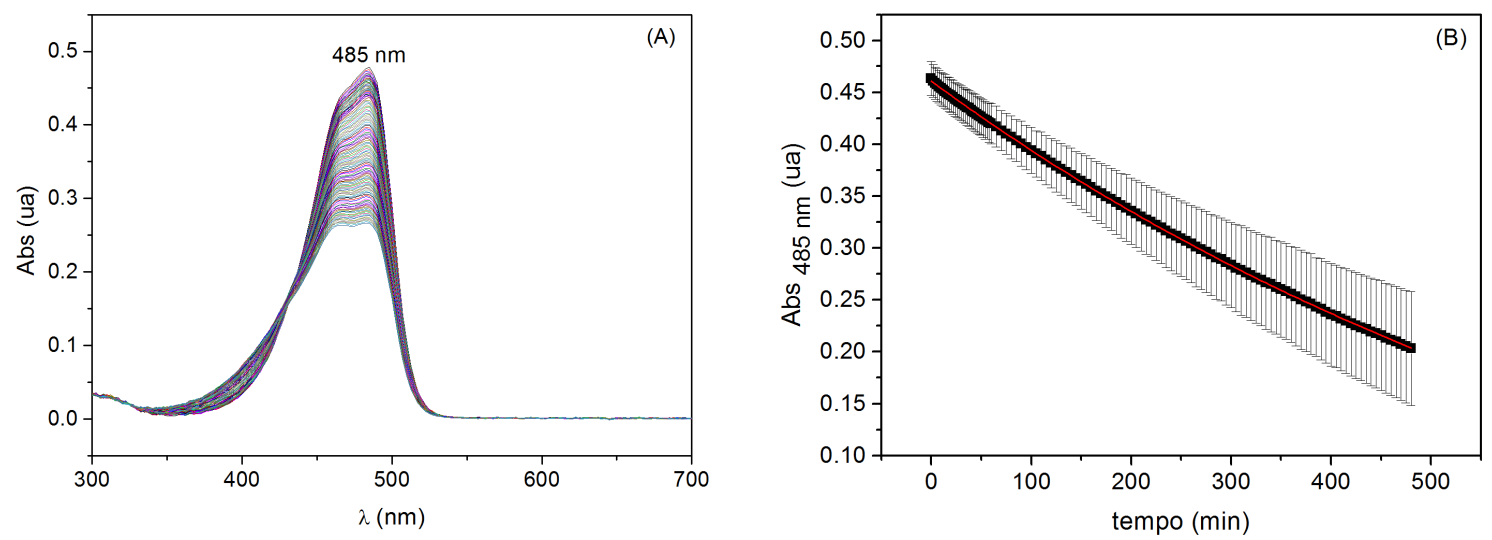

Figura 10. (A) Espectros de absorção de BtP em água ([BtP] $=10 \mu \mathrm{mol} \mathrm{L}{ }^{-1}$ ) em função do tempo a $60^{\circ} \mathrm{C}$. (B) Cinética de decaimento da absorção de BtP em $\lambda=485 \mathrm{~nm}$. O valores de $k_{\mathrm{obs}}(1,2 \pm 0,1) \times 10^{-3} \mathrm{~min}^{-1}$; $\mathrm{t}_{1 / 2}=594 \pm 57 \mathrm{~min}, 60^{\circ} \mathrm{C}$.

A análise do perfil de absorção de BtP em água indica a diminuição da banda de absorção com máximo em $485 \mathrm{~nm}$ (correspondente a BtP) em função do tempo. Os dados para a degradação de $\operatorname{BtP}(\lambda=485 \mathrm{~nm})$ foram ajustados utilizando-se uma função 
monoexponencial e a constante cinética observada $\left(k_{\text {obs }}\right)$ foi calculada em $(1,2 \pm 0,1) \times$ $10^{-3} \mathrm{~min}^{-1}$, correspondendo a um tempo de meia-vida $\left(\mathrm{t}_{1 / 2}\right)$ de $594 \pm 57 \mathrm{~min}$. A cinética de decomposição de BtP a $60{ }^{\circ} \mathrm{C}$ é muito lenta e, por isso, mesmo acompanhando sua degradação por 8 h, a meia-vida não foi atingida.

\subsubsection{Efeito do pH em tampão fosfato}

O valor de $k_{\text {obs }}$ para a decomposição de BtP meio aquoso tamponado (TPi 10 mmol $\mathrm{L}^{-1}$ ) foi determinado em diferentes pHs (Figura 11). Observa-se um perfil semelhante ao observado com o estudo de Bn. Contudo, há uma diferença notável: uma tendência linear na diminuição do $\log$ de $k_{\mathrm{obs}} \operatorname{com} \mathrm{o} \mathrm{pH}$ até $\mathrm{pH}=6$, ponto mínimo da curva. A constante de velocidade de degradação de BtP aumenta com o aumento do $\mathrm{pH}$ a partir de $\mathrm{pH}=6$. Os valores de $k_{\mathrm{obs}}$ e tempo de meia-vida para BtP estão apresentados na Tabela 10.

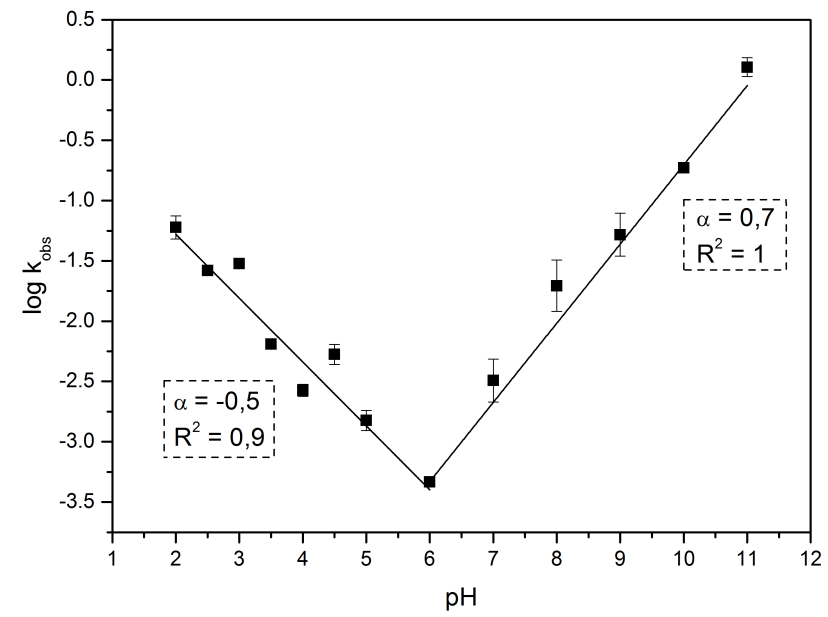

Figura 11. Logaritmo das constantes de decaimento exponencial de absorção de BtP em função do pH a $60^{\circ} \mathrm{C}$. 
Tabela 10. Valores de constante cinética observada $\left(k_{\text {obs }}\right)$ e tempo de meia-vida $\left(t_{1 / 2}\right)$ para a decomposição de BtP em diferentes $\mathrm{pHs}$, a $60^{\circ} \mathrm{C}$.

\begin{tabular}{|c|c|c|}
\hline pH & $k_{\text {obs }}\left(\mathrm{min}^{-1}\right)$ & $t_{1 / 2}(\min )$ \\
\hline 2 & $0,061 \pm 0,013$ & $12 \pm 3$ \\
\hline 2,5 & $0,026 \pm 0,001$ & $26 \pm 1$ \\
\hline 3 & $0,030 \pm 0,001$ & $23 \pm 1$ \\
\hline 3,5 & $0,0064 \pm 0,0002$ & $108 \pm 4$ \\
\hline 4 & $0,0027 \pm 0,0003$ & $261 \pm 29$ \\
\hline 4,5 & $0,0054 \pm 0,0010$ & $133 \pm 25$ \\
\hline 5 & $0,0015 \pm 0,0003$ & $468 \pm 88$ \\
\hline 6 & $0,00047 \pm 0,00003$ & $1490 \pm 106$ \\
\hline 7 & $0,0034 \pm 0,0015$ & $227 \pm 81$ \\
\hline 8 & $0,021 \pm 0,011$ & $38 \pm 15$ \\
\hline 9 & $0,055 \pm 0,024$ & $14 \pm 5$ \\
\hline 10 & $0,19 \pm 0,01$ & $3,7 \pm 0,2$ \\
\hline 11 & $1,3 \pm 0,2$ & $0,55 \pm 0,10$ \\
\hline
\end{tabular}




\section{DISCUSSÃO}

\subsection{Semissíntese de indicaxantina}

Betanina (Bn) foi obtida pelo método desenvolvido anteriormente no grupo, cuja principal limitação é a escala de obtenção de betalaína. Entretanto, observa-se no cromatograma da Figura 1 que somente betanina é obtida, não sendo observada a presença de isobetanina.

Indicaxantina (BtP) foi inicialmente produzida em meio aquoso alcalino, conforme descrito em trabalho anterior do grupo ${ }^{37}$. Ao adicionar a BtP obtida por este método nas soluções tampão utilizadas no estudo do efeito do pH sobre a decomposição desta betalaína, observou-se que o $\mathrm{pH}$ de todos os tampões era alterado para $\mathrm{pH}=5$. Este resultado pode ser interpretado considerando-se que a semissíntese depende da adição de ácido acético glacial, o que torna a solução de BtP uma solução tampão acetato $\left(\mathrm{AcOH} / \mathrm{AcONa}, \mathrm{p} K_{\mathrm{a}}=4,8\right)$. Desta forma, optou-se por preparar a BtP de uma forma alternativa que evitasse a adição de ácido acético.

Ácido betalâmico é solúvel em acetato de etila em meio ácido. ${ }^{3,}{ }^{37}$ Embora L-prolina seja insolúvel neste solvente orgânico, observa-se a reação em meio heterogêneo, ou seja, a adição de prolina ao $\mathrm{HBt}$ em $\mathrm{AcOEt} / \mathrm{H}^{+}$resulta na formação de BtP na superfície do aminoácido sólido. Como se trata de um equilíbrio (Esquema 5), a reação exige um excesso de L-pro de cerca de 100 equiv.. Nestas condições, BtP é formada quantitativamente, mas sua hidrólise durante a etapa de purificação por cromatografia de coluna em condições de fase reversa compromete o rendimento global do processo que foi calculado em cerca de 70\%. Com esse método foi possível obter BtP sem acetato, o que viabilizou os estudos posteriores de efeito de $\mathrm{pH}$. 


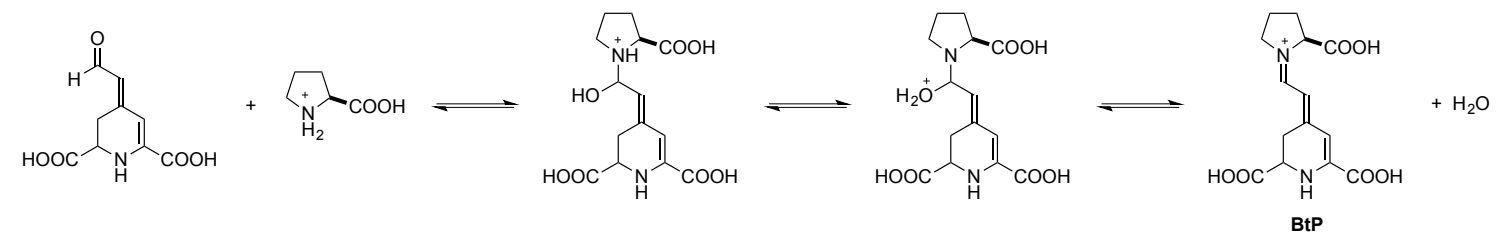

Esquema 5. Formação de BtP a partir da reação de HBt e L-pro.

\subsection{Cinéticas de hidrólise}

A decomposição de betanina em temperatura ambiente é muito lenta para ser monitorada por mais de uma meia-vida antes que sinais de contaminação microbiológica sejam observados na solução. Estudos realizados nestas condições (25 $\left.{ }^{\circ} \mathrm{C}\right)$, apresentam valores conflitantes de constante cinética de degradação $\left(k_{\mathrm{obs}}\right)$ de $\mathrm{Bn} .{ }^{9}$ ${ }^{16,20}$ Os valores de $k_{\text {obs }}$ e tempo de meia-vida $\left(\mathrm{t}_{1 / 2}\right)$ reportados na literatura estão na Tabela 11. A variação nos valores do $k_{\text {obs }}$ pode ser resultado da dificuldade em acompanhar a degradação de Bn por tempo suficiente para a realização de um bom ajuste não linear (i.e., pelo menos duas meias-vidas). Além disso, no caso de estudos com Bn não purificada, o valor obtido pode ser resultado da presença de compostos que aumentam a estabilidade desta betalaína em solução.

Tabela 11. Valores da literatura para a constante de decomposição e tempo de meia-vida para betanina pura e misturas brutas.

\begin{tabular}{lllll}
\hline & Cond $^{\mathbf{a}}$ & $\boldsymbol{k}_{\mathbf{o b s}}\left(\mathbf{h}^{-\mathbf{1}}\right)$ & $\mathbf{t}_{\mathbf{1} / \mathbf{2}}(\mathbf{h})$ & Ref \\
\hline Bn bruta & $\mathrm{pH}=5$ & 0,0027 & 252 & 20 \\
Bn & $\mathrm{pH}=5$ & 0,036 & 19 & 16 \\
Bn & $\mathrm{em} \mathrm{água}$ & 0,0053 & 130 & $\mathbf{9}$ \\
Bn & $\mathrm{pH}=5,5 ; 86^{\circ} \mathrm{C}$ & $2,8\left(0,046 \mathrm{~min}^{-1}\right)$ & $0,25(15 \mathrm{~min})$ & 40 \\
Bn & em água, $85^{\circ} \mathrm{C}$ & $2,9\left(0,048 \mathrm{~min}^{-1}\right)$ & $0,24(14,5 \mathrm{~min})$ & este trabalho \\
\hline
\end{tabular}


Os dados da variação da absorção em $536 \mathrm{~nm}$ em função do tempo indicam uma diminuição monoexponecial da absorção de $\mathrm{Bn}$, de acordo com o reportado para a decomposição térmica de Bn purificada e em suco de beterraba ${ }^{16}$. Além disso, os valores determinados estão de acordo com aqueles reportados para a decomposição de Bn em tampão citrato-fosfato $0,1 \mathrm{~mol} \mathrm{~L}^{-1}, \mathrm{pH} 5,5$, a $86{ }^{\circ} \mathrm{C}\left(k_{\mathrm{obs}}=4,6 \times 10^{-2} \min ^{-1}, \mathrm{t}_{1 / 2}=\right.$ 15 min, Tabela 11). ${ }^{40}$ Este resultado é o controle negativo para analisar os efeitos de diferentes tampões e sais. O fato do HBt ser formado com constante cinética similar ao desaparecimento de Bn e da ocorrência de ponto isosbéstico (Figura 3) sugere que os dois eventos estão diretamente relacionados. Um dado importante é a ocorrência de decomposição do HBt, que compromete o tempo de vida das betalaínas em solução, visto que a formação e hidrólise de betalaínas estão em equilíbrio e que o consumo de HBt desloca este equilíbrio na direção da hidrólise (Esquema 5).

\subsubsection{Efeito de tampões}

Tampões acetato e citrato, embora capazes de atuar como bases gerais, não afetam a constante cinética de decomposição de $\mathrm{Bn}$ a $85^{\circ} \mathrm{C}$. Além disso, para o tampão acetato, tanto a variação de $\mathrm{pH}$ entre 4,8 e 5,8 quanto a variação da concentração de tampão entre 10 e $500 \mathrm{mmol} \mathrm{L}^{-1}$ não provocam efeito significativo sobre o valor médio de $k_{\text {obs }}\left((4,7 \pm 0,2) \times 10^{-2} \min ^{-1}\right.$ e $(4,5 \pm 0,4) \times 10^{-2} \mathrm{~min}^{-1}$, respectivamente $)$. Novamente, o $\mathrm{HBt}$ apresenta valores de $k_{\mathrm{obs}}$ para sua formação compatíveis com a decomposição de Bn. Com isso, os dois tampões, acetato e citrato, podem ser usados no estudo do efeito dos sais sobre a degradação de Bn. O fator limitante para o uso destes tampões é a sua faixa de tamponamento.

Para o tampão fosfato, entretanto, os resultados são mais complexos. Em meio ácido $(\mathrm{pH}=2,1)$ o aumento da concentração do tampão resulta em diminuição sutil do 
valor de $k_{\text {obs; }}$ entretanto, o valor de $k_{\text {obs }}$ para a formação de HBt aumenta com o aumento da concentração. Além disso, o valore de $k_{\text {obs }}$ para o desaparecimento de Bn são duas vezes maior do que a formação de HBt em concentrações baixas de TPi $\left(10 \mathrm{mmol} \mathrm{L}^{-1}\right)$, mas ligeiramente diferentes em TPi $500 \mathrm{mmol} \mathrm{L}^{-1}$. Este resultado poderia ser explicando se o aumento da concentração de TPi neste $\mathrm{pH}$ favorecesse a hidrólise de betanina em detrimento de um outro processo de decomposição que ocorra em paralelo. Em $\mathrm{pH}=6,2$, este efeito não é observado e os valores de $k_{\mathrm{obs}}$ para a decomposição de Bn e formação de $\mathrm{HBt}$ são similares e praticamente duplicam com o aumento da concentração do tampão de 10 para $500 \mathrm{mmol} \mathrm{L}^{-1}$, sugerindo catálise básica geral ou catálise nucleofílica. Em $\mathrm{pH}=8,2$ os valores das constantes aumentam quase cinco vezes, corroborando a hipótese de catálise pelo fosfato.

Estes resultados poderiam ser racionalizados considerando-se que a hidrólise direta concorre com uma via de hidrólise que passa por intermediários cujo anel 1,2,3,4-tetrahidropiridínico (tHpy) foi hidrolisado anteriormente (Esquema 6). Em meio ácido $\mathrm{pH}=2,1$, betanina poderia ser protonada no anel tHpy, resultando em um aumento de eletrofilicidade nos carbonos vizinhos, mas principalmente no carbono $\mathrm{sp}^{2}$. $\mathrm{O}$ ataque nucleofílico da água a esse carbono (uma das possíveis etapas lentas da reação, junto ao ataque que leva a hidrólise direta) leva ao intermediário op-Bn, que está sujeito a uma série de reações, incluindo a hidrólise, que levaria ao aldeído op-HBt que cicliza espontaneamente ao ácido betalâmico. Este mecanismos poderia explicar como a cinética de decomposição de Bn ocorre mais rapidamente do que a formação de ácido betalâmico em meio ácido se a via que passa pelos intermediários abertos ganhar importância, ou seja, dependendo das constantes de equílibrio. O efeito da diminuição do valor de $k_{\mathrm{obs}}$ com o aumento da concentração do tampão em meio ácido $\mathrm{pH}=2,1$ 
poderia ser explicado se o íon fosfato tiver algum papel de assistência nucleofílica na hidrólise direta de Bn.

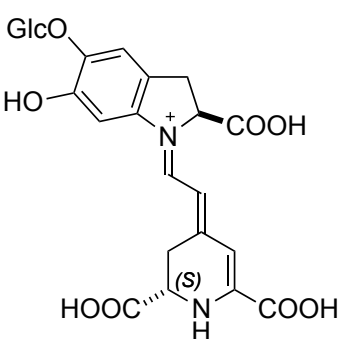

Betanina (Bn)

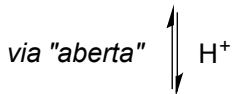<smiles>COc1cc2c(cc1O)N(CC=C1C=C(C(=O)O)N[C@H](C(=O)O)C1)C(C(=O)O)C2</smiles>

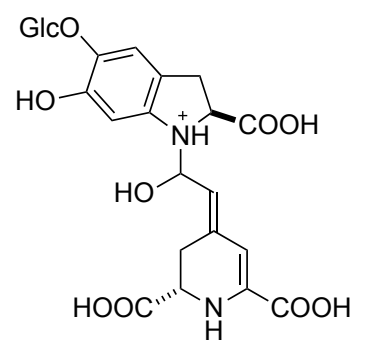

Betanina (Bn)

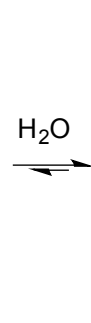

via "direta"

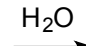

$\mathrm{H}_{2} \mathrm{O}$<smiles>N[C@@H](C/C(=C\CN1c2cc(O)c(OC(=O)O)cc2CC1C(=O)O)CC(=O)O)C(=O)O</smiles>

(op-Bn)<smiles>COc1cc2c(cc1O)NC(C(=O)O)C2</smiles><smiles>CCCCCCCCC(=O)O</smiles>

HBt

$$
\mathrm{H}^{+}, \mathrm{H}_{2} \mathrm{O}
$$<smiles>COCCO</smiles>

$\mathrm{GlcO}$<smiles>CCc1cc2c(cc1O)NC(C(=O)O)C2</smiles>

(op-HBt)

Esquema 6. Formação de HBt a partir de betanina: hidrólise direta e hidrólise via intermediários abertos.

O tampão fosfato $\left(100 \mathrm{mmol} \mathrm{L}^{-1}\right) \mathrm{em} \mathrm{pH}=6,2$ foi escolhido para estudos posteriores com a adição de sais pois o valor determinado para $k_{\mathrm{obs}}$ é similar àquele obtido com o controle em água. Além disso, tampão fosfato permite uma maior faixa de tamponamento comparada a tampão acetato ou citrato, incluindo $\mathrm{pH}=3$ no qual as porções carboxílicas das betalaínas estão supostamente protonadas. ${ }^{41}$ Os resultados nos pHs 2,1, 6,2 e 8,2 também nos levaram a realizar um estudo sistemático do efeito de pH sobre a cinética de decomposição de Bn e BtP em TPi. 


\subsubsection{Efeito de sais}

O caráter ácido-base de diferentes sais torna impossível que soluções aquosas de um conjunto dessas substâncias tenha o mesmo $\mathrm{pH}$, embora soluções de sais de $\mathrm{Na}^{+}$ tenham sido relatadas ${ }^{42}$ como tendo impacto mínimo sobre o $\mathrm{pH}$ da água. Nossos resultados com alguns dos sais empregados no trabalho de Mooi e Heyne ${ }^{42}$ indicam que o pH sofre uma variação enorme, entre 3,5 e 8,4 (Tabela 5). Isso nos levou a realizar todo o estudo para encontrar um sistema tamponado que não afetasse as características de hidrólise de betalaínas, discutido no item anterior.

O sistema tampão escolhido deve manter o $\mathrm{pH}$ do meio constante na presença de diferentes concentrações de sal. Porém, a adição de sal resultou, em alguns casos, em alteração no $\mathrm{pH}$ do meio, o que levou à necessidade de ajuste do $\mathrm{pH}$ com volumes mínimos de $\mathrm{HCl}$ ou $\mathrm{NaOH}\left(1,0 \mathrm{~mol} \mathrm{~L}^{-1}\right)$. Desta forma, somente o efeito dos sais deve ter influência sobre a cinética de decomposição de betalaínas em pH fixo.

Os estudos foram conduzidos em TPi $\left(100 \mathrm{mmol} \mathrm{L}^{-1}\right) \mathrm{pHs}=3,0$ e $6,2 \mathrm{com} \mathrm{a}$ adição de sais em concentração final de $500 \mathrm{mmol} \mathrm{L}^{-1}$ para garantir que o efeito do sal adicionado fosse mais importante do que o fosfato de sódio presente no tampão. Tanto em $\mathrm{pH}=3$ quanto 6,2 , o efeito de sais de sódio sobre o $k_{\mathrm{obs}}$ de hidrólise de Bn é sutil (Tabela 6 e Figura 6). Os maiores efeitos notados reduzem o valor de $k_{\text {obs }}$ em pouco mais do que a metade (fator entre 1,4 e 1,7 ) e foram provocados principalmente pelo $p$ TsONa nos dois pHs. Sulfonatos são aplicados em cromatografia de íons dada a sua capacidade de formar pares iônicos e o ânion $p$ - $\mathrm{TsO}^{-}$é conhecido pela sua capacidade de formar pares iônicos em solução. ${ }^{43}$ Em meio ácido, a Bn totalmente protonada tem carga +2 , o que a torna propícia para formar pares iônicos com ânions adequados (Esquema 7). A formação estabiliza a carga positiva, o que deveria em princípio 
aumentar a estabilidade da betalaína frente à hidrolise resultou no aumento do valor de $k_{\text {obs, }}$ o que poderia ser explicado eventualmente por um efeito de catálise nucleofílica ou por um efeito da força iônica sobre o $\mathrm{p} K_{\mathrm{a}}$ da betanina (diminuição do $\mathrm{p} K_{\mathrm{a}}$ das porções tHpyH $^{+}$e/ou $\mathrm{COOH}$ com o aumento da força iônica), como observado para diversos ácidos como, por exemplo, o ácido acético. ${ }^{44}$

No caso de sais de amônio, em TPi $\mathrm{pH}=6,2$ o equilíbrio entre amônio e amina em solução deve ser o fator mais importante para explicar o efeito catalítico destes sais sobre a decomposição de $\mathrm{Bn}$ (aumento de 2 vezes na magnitude de $k_{\mathrm{obs}}$ ). O resultado com cloreto de amônio em meio ácido não pode ser explicado com facilidade, visto que entre os cloretos, somente o cátion amônio e tetrabutilamônio apresentaram atividade catalítica importante para a decomposição. $\mathrm{O}$ efeito do cátion tetrabutilamônio também pode estar ligado à formação de par iônico. ${ }^{43 \mathrm{~b}} \mathrm{Em} \mathrm{pH}=6,2$, Bn está desprotonada, supostamente com carga -2 ; a formação de par iônico estabiliza a carga negativa (Esquema 7), o que provocaria um aumento da susceptibilidade da molécula a hidrólise.
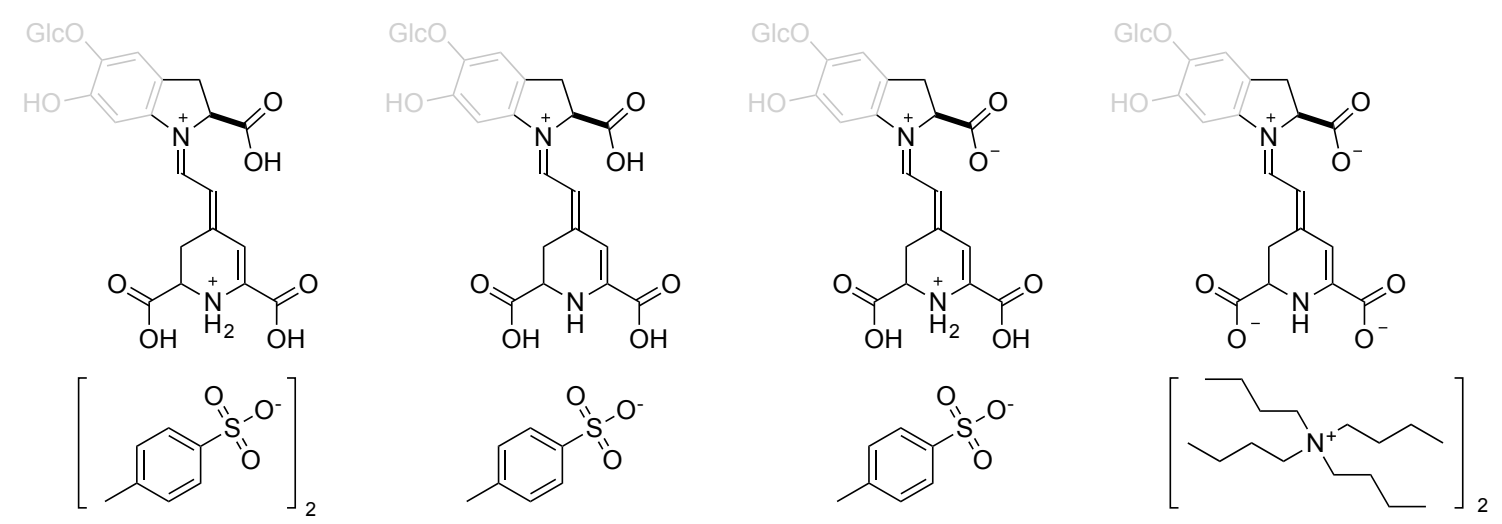

Esquema 7. Possíveis pares iônicos formados com Bn em diferentes estados de protonação e os íons p$\mathrm{TsO}^{-}$e $\mathrm{Bu}_{4} \mathrm{~N}^{+}$. Dada a incerteza na desprotonação do anel tHpy ou de uma porção carboxílica (representada aqui pela porção carboxílica da 5-O-glicosil ciclo-DOPA), ambas as possibilidades são apresentadas. 
Estes supostos efeitos de formação de par iônico deveriam ser, em princípio, observáveis por espectroscopia de absorção dado o efeito da estabilização das cargas sobre as propriedades eletrônicas de betalaínas. $\mathrm{O}$ pH não afeta o máximo de absorção de Bn quando variado entre 3 e 6 em TPi $100 \mathrm{mmol} \mathrm{L}^{-1}$, mas a adição de $p$-TsONa ou $\mathrm{Bu}_{4} \mathrm{NCl}$ provoca o mesmo deslocamento de $2 \mathrm{~nm}$ do máximo de absorção (Figura 12). Sabe-se que betalaínas são pouco sensíveis a efeitos da polaridade do meio ou presença de cátions metálicos, ${ }^{25}$ e a análise dos espectros não foi conclusiva.

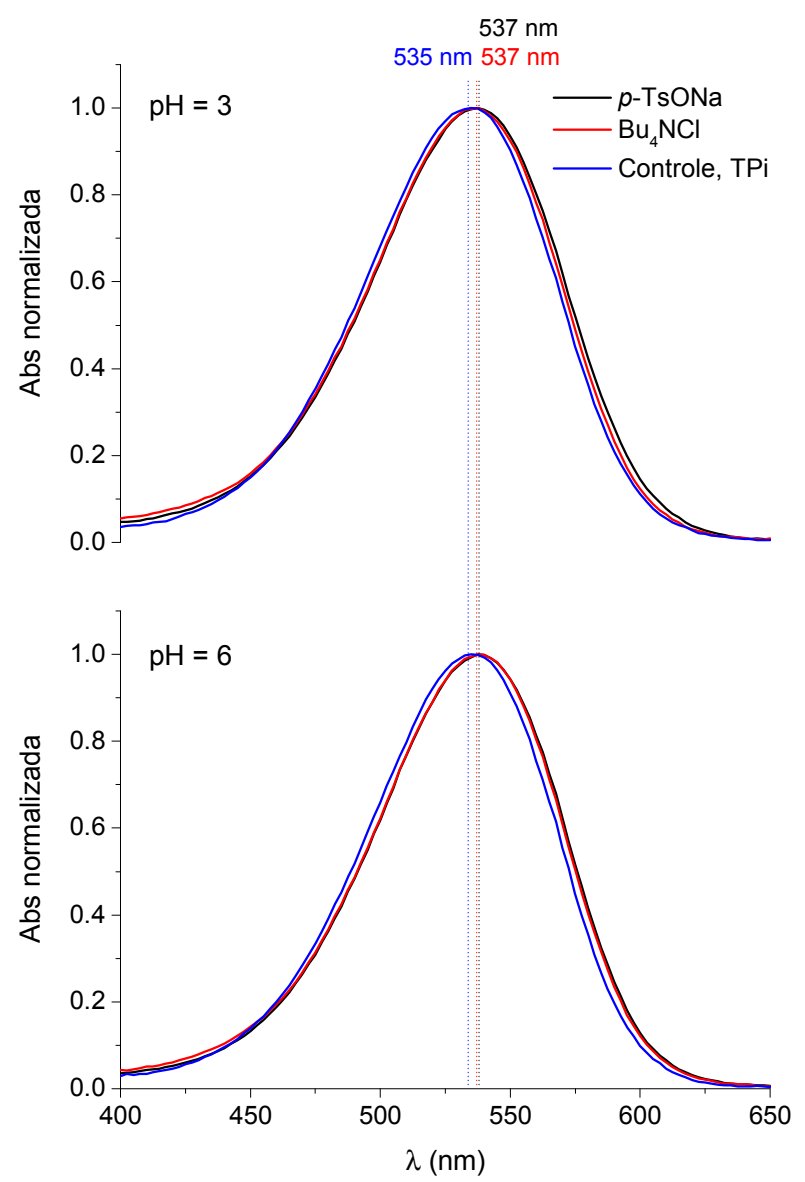

Figura 12. Espectros de absorção de Bn em tampão fosfato $\left(100 \mathrm{mmol} \mathrm{L}^{-1}\right) \mathrm{pHs} 3$ e 6 e na presença de $p$ toluenosulfonato de sódio ou cloreto de tetrabutilamônio $\left(500 \mathrm{mmol} \mathrm{L}^{-1}\right)$. 


\subsubsection{Efeito do pH sobre a hidrólise de betalaínas}

O estudo da estabilidade térmica de Bn permitiu o cálculo da energia de ativação ( $\left.\mathrm{E}_{\mathrm{a}}\right)$ para cada $\mathrm{pH}$ estudado, por meio da equação de Arrhenius. Os valores de $\mathrm{E}_{\mathrm{a}}$ (Tabela 12) estão de acordo com o observado anteriormente: maior energia de ativação nos $\mathrm{pHs}$ intermediários. Estes dados reafirmam que tanto o $\mathrm{pH}$ quanto a temperatura são fatores críticos para a decomposição de betanina, embora a variação do tempo de meia vida com o pH seja mais pronunciada (cerca de $20 \times$ ) do que a variação com a temperatura $(4 \times)$.

Os experimentos de efeito do $\mathrm{pH}$ (usando TPi) com BtP foi realizado a $60{ }^{\circ} \mathrm{C}$ e o estudo da hidrólise de $\mathrm{Bn}$ a $65^{\circ} \mathrm{C}$ por conta de uma complicação experimental ligada a troca do banho termostático. Contudo, quando os valores de $k_{\text {obs }}$ obtidos para as duas betalaínas nestas condições são comparados, é possível observar que BtP é um pouco mais estável que Bn somente entre pHs 4 e 7 , tendo $k_{\text {obs }}$ semelhante aos da Bn em meio fortemente ácido ou alcalino (Figura 13).

O gráfico de $\log k_{\mathrm{obs}}$ versus o $\mathrm{pH}$ mostra catálise ácida e básica nas extremidades (Figura 13, regiões 1 e 3/4, respectivamente), separados por uma faixa $\mathrm{pH}$-independente (Figura 13, região 2). Este perfil é relatado na literatura para diversos processos de hidrólise, sendo o exemplo mais conhecido o da hidrolise da aspirina. ${ }^{45} \mathrm{O}$ dado pode ser considerado como uma sequência de catálise ácida específica (CAE), catálise básica geral (CBG) e catálise básica específica (CBE).

Dado que não há praticamente variação dos valores de $k_{\text {obs }}$ com o aumento da concentração de fosfato, pode-se inferir que em $\mathrm{pH}=2$ ocorre CAE. Considerando-se que a adição de água tanto para a abertura do anel tHpy quanto para a hidrólise da porção iminio poderiam ser a etapa lenta desta reação (Esquema 8) e que esta reação 
concorre com uma via não catalisada por ácido (Esquema 6), cujo passo limitante é o ataque nucleofílico da água ao carbono imínico são formuladas duas hipóteses para explicar esses resultados.

Tabela 12. Tempo de meia-vida $\left(t_{1 / 2}\right)$ em função do $\mathrm{pH}$ e temperatura e valores dos parâmetros de Arrhenius em função do $\mathrm{pH}$.

\begin{tabular}{|c|c|c|c|c|c|c|c|}
\hline & \multicolumn{5}{|c|}{$t_{1 / 2}(\min )$} & \multirow[t]{2}{*}{$\mathbf{A}$} & \multirow{2}{*}{$\mathrm{E}_{\mathrm{a}}\left(\mathrm{kJ} \mathrm{mol}^{-1}\right)$} \\
\hline pH & $65^{\circ} \mathrm{C}$ & $70^{\circ} \mathrm{C}$ & $75^{\circ} \mathrm{C}$ & $80^{\circ} \mathrm{C}$ & $85^{\circ} \mathrm{C}$ & & \\
\hline 2 & $4,5 \pm 0,4$ & $2,9 \pm 0,2$ & $2,3 \pm 0,1$ & $1,6 \pm 0,1$ & $1,38 \pm 0,03$ & $3,6 \times 10^{7}$ & 53,8 \\
\hline 3 & $19 \pm 5$ & $12 \pm 2$ & $9 \pm 1$ & $7 \pm 1$ & $5 \pm 1$ & $4,0 \times 10^{7}$ & 58,1 \\
\hline 4 & $63 \pm 17$ & $31 \pm 9$ & $19 \pm 9$ & $17 \pm 3$ & $14 \pm 1$ & $5,4 \times 10^{7}$ & 62,0 \\
\hline 5 & $97 \pm 1$ & $50 \pm 3$ & $37 \pm 3$ & $25 \pm 1$ & $20 \pm 1$ & $7,8 \times 10^{10}$ & 84,4 \\
\hline 6 & $100 \pm 1$ & $56 \pm 1$ & $40 \pm 1$ & $25,8 \pm 0,3$ & $20,7 \pm 0,1$ & $1,1 \times 10^{10}$ & 78,9 \\
\hline 7 & $71 \pm 3$ & $39 \pm 1$ & $28 \pm 1$ & $18,4 \pm 0,4$ & $14,6 \pm 0,4$ & $7,0 \times 10^{9}$ & 76,3 \\
\hline 8 & $37,7 \pm 0,1$ & $22 \pm 1$ & $15,6 \pm 0,5$ & $10,5 \pm 0,2$ & $8,4 \pm 0,2$ & $7,3 \times 10^{10}$ & 81,6 \\
\hline 9 & $24 \pm 4$ & $16,2 \pm 0,3$ & $10 \pm 1$ & $7 \pm 1$ & $6 \pm 1$ & $2,4 \times 10^{9}$ & 70,6 \\
\hline 10 & $12 \pm 1$ & $9 \pm 1$ & $7 \pm 1$ & $5 \pm 1$ & $4 \pm 1$ & $1,1 \times 10^{7}$ & 53,5 \\
\hline 11 & $2,81 \pm 0,03$ & $1,9 \pm 0,4$ & $2 \pm 0,05$ & $1,8 \pm 0,2$ & $1,25 \pm 0,04$ & $3,3 \times 10^{5}$ & 39,7 \\
\hline
\end{tabular}




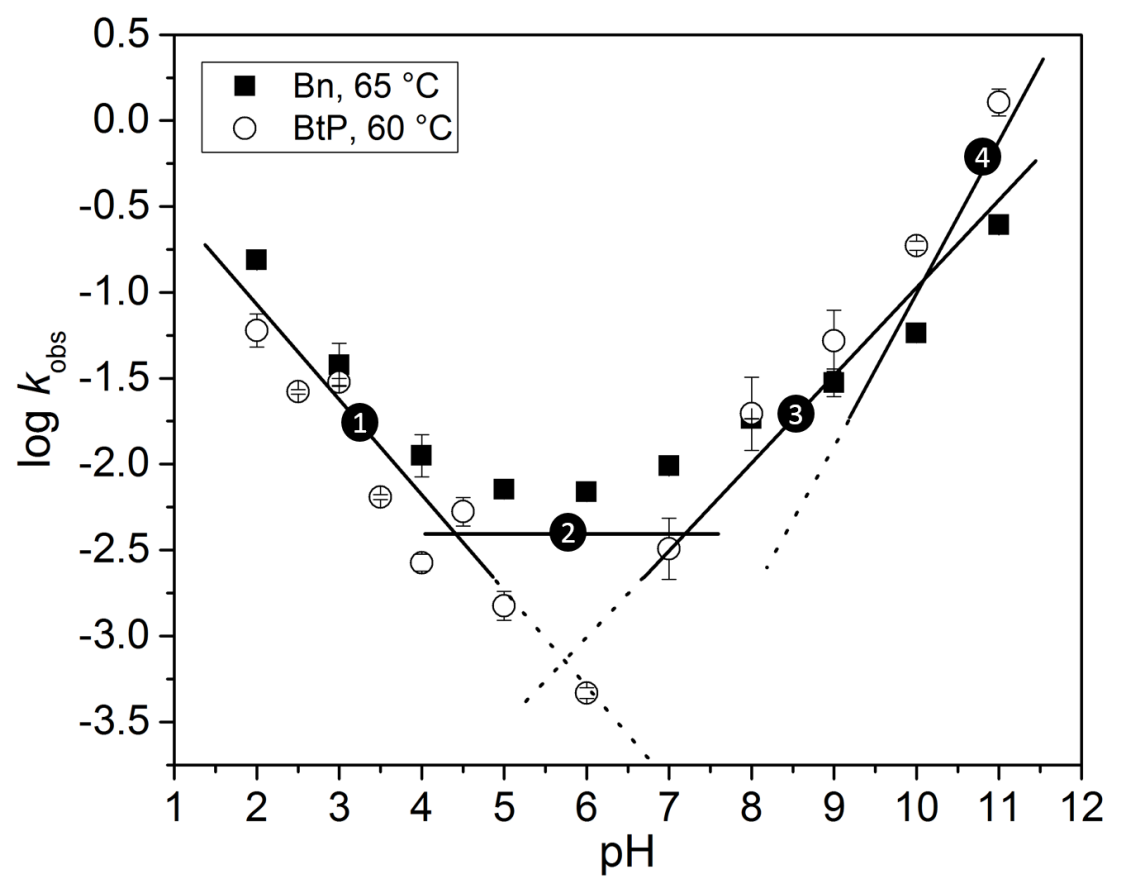

Figura 13. Dependência do valor de log $k_{\text {obs }} \mathrm{com}$ o pH do meio para betanina (Bn) a $65{ }^{\circ} \mathrm{C}$ e indicaxantina (BtP) a $60{ }^{\circ} \mathrm{C}$ e projeções de quatro regiões distintas.

A hipótese 1 (Esquema 8) é que a protonação do anel tHpy catalisa a reação via intermediários abertos, que se torna mais rápida do que a via não catalisada. A hipótese 2 se baseia na betalaína com a porção tHpy desprotonada mesmo em meio fortemente ácido. $\mathrm{O}$ aumento do $\mathrm{pH}$ do meio leva a uma desprotonação das porções carboxílicas, deixando o carbono imínico menos susceptível ao ataque dado a carga geral negativa da betalaína em pH neutro. Ou seja, a protonação das porções carboxílicas teria efeito catalítico sobre a hidrólise.

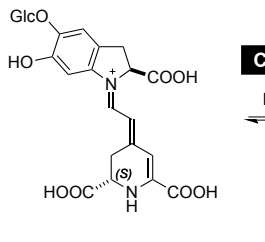

Betanina (Bn)

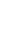

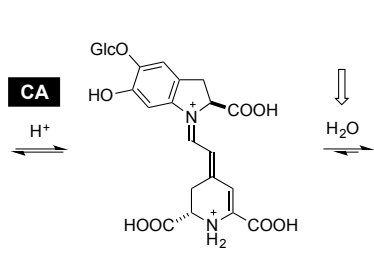

1

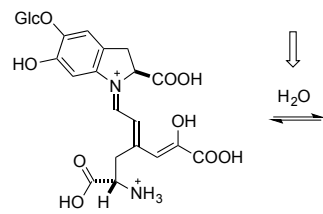

(op-Bn)

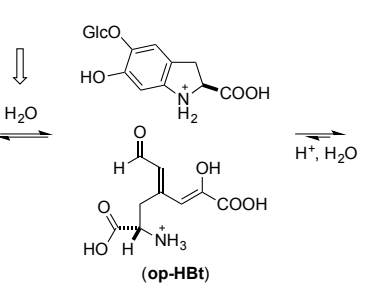

(op-HBt)

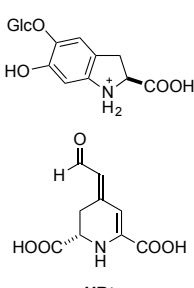

HBt

Esquema 8. Proposta 1 para o efeito catalítico de ácido sobre a hidrólise de betanina. As setas indicam os possíveis passos lentos da reação. 


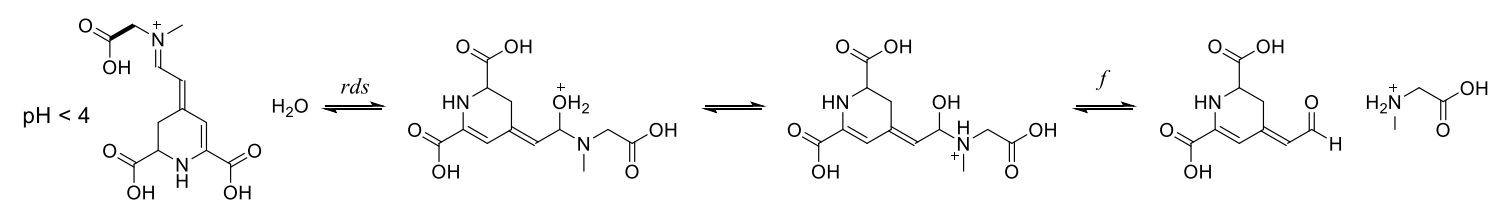

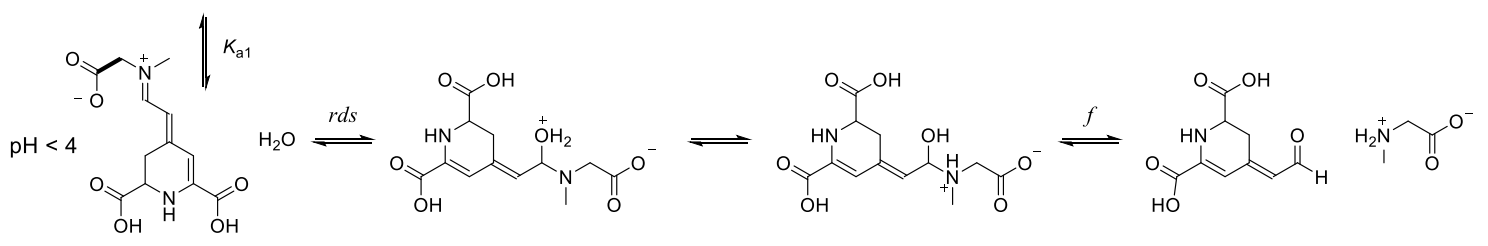

Esquema 9. Proposta 2 para o efeito de catálise. Para simplicidade é apresentada uma betalaína mais simples do que a Bn e a BtP.

Na região de pH entre 4 e 8 (Figura 13, região 2) observa-se que a hidrólise se torna independente do $\mathrm{pH}$ que poderia resultar da soma dos efeitos de CAE com CBG. Para que essa suposição faça sentido é necessário que se caracterize CBG pela ocorrência de um perfil de saturação (subida e plateau) que pode ser observado se as regiões 2 e 3 (Figura 13) são analisadas em conjunto e se em $\mathrm{pH}=9$ considera-se que a ocorrência de CBE se torna relevante. Para a CBG pode-se considerar a ocorrência de um processo intermolecular catalisado por bases gerais presentes em solução (e.g., fosfato) ou um processo intramolecular catalisado pela porção carboxílica desprotonada (Esquema 10).

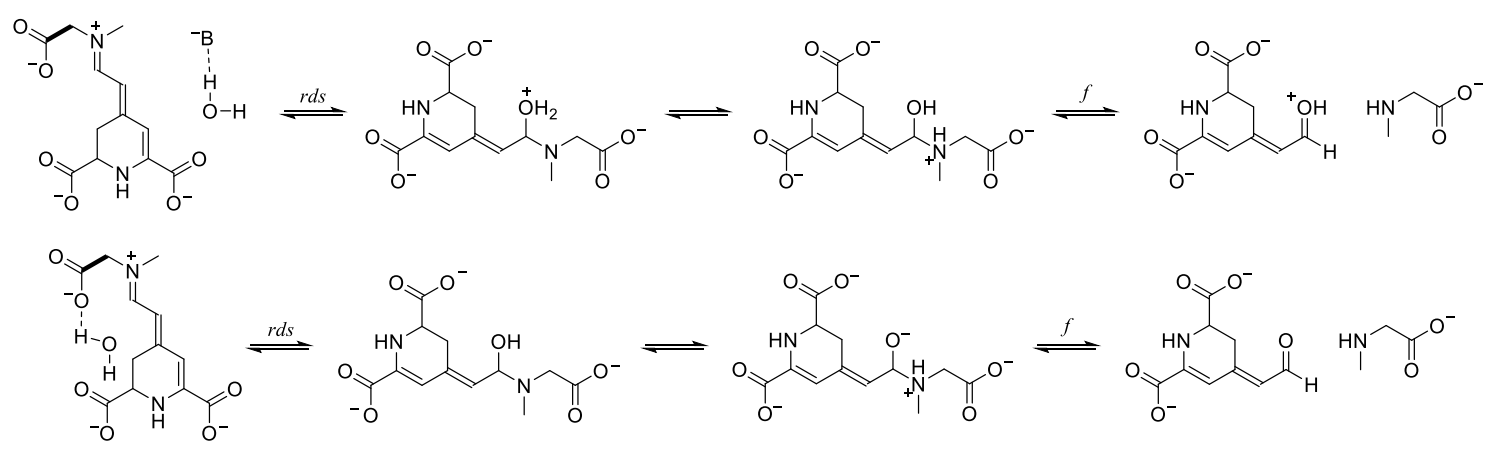

Esquema 10. Possíveis vias de catálise básica geral para a hidrólise de betalaínas. 
O aumento na velocidade da reação de degradação em $\mathrm{pH}$ acima de 9 pode ser explicado considerando-se a ocorrência de CBE (i.e., ataque direto da hidroxila, Esquema 11).

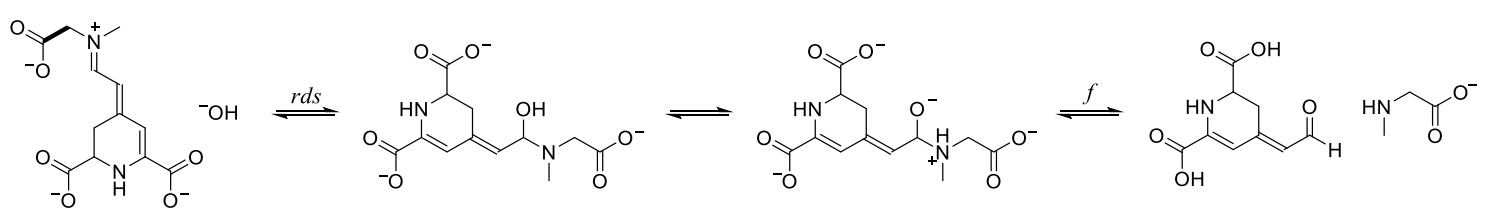

Esquema 11. Possível via de catálise básica específica para a hidrólise de betalaínas.

A maior dificuldade para a racionalização dos resultados é a falta de dados precisos a respeito dos $\mathrm{p} K_{\mathrm{a}} \mathrm{s}$ de betalaínas. O motivo da quase inexistência de informações na literatura está ligado à baixa quantidade de composto que normalmente é obtido, o que dificulta titulações potenciométricas (que exigem soluções com concentração na faixa de $10 \mathrm{mmol} \mathrm{L}{ }^{-1}$ em volumes mínimos de cerca de $\left.10 \mathrm{~mL}\right),{ }^{46}$ e à sobreposição de bandas de absorção dos ácidos e bases conjugadas durante a titulação espectrofotométrica, o que impede a localização de um comprimento de onda de monitoramento ideal. ${ }^{46}$

Os $\mathrm{p} K_{\mathrm{a}} \mathrm{s}$ de $\mathrm{Bn}$ foram relatados como sendo entre 2,9 e 3,4 para as porções carboxílicas e 8,5 e 8,7 para a hidroxila fenólica. ${ }^{41,47}$ Foi também relatado que o ponto isoelétrico (ponto de neutralidade de carga) de Bn está na faixa de $\mathrm{pH}$ entre 1,5 e 2,0. ${ }^{41}$ Indicaxantina (BtP) teve seus $\mathrm{pK}_{\mathrm{a}} \mathrm{s}$ relatados como $3,3,{ }^{48}$ não sendo possível diferenciar entre os grupos carboxílicos.

Betalaínas neutras poderiam indicar que a porção tHpy estaria protonada e que dois grupos $\mathrm{COOH}$ estão desprotonados (há duas cargas positivas e duas cargas negativas na betalaína) ou que somente um grupo carboxílico foi desprotonado. 
A primeira hipótese não é absurda considerando-se que o $\mathrm{p} K_{\mathrm{aH}}$ de iminas é, em geral, $2-4$ unidades abaixo da amina correspondente, ${ }^{49}$ ou seja, os valores de $\mathrm{p} K_{\mathrm{aH}}$ para imino ácidos seriam entre 6 e 8 visto que aminoácidos tem $\mathrm{p} K_{\mathrm{aH}}$ da porção amina próximo de 10. Um cálculo simples de distribuição média de carga foi feito com o programa MarvinSkecth e contraria o resultado experimental de 1970 de Nilsson quanto ao valor de ponto isoelétrico (PI) da $\mathrm{Bn}$ ao determinar $\mathrm{PI}=3,5$ para $\mathrm{Bn}$ e 3,9 para BtP. Entretanto, o cálculo mostra uma tendência que parece ir de encontro com os resultados de hidrólise: a diminuição da densidade positiva é acompanhada pela estabilização das betalaínas que, com carga -1 são menos susceptíveis à hidrólise. $O$ aumento da concentração de $\mathrm{HO}-$ provoca a hidrólise, independente da carga negativa das betalaínas; desta forma, a estabilização da carga pela formação de pares iônicos poderia favorecer a hidrólise ao invés de preveni-la.

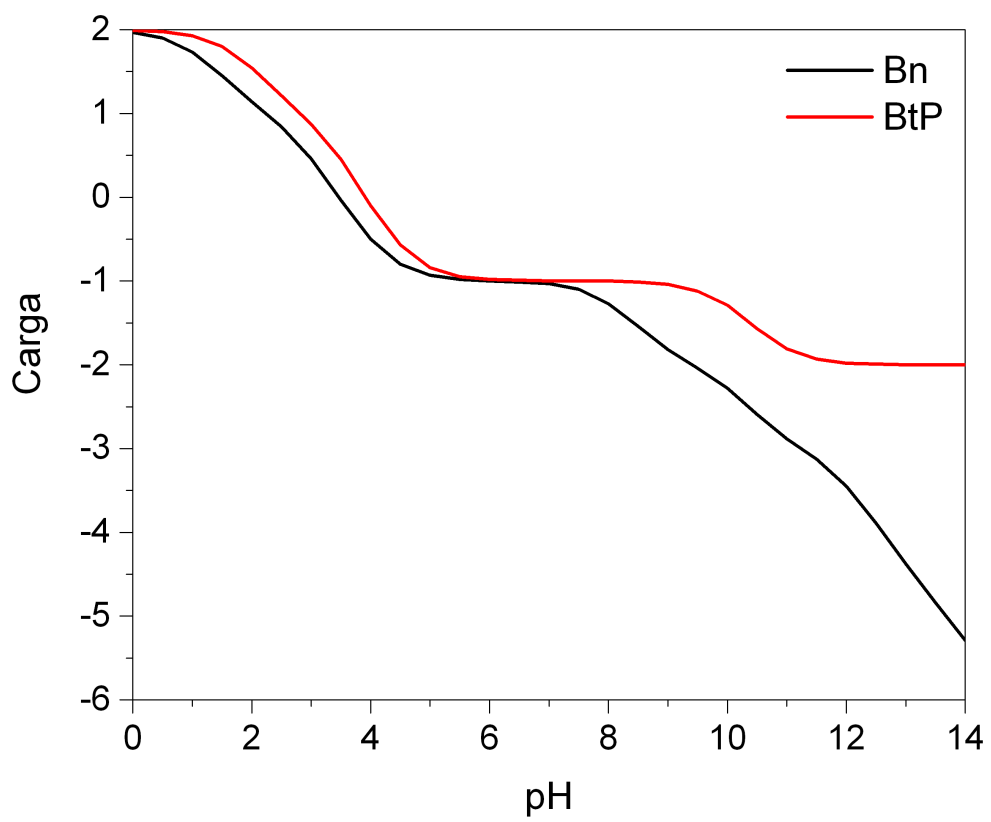

Figura 14. Distribuição de carga média para $\mathrm{Bn}$ e BtP em função do $\mathrm{pH}$ calculado pelo programa MarvinSketch através de método aditivo.

Foi realizado um ajuste não linear multiparamétrico para determinar os valores das constantes de proporcionalidade para os diferentes processos catalíticos (Eq. (1), 
Figura 15). As concentrações de $\mathrm{H}_{3} \mathrm{O}^{+}, \mathrm{HO}^{-}$, dihidrogenofosfato $\left(\mathrm{H}_{2} \mathrm{PO}_{4}^{-}\right)$e monohidrogenosulfato $\left(\mathrm{HPO}_{4}{ }^{2-}\right)$ foram determinadas em cada $\mathrm{pH}$ e o ajuste foi realizado para as decomposições de $\mathrm{Bn}$ e $\mathrm{BtP}$ a $65^{\circ} \mathrm{C}$ e $60{ }^{\circ} \mathrm{C}$ respectivamente .

$$
k_{o b s}=k_{0}+k_{C A E}\left[H_{3} O^{+}\right]+k_{1}\left[H_{2} P O_{4}^{-}\right]+k_{2}\left[H P O_{4}^{2-}\right]+k_{C B E}\left[H O^{-}\right]
$$

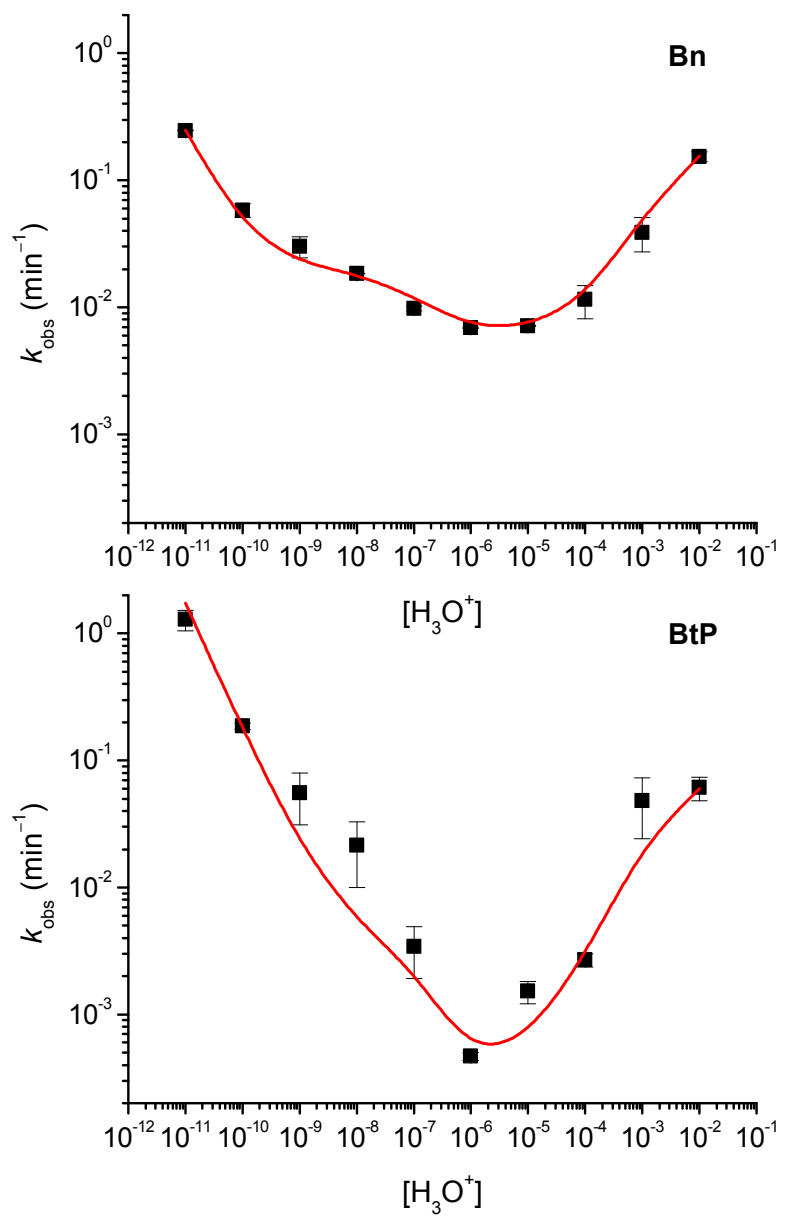

Figura 15. Concentração de $\mathrm{H}_{3} \mathrm{O}^{+}$versus $k_{\mathrm{obs}}$, ambos em escala $\log _{10}$. O ajuste multiparamétrico gerou os demais gráficos, mas somente este é apresentado para facilitar a análise. Adj- $R^{2}=0,998$ para Bn e 0,915 para BtP.

Os valores calculados para as constantes são apresentados na Tabela 3. Observase que a constante referente à $\mathrm{CBE}$ tem valores mais altos, seguidas pelas constantes de 
CAE. Os íons fosfato tem importância muito menor do que as catálises específicas, assim como a hidrólise pela água somada à possíveis processos de CBG intramoleculares $\left(\mathrm{k}_{0}\right)$. O comportamento de Bn e BtP é similar, mas BtP embora mais estável na faixa de $\mathrm{pH}$ entre 4 e 8 parece ser mais sensível ao ataque do íons $\mathrm{HO}^{-}$do que $\mathrm{Bn}$.

Tabela 13. Valores para as constantes obtidos com o ajuste não linear dos dados de $k_{\mathrm{obs}} v s$. pH com a Eq. 1.

\begin{tabular}{ccccc}
\hline & $\mathrm{Bn}$ & $\mathrm{dp}$ & $\mathrm{BtP}$ & $\mathrm{dp}$ \\
\hline $\boldsymbol{k}_{\mathrm{CAE}}$ & $-12.7 \mathrm{~min}^{-1}$ & 11.7 & $-7.6 \mathrm{~min}^{-1}$ & 6.3 \\
$\boldsymbol{k}_{\mathbf{0}}$ & $0.5 \mathrm{~min}^{-1}$ & 0.2 & $0.2 \mathrm{~min}^{-1}$ & 0.1 \\
$\boldsymbol{k}_{\mathbf{1}}$ & $-4.7 \mathrm{~L} \mathrm{~mol}^{-1} \mathrm{~min}^{-1}$ & 1.8 & $-2.3 \mathrm{~L} \mathrm{~mol}^{-1} \mathrm{~min}^{-1}$ & 0.9 \\
$\boldsymbol{k}_{\mathbf{2}}$ & $-4.6 \mathrm{~L} \mathrm{~mol}^{-1} \mathrm{~min}^{-1}$ & 1.8 & $-2.3 \mathrm{~L} \mathrm{~mol}^{-1} \mathrm{~min}^{-1}$ & 0.8 \\
$\boldsymbol{k}_{\mathrm{CBE}}$ & $208.7 \mathrm{~min}^{-1}$ & 10.0 & $1720.3 \mathrm{~min}^{-1}$ & 207.3 \\
\hline
\end{tabular}




\section{CONCLUSÃO}

O estudo da hidrólise de betanina em função do $\mathrm{pH}$ na presença e na ausência de sais revelou que tampões acetato e citrato em $\mathrm{pH}$ entre 4,8 e 5,8 não afetam as constantes cinéticas de hidrólise. Entretanto, a variação da concentração de tampão fosfato sugere a ocorrência de catálise básica geral, embora a ocorrência de catálise nucleofílica não possa ser descartada.

Soluções de sais de sódio, cloretos e amônio alteram o pH do meio. Desta forma, as soluções preparadas em tampão fosfato pHs 3 e 6,2 com concentração 100 mmol $\mathrm{L}^{-1}$ permitiram o estudo do efeito de diferentes íons sobre a cinética de decomposição de Bn. Nestas condições o tampão não afeta a hidrólise e os resultados obtidos sugerem a formação de pares iônicos, em diferentes $\mathrm{pHs}$, entre $\mathrm{Bn}$ e $p$ - $\mathrm{TsO}^{-}$e entre $\mathrm{Bn}$ e $\mathrm{Bu}_{4} \mathrm{~N}^{+}$. A formação dos pares iônicos compromete a estabilidade de betanina em solução provavelmente pela diminuição dos valores de $\mathrm{pKa}$ ou pela estabilização das cargas negativas da Bn em meio alcalino.

O efeito do pH sobre a hidrólise de Bn e BtP indica a ocorrência de CAE na região de $\mathrm{pH}$ entre 2 e 4 , seguida por $\mathrm{CBG}$ entre 4 e 8 . Acima de $\mathrm{pH}=8$, observa-se ocorrência de $\mathrm{CBE}$ pela $\mathrm{HO}^{-}$. Embora $\mathrm{BtP}$ seja mais estável frente à hidrólise na região independente do $\mathrm{pH}$, ela é mais sensível à presença de $\mathrm{HO}-\mathrm{em} \mathrm{pH}>8$, conforme determinado pelo ajuste não linear dos dados com uma função multiparamétrica, que relaciona $k_{\mathrm{obs}}$ com as concentrações de espécies com potencial catalítico, suas constantes de proporcionalidade e com uma constante que reflete a atividade de água somada a catálise intramolecular. 



\section{MATERIAL E MÉTODOS}

\subsection{Reagentes e solventes}

Os reagentes e solventes apresentados na Tabela 14 foram adquiridos em alto grau de pureza e utilizados sem tratamento prévio.

Tabela 14. Reagentes usados no trabalho e seus respectivos fornecedores.

\begin{tabular}{|c|c|c|}
\hline Reagente & Fórmula & Fornecedor \\
\hline acetato de amônio & $\mathrm{CH}_{3} \mathrm{COONH}_{4}$ & Sigma-Aldrich \\
\hline acetato de etila & $\mathrm{CH}_{3} \mathrm{COOC}_{2} \mathrm{H}_{5}$ & Vetec \\
\hline acetato de sódio tri-hidratado & $\mathrm{CH}_{3} \mathrm{COONa}$ & Sigma-Aldrich \\
\hline ácido acético glacial & $\mathrm{CH}_{3} \mathrm{COOH}$ & Sigma-Aldrich, 99\% \\
\hline ácido cítrico & $\mathrm{HOC}(\mathrm{COOH})\left(\mathrm{CH}_{2} \mathrm{COOH}\right)_{2}$ & Sigma-Aldrich, $99 \%$ \\
\hline ácido clorídrico & $\mathrm{HCl}$ & Vetec, $37 \%$ \\
\hline ácido fosfórico & $\mathrm{H}_{3} \mathrm{PO}_{4}$ & Synth, $85 \%$ \\
\hline brometo de sódio & $\mathrm{NaBr}$ & Sigma-Aldrich \\
\hline citrato de sódio tribásico di-hidratado & $\mathrm{HOC}(\mathrm{COONa})\left(\mathrm{CH}_{2} \mathrm{COONa}\right)_{2}$ & Sigma-Aldrich \\
\hline cloreto de amônio & $\mathrm{NH}_{4} \mathrm{Cl}$ & Sigma-Aldrich \\
\hline cloreto de lítio & $\mathrm{LiCl}$ & Sigma-Aldrich \\
\hline cloreto de magnésio & $\mathrm{MgCl}_{2}$ & Sigma-Aldrich \\
\hline cloreto de potássio & $\mathrm{KCl}$ & Sigma-Aldrich \\
\hline cloreto de sódio & $\mathrm{NaCl}$ & Sigma-Aldrich \\
\hline cloreto de tetrabutilamônio & $\mathrm{Bu}_{4} \mathrm{NCl}$ & Sigma-Aldrich \\
\hline fluoreto de amônio & $\mathrm{NH}_{4} \mathrm{~F}$ & Sigma-Aldrich \\
\hline fluoreto de sódio & $\mathrm{NaF}$ & Vetec \\
\hline fosfato de sódio monobásico & $\mathrm{NaH}_{2} \mathrm{PO}_{4}$ & Sigma-Aldrich \\
\hline
\end{tabular}




\begin{tabular}{lll}
\hline fosfato de sódio dibásico & $\mathrm{Na}_{2} \mathrm{HPO}_{4}$ & Sigma-Aldrich \\
\hline hidróxido de amônio & $\mathrm{NH}_{4} \mathrm{OH}$ & Sigma-Aldrich \\
\hline hidróxido de sódio & $\mathrm{NaOH}$ & Sigma-Aldrich \\
\hline iodeto de amônio & $\mathrm{NH}_{4} \mathrm{I}$ & Sigma-Aldrich \\
\hline iodeto de sódio & $\mathrm{NaI}$ & Sigma-Aldrich \\
\hline L-prolina & & Sigma-Aldrich \\
\hline metanol & $\mathrm{CH}_{3} \mathrm{OH}$ & Vetec, 99,8\% \\
\hline$p$-toluenosulfonato de sódio & $\mathrm{CH}_{3} \mathrm{C}_{6} \mathrm{H}_{4} \mathrm{SO}_{3} \mathrm{Na}(p-\mathrm{TsONa})$ & Sigma-Aldrich \\
\hline sulfato de amônio & $\left(\mathrm{NH}_{4}\right)_{2} \mathrm{SO}_{4}$ & Sigma-Aldrich \\
\hline sulfato de sódio & $\mathrm{NaSO}_{4}$ & Sigma-Aldrich \\
\hline tetrafluorborato de sódio & $\mathrm{NaBF}_{4}$ & Sigma-Aldrich \\
\hline
\end{tabular}

\subsection{Soluções}

Todas as soluções estoque de sais e soluções tampão foram preparadas com água deionizada com resistividade em temperatura ambiente $\geq 18,2 \mathrm{M} \Omega \cdot \mathrm{cm}$ (Milli-Q, Millipore, Direct-Q 3). $\mathrm{O} \mathrm{pH}$ das soluções foi aferido empregando-se um pHmetro (Metrohm, 827 pH lab) com eletrodo de vidro (Metrohm, Primatode NTC, 6.0203.100).

\subsubsection{Soluções tampão}

Soluções tampão-estoque foram preparadas pela mistura de volumes adequados de soluções de mesma concentração de um ácido fraco e da sua base conjugada, de forma a atingir os pHs desejados (Tabela 15). 
Tabela 15. Ácidos e bases usados para a preparação das soluções tampão-estoque e suas concentrações.

\begin{tabular}{lccccccccccc}
\hline Tampão & $\mathbf{p H}$ & $\mathbf{c}^{\mathbf{a}}$ & $\mathbf{V}^{\mathbf{b}}$ & $\mathbf{H A}$ & $\mathbf{c}^{\mathbf{a}}$ & $\mathbf{V}^{\mathbf{b}}$ & $\boldsymbol{n}$ & $\mathbf{A}^{-}$ & $\mathbf{c}^{\mathbf{a}}$ & $\mathbf{V}^{\mathbf{b}}$ & $\boldsymbol{n}$ \\
\hline Acetato & 4,8 & 500 & 100 & $\mathrm{HOAc}$ & 500 & 39 & 0,019 & $\mathrm{NaOAc}$ & 500 & 61 & 0,030 \\
& 5,8 & 500 & 100 & $\mathrm{HOAc}$ & 500 & 6,5 & 0,0032 & $\mathrm{NaOAc}$ & 500 & 93,5 & 0,047 \\
& & & & ácido & & & & citrato de & & \\
Citrato & 4,8 & 500 & 100 & cítrico & 500 & 25 & 0,012 & śdio & & 75 & 0,037 \\
& & & & & & & sodio & & & \\
Fosfato & 2,1 & 500 & 100 & $\mathrm{H}_{3} \mathrm{PO}_{4}$ & 500 & 44 & 0,022 & $\mathrm{NaH}_{2} \mathrm{PO}_{4}$ & 500 & 56 & 0,028 \\
& 3,0 & 100 & 100 & $\mathrm{H}_{3} \mathrm{PO}_{4}$ & 100 & 10 & 0,0009 & $\mathrm{NaH}_{2} \mathrm{PO}_{4}$ & 100 & 90 & 0,009 \\
& 6,2 & 500 & 100 & $\mathrm{NaH}_{2} \mathrm{PO}_{4}$ & 500 & 76,5 & 0,038 & $\mathrm{Na}_{2} \mathrm{HPO}_{4}$ & 500 & 23,5 & 0,012 \\
& 8,2 & 500 & 100 & $\mathrm{NaH}_{2} \mathrm{PO}_{4}$ & 500 & 4 & 0,0019 & $\mathrm{Na}_{2} \mathrm{HPO}_{4}$ & 500 & 96 & 0,048 \\
\hline
\end{tabular}

${ }^{a}$ concentração em mmol L ${ }^{-1} ;{ }^{b}$ volume em $\mathrm{mL}$.

As soluções tampão de trabalho $\left(10,50,100\right.$, e $\left.250 \mathrm{mmol} \mathrm{L}^{-1}\right)$ foram preparadas pela diluição seriada das soluções-estoque, aferindo-se o pH após a diluição. O tampão fosfato $\mathrm{pH}=3$ foi utilizado apenas na concentração $100 \mathrm{mmol} \mathrm{L}^{-1}$.

\subsubsection{Soluções de fosfato com pH entre 2 e 11}

Foram preparadas soluções tampão de $10 \mathrm{mmol} \mathrm{L}^{-1}$ de fosfato dibásico e 200 mmol L ${ }^{-1}$ de cloreto de sódio, utilizando-se de $\mathrm{HCl}$ ou $\mathrm{NaOH}\left(1,0 \mathrm{~mol} \mathrm{~L}^{-1}\right)$ para se atingir o $\mathrm{pH}$ desejado, no intervalo entre $\mathrm{pH} 2-11 .^{50}$

\subsubsection{Soluções de sais em meio tamponado}

As soluções de diferentes sais $\left([s a l]_{\text {final }}=500 \mathrm{mmol} \mathrm{L}^{-1}\right)$ foram preparadas em balão volumétrico $(25 \mathrm{~mL})$ pela dissolução da massa adequada dos sólidos em tampão fosfato (100 mmol L $\mathrm{m}^{-1}, \mathrm{pH}=3,0$ ou 6,2$)$.

\subsection{Obtenção de betanina a partir de suco de beterraba}

Betanina foi obtida a partir de suco de beterraba bruto por purificação por cromatografia de coluna em condições de fase reversa. ${ }^{7} \mathrm{O}$ preparo e a filtração do suco 
foram feitos da seguinte forma: beterrabas frescas (Beta vulgaris, subsp. vulgaris) foram processadas em uma centrífuga tipo juicer (Phillips-Wallita RI1855/01) e o suco resultante foi centrifugado $\left(10 \mathrm{~min}, 7500 \times \mathrm{g},-10^{\circ} \mathrm{C}\right.$ ), filtrado com papel de filtro e, posteriormente, submetido a filtração em coluna de sílica gel $(20 \mathrm{~mm})$ a pressão reduzida $(50 \mathrm{mmHg})$.

O filtrado foi refrigerado $\left(-20{ }^{\circ} \mathrm{C}\right)$ e centrifugado $\left(10 \mathrm{~min},-10{ }^{\circ} \mathrm{C}, 7500 \times \mathrm{g}\right) \mathrm{e}$ filtrado em papel de filtro pregueado antes do uso. Após este processo, o suco foi submetido a cromatografia de coluna em condições de fase reversa $\left(\mathrm{SiO}_{2}-\mathrm{C} 18\right)$, utilizando-se água como eluente ( $20 \mathrm{~g} \mathrm{SiO}_{2}-\mathrm{C} 18$ para $5 \mathrm{mg}$ de amostra). As frações de cor magenta $\left(\lambda_{\mathrm{abs}}=536 \mathrm{~nm}\right)$ foram analisadas por HPLC e as frações contendo betanina pura foram reunidas e armazenadas a $-20^{\circ} \mathrm{C}{ }^{7}$

\subsection{Semissíntese de indicaxantina}

\subsubsection{Obtenção de ácido betalâmico em acetato de etila}

Suco de beterraba $(500 \mathrm{~mL})$ em um béquer $(1 \mathrm{~L})$ munido de agitação mecânica foi refrigerado $\left(\sim 10^{\circ} \mathrm{C}\right)$ e o $\mathrm{pH}$ do meio foi levado a 11,4 com a adição de $\mathrm{NH}_{4} \mathrm{OH} 30 \%$ (70 a $90 \mathrm{~mL})$. A reação foi mantida sob agitação até que a solução atingisse uma coloração esverdeada com filme amarelo brilhante, característico do ácido betalâmico (cerca de $60 \mathrm{~min}$ ). A solução foi então resfriada a $5{ }^{\circ} \mathrm{C}$ e, em seguida, o $\mathrm{pH}$ foi levado a uma valor entre 1,5 e 2 com a adição de $\mathrm{HCl}_{(\mathrm{aq})} 37 \%$ v/v (ca. $100 \mathrm{~mL}$ ). Em seguida, a agitação foi interrompida e o macaco abaixado. A solução foi transferida para um funil de separação de $1,0 \mathrm{~L}$ e foram adicionados $50 \mathrm{~mL}$ de acetato de etila $(10 \%$ do volume inicial de suco). O funil foi agitado com movimento precessional e foi observado um pequeno volume na fase superior. A fase inferior (aquosa) foi reservada para segunda extração e cerca de $90 \mathrm{~mL}$ restantes (contendo a fase orgânica) foram transferidos, 
vertendo pela boca de cima do funil, para tubos falcon de $50 \mathrm{~mL}$ e centrifugados a 5000 xg durante 2 minutos. A fase orgânica amarela foi separada com o auxílio de uma pipeta pasteur. O procedimento de extração foi repetido com a fase aquosa separada anteriormente para a segunda extração. O ácido betalâmico obtido com as duas extrações foi reunido e congelado em um banho de $\mathrm{CO}_{2}(\mathrm{~s}) / \mathrm{EtOH}$. Ocorre a formação de uma suspensão que foi filtrada rapidamente a vácuo, com o auxílio de um funil de Büchner, para eliminar a água e o sal em suspensão.

\subsubsection{Semissíntese e purificação de indicaxantina}

Indicaxantina foi preparada a partir do acoplamento aldimínico entre o ácido betalâmico em acetato de etila e L-prolina. A L-prolina (10 equiv.) foi adicionada ao ácido betalâmico e a reação foi mantida em um banho de ultrassom a temperatura ambiente por cerca de 10 min. A L-prolina não é solúvel em acetato de etila e, portanto, a reação de formação da indicaxantina ocorre na superfície do sólido. Após este período, observou-se a mudança na coloração do sólido, de branco para amarelo alaranjado. Neste momento, o sólido foi filtrado a vácuo, com o auxílio de um funil de Büchner, e em seguida, solubilizado em água. A purificação de indicaxantina foi feita por cromatografia de coluna em condições de fase reversa $\left(\mathrm{SiO}_{2}-\mathrm{C} 18\right)$, utilizando água como eluente.

\subsection{Caracterização das betalaínas}

\subsubsection{Espectroscopia de absorção}

Espectros de absorção foram obtidos em meio aquoso empregando-se celas de acrílico (caminho ótico: $1 \mathrm{~cm}$, volume total: 1,5 $\mathrm{mL}$ ), com o auxílio de um espectrofotômetro Varian Cary 50 Bio. 


\subsubsection{Cromatografia líquida de alta eficiência}

Para análise cromatográfica das betalaínas foi utilizada cromatografia líquida de alta eficiência em escala analítica em um equipamento Shimadzu 20A equipado com detector PDA SPD20A com coluna de fase reversa C18 Ascentis ${ }^{\circledR}(250 \times$ x 4,6 mm, Supelco). Os dados foram obtidos utilizando o programa de aquisição LCSolution. A mistura de solventes utilizada foi: $5-95 \%$ B em $20 \mathrm{~min}$, sendo o solvente A: $0,1 \%$ TFA/água e solvente B: $0,1 \% \mathrm{TFA} / 60 \% \mathrm{MeCN} / a ́ g u a$ com fluxo de $1 \mathrm{~mL} \mathrm{~min}{ }^{-1}$.

\subsection{Estudo cinético da decomposição de betalaínas}

\subsubsection{Efeito da concentração do tampão}

A decomposição de betanina em meio aquoso foi monitorada a $85^{\circ} \mathrm{C}$ utilizandose um espectrofotômetro de absorção Varian Cary 50 Bio com porta cubeta termostatizado com um banho termostático Lauda RP845, e cubeta de quartzo de $4 \mathrm{~mL}$ de volume total. Espectros de absorção (200 a $700 \mathrm{~nm}$ ) foram registrados a cada 1, 3 ou 5 min por, no mínimo duas meia-vidas da betanina. Para os ensaios cinéticos, foram utilizadas soluções tampão acetato $(\mathrm{pHs}=4,8$ e 5,8), citrato $(\mathrm{pH}=4,8)$ e fosfato $(\mathrm{pHs}=$ 2,1, 6,2 e 8,2), nas concentrações 10, 50, 100, 250 e $500 \mathrm{mmol} \mathrm{L}^{-1}$.

\subsubsection{Efeito da presença de sais}

A decomposição de betanina na presença de sais foi monitorada a $60^{\circ} \mathrm{C}$ utilizando-se um espectrofotômetro de absorção Varian Cary 50 Bio, com um porta cubetas para 18 cubetas, termostatizado com um banho termostático Lauda RP845, e cubetas de acrílico de 3,5 mL de volume total. Os espectros de absorção (300 a $700 \mathrm{~nm}$ ) foram obtidos a cada 1,5 ou 2,5 min durante $360 \mathrm{~min}$. Para estes ensaios foram utilizadas solução de sais na concentração de $500 \mathrm{mmol} \mathrm{L}^{-1}$ em tampão fosfato 100 mmol L ${ }^{-1}, \mathrm{pHs}=3$ e 6,2. Os sais utilizados foram: cloreto de sódio, brometo de sódio, 
iodeto de sódio, sulfato de sódio, acetato de sódio, $p$-toluenosulfonato de sódio, cloreto de lítio, cloreto de potássio, cloreto de magnésio, cloreto de tetrabutilamônio, cloreto de amônio, iodeto de amônio, fluoreto de amônio, sulfato de amônio e acetato de amônio.

\subsubsection{Efeito do $\mathrm{pH}$}

A decomposição de betanina em meio tamponado foi monitorada a $65,70,75$, 80 e $85^{\circ} \mathrm{C}$ e a decomposição de indicaxantina em meio tamponado foi monitorada a 60 ${ }^{\circ} \mathrm{C}$. Em ambos os casos utilizou-se um espectrofotômetro de absorção Varian Cary 50 Bio, com um porta cubetas para 18 cubetas, termostatizado com um banho termostático Lauda RP845, e cubetas de acrílico de 3,5 mL de volume total. Para Bn, os espectros de absorção (300 a $700 \mathrm{~nm}$ ) foram obtidos a cada 1,5 min durante $150 \mathrm{~min}$. Para estes ensaios foram utilizadas solução tampão fosfato $10 \mathrm{mmol} \mathrm{L}^{-1}$, variando o $\mathrm{pH}$ entre 2 11. No caso de BtP, os espectros de absorção $(300 \mathrm{a} 700 \mathrm{~nm})$ foram obtidos a cada 2 ou 5 min durante 480 min. Para estes ensaios foram utilizadas solução tampão fosfato 10 mmol L $\mathrm{L}^{-1}$, variando o $\mathrm{pH}$ entre $2-11$.

\subsection{Determinação das constantes cinéticas observadas ( $\left.\mathbf{k}_{\mathrm{obs}}\right)$}

Os dados de variação da absorção em diferentes comprimentos de onda vs. o tempo foram ajustados a um modelo cinético de primeira ordem, empregando-se funções mono (Eq. (2)) ou biexponenciais (Eq. (3)), conforme necessário. Assim, foram determinados os valores das constantes cinéticas observadas $\left(k_{o b s}\right)$.

$$
\begin{gathered}
A b s=A b s_{0}+A_{1} e^{-k_{o b s} t} \\
A b s=A b s_{0}+A_{1} e^{-k_{o b s} t^{t}}+A_{2} e^{-k_{o b s} t^{2}}
\end{gathered}
$$

Cálculo das constantes cinéticas bimoleculares $\left(\mathrm{k}_{\mathrm{bi}}\right)$

$$
A+B \rightarrow P
$$

a constante bimolecular $\left(k_{\mathrm{bi}}\right)$ é obtida de acordo com: 


$$
\frac{d[P]}{d t}=k_{b i}[A][B]
$$

mas, para $\mathrm{A}$ em excesso ( $>10$ equiv. em relação a $\mathrm{B}$, condição de pseudo-primeira ordem), tem-se um valor de constante observada ( $\left.k_{\mathrm{obs}}\right)$ determinado por:

$$
\frac{d[P]}{d t}=k_{o b s}[B]
$$

onde $k_{\mathrm{obs}}=k_{\mathrm{bi}}[\mathrm{A}]$. Assim, as constantes bimoleculares para a decomposição de betanina na presença de excesso de sal foram determinadas correlacionando-se as constantes cinéticas observadas com a concentração do sal e calculando-se o coeficiente angular.

\subsection{Análise dos resultados}

Os ajustes matemáticos e análises estatísticas foram feitos empregando-se o programa Origin (v.9.1, OriginLab, 2013). 


\section{REFERÊNCIAS}

1. Azeredo, H. M. C., Betalains: properties, sources, applications, and stability - a review. Int. J. Food Sci. Technol. 2009, 44 (12), 2365-2376.

2. Steglich, W.; Strack, D., Betalains. In The Alkaloids, Brossi, A., Ed. Academic Press: London, 1990; pp 1-62.

3. Schliemann, W.; Kobayashi, N.; Strack, D., The decisive step in betaxanthin biosynthesis is a spontaneous reaction. Plant Physiol. 1999, 119 (4), 1217-1232.

4. Gonçalves, L. C. P.; Marcato, A. C.; Rodrigues, A. C. B.; Pagano, A. P. E.; De Freitas, B. C.; De Machado, C. O.; Nakashima, K. K.; Esteves, L. C.; Lopes, N. B.; Bastos, E. L., Betalains: From the colors of beetroots to the fluorescence of flowers. Revista Virtual de Quimica 2015, 7 (1), 292-309.

5. Stintzing, F.; Schliemann, W., Pigments of fly agaric (Amanita muscaria). $Z$ Naturforsch C 2007, 62 (11-12), 779-85.

6. Herbach, K. M.; Stintzing, F. C.; Carle, R., Betalain stability and degradation Structural and chromatic aspects. J. Food Sci. 2006, 71 (4), R41-R50.

7. Gonçalves, L. C. P.; Trassi, M. A. D.; Lopes, N. B.; Dörr, F. A.; Santos, M. T.; Baader, W. J.; Oliveira, V. X.; Bastos, E. L., A comparative study of the purification of betanin. Food Chem. 2012, 131 (1), 231-238.

8. Gandia-Herrero, F.; Garcia-Carmona, F.; Escribano, J., Floral fluorescence effect. Nature 2005, 437 (7057), 334-334.

9. Bartoloni, F. H.; Gonçalves, L. C. P.; Rodrigues, A. C. B.; Dörr, F. A.; Pinto, E.; Bastos, E. L., Photophysics and hydrolytic stability of betalains in aqueous trifluoroethanol. Monatsh. Chem. 2013, 144, 567-571.

10. Gonçalves, L. C. P.; Di Genova, B. M.; Dörr, F. A.; Pinto, E.; Bastos, E. L., Effect of dielectric microwave heating on color and antiradical capacity of betanin. $J$. Food. Eng. 2013, 118, 49-55.

11. Esatbeyoglu, T.; Wagner, A. E.; Schini-Kerth, V. B.; Rimbach, G., Betanin-A food colorant with biological activity. Molecular Nutrition \& Food Research 2015, 59 (1), 36-47.

12. Pasch, J. H.; Von Elbe, J. H., Betanine degradation as influenced by water activity. J. Food Sci. 1975, 40 (6), 1145-1147.

13. Cohen, E.; Saguy, I., Effect of water activity and moisture content on the stability of beet powder pigments. J. Food Sci. 1983, 48, 703-707.

14. Huang, A. S.; von Elbe, J. H., Kinetics of the degradation and regeneration of betanine. J. Food Sci. 1985, 50, 1115-1120.

15. von Elbe, J. H.; Schwartz, S. J.; Hildenbrand, B. E., Loss and regeneration of betacyanin pigments during processing of red beets. J. Food Sci. 1981, 46 (6), 17131715. 
16. von Elbe, J. H.; Maing, I.-Y.; Amundson, C. H., Color stability of betanin. J. Food Sci. 1974, 39 (2), 334-7.

17. Herbach, K. M.; Stintzing, F. C.; Carle, R., Thermal degradation of betacyanins in juices from purple pitaya Hylocereus polyrhizus (Weber) Britton \& Rose monitored by high-performance liquid chromatography-tandem mass spectometric analyses. Eur. Food Res. Technol. 2004, 219 (4), 377-385.

18. Herbach, K. M.; Stintzing, F. C.; Carle, R., Impact of thermal treatment on color and pigment pattern of red beet (Beta vulgaris L.) preparations. J. Food Sci. 2004, 69 (6), C491-C498.

19. Saguy, I., Thermostability of red beet pigments (betanine and vulgaxanthin-I): influence of pH and temperature. J. Food Sci. 1979, 44 (5), 1554-1555.

20. Sapers, G. M.; Hornstein, J. S., Varietal differences in colorant properties and stability of red beet pigments. J. Food Sci. 1979, 49, 99-101.

21. Stintzing, F. C.; Carle, R., Functional properties of anthocyanins and betalains in plants, food, and in human nutrition. Trends Food Sci. Technol. 2004, 15 (1), 19-38.

22. Huang, A. S.; von Elbe, J. H., Effect of $\mathrm{pH}$ on the degradation and regeneration of betanine. J. Food Sci. 1987, 52 (6), 1689-1693.

23. Cai, Y.; Sun, M.; Schliemann, W.; Corke, H., Chemical stability and colorant properties of betaxanthin pigments from Celosia argentea. J. Agric. Food Chem. 2001, 49 (9), 4429-35.

24. Schwartz, S. J.; von Elbe, J. H., Identification of betanin degradation products. Zeitschrift für Lebensmitteluntersuchung und -Forschung A 1983, 176 (6), 448-453.

25. Goncalves, L. C. P. Betalaínas: semissíntese, capacidade antirradicalar e aplicação como sondas em sistemas biológicos. Doctorate, Universidade Federal do ABC, Santo André, 2012.

26. (a) Sollenberger, P. Y.; Martin, R. B., Carbon-nitrogen and nitrogen-nitrogen double bond condensation reactions. In The Chemistry of the Amino Group, Patai, S., Ed. Wiley: London, 1968; pp 349-406; (b) Saggiomo, V.; Lüning, U., On the formation of imines in water--a comparison. Tetrahedron Lett. 2009; (c) Godoy-Alcantar, C.; Yatsimirsky, A. K.; Lehn, J. M., Structure-stability correlations for imine formation in aqueous solution. J. Phys. Org. Chem. 2005, 18 (10), 979-985.

27. Wybraniec, S., Formation of decarboxylated betacyanins in heated purified betacyanin fractions from red beet root (Beta vulgaris L.) monitored by LC-MS/MS. $J$. Agric. Food Chem. 2005, 53 (9), 3483-3487.

28. Herbach, K. M.; Stintzing, F. C.; Carle, R., Identification of heat-induced degradation products from purified betanin, phyllocactin and hylocerenin by highperformance liquid chromatography/electrospray ionization mass spectrometry. Rapid Commun. Mass Spectrom. 2005, 19 (18), 2603-2616.

29. Johnson, J.; Morales, N.; Gorczyca, A.; Dolliver, D.; McAllister, M., Mechanisms of acid-catalyzed Z/E isomerization of imines. J. Org. Chem 2001, 66 (24), 7979-7985. 
30. Singer, J. W.; Von Elbe, J. H., Degradation rates of vulgaxanthine I. J. Food Sci. 1980, 45, 489-491.

31. (a) Simon, P.; Drd·k, M.; Altamirano, R. C., Influence of water activity on the stability of betanin in various water/alcohol model systems. Food Chem. 1993, 46 (2), 155-158; (b) Savolainen, K.; Pyysalo, H.; Kallio, H., The influence of water activity on the stability of vulgaxanthin I. Z. Lebensm.-Unters. Forsch. 1978, 167 (4), 250-1; (c) Blandamer, M. J.; Engberts, J. B. F. N.; Gleeson, P. T.; Reis, J. C. R., Activity of water in aqueous systems; A frequently neglected property. Chem. Soc. Rev. 2005, 34 (5).

32. von Elbe, J. H.; Attoe, E. L., Oxygen involvement in betalain degradation Measurement of active oxygen species and oxidation redution potentials. Food Chem. 1985, 16, 49-67.

33. Huang, A. S.; Von Elbe, J. H., Stability comparison of two betacyanine pigments - amaranthine and betanine. J. Food Sci. 1986, 51 (3), 670-674.

34. Pasch, J. H.; Von Elbe, J. H., Betanine stability in buffered solutions containing organic acids, metal cations, antioxidants, or sequestrants. J. Food Sci. 1979, 44 (1), $72-$ 75 .

35. (a) Attoe, E. L.; Von Elbe, J. H., Oxygen involvement in betanine degradation: effect of antioxidants. J. Food Sci. 1985, 50 (1), 106-110; (b) Bilyk, A.; Kolodij, M. A.; Sapers, G. M., Stabilization of red beet pigments with isoascorbic acid. J. Food Sci. 1981, 46 (5), 1616-1617; (c) Bilyk, A.; Howard, M., Reversibility of ThermalDegradation of Betacyanines under the Influence of Isoascorbic Acid. J. Agric. Food Chem. 1982, 30 (5), 906-908.

36. Attoe, E. L.; Von Elbe, J. H., Oxygen involvement in betanin degradation. Oxygen uptake and influence of metal ions. Z. Lebensm.-Unters. Forsch. 1984, 179 (3), 232-6.

37. Gonçalves, L. C. P.; Tonelli, R. R.; Bagnaresi, P.; Mortara, R. A.; Ferreira, A. G.; Bastos, E. L., A Nature-Inspired Betalainic Probe for Live-Cell Imaging of Plasmodium-Infected Erythrocytes. Plos One 2013, 8 (1), e53874.

38. Trezzini, G. F.; Zryd, J. P., Characterization of some natural and semi-synthetic betaxanthins. Phytochem. 1991, 30 (6), 1901-3.

39. CRC Handbook of Chemistry and Physics. http://www.hbcpnetbase.com/ (acessado em 02/12/2015).

40. Saguy, I.; Kopelman, I. J.; Mizrahi, S., Thermal kinetic degradation of betanin and betalamic acid. J. Agric. Food Chem. 1978, 26 (2), 360-362.

41. Nilsson, T., Studies into the pigments in beetroot (Beta vulgaris L. ssp.vulgaris var. rubra L.). Lantbruks-Hoegsk. Ann. 1970, 36 (2), 179-219.

42. Mooi, S. M.; Heyne, B., Size Does Matter: How To Control Organization of Organic Dyes in Aqueous Environment Using Specific Ion Effects. Langmuir 2012, 28 (48), 16524-16530.

43. (a) Fainberg, A. H.; Winstein, S., Salt Effects and Ion Pairs in Solvolysis and Related Reactions. VII. Salt Effects in Acetolysis of some Secondary Arylsulfonates. $J$. Am. Chem. Soc. 1956, 78 (12), 2780-2784; (b) Fritz, J. S., Factors affecting selectivity in ion chromatography. J. Chrom A 2005, 1085 (1), 8-17. 
44. Rossotti, F. J. C.; Rossotti, H., The determination of stability constants, and other equilibrium constants in solution. McGraw-Hill: New York,, 1961; p 425 p.

45. (a) Marrs, P. S., Class projects in physical organic chemistry: The hydrolysis of aspirin. J. Chem. Educ. 2004, 81 (6), 870-873; (b) Fersht, A. R.; Kirby, A. J., Intramolecular Nucleophilic Catalysis in Hydrolysis of Substituted Aspirin Acids. $J$. Am. Chem. Soc. 1968, 90 (21), 5826-5832; (c) Fersht, A. R.; Kirby, A. J., Hydrolysis of Aspirin . Intramolecular General Base Catalysis of Ester Hydrolysis. J. Am. Chem. Soc. 1967, 89 (19), 4857-4863; (d) Edwards, L. J., The Hydrolysis of Aspirin .2. Trans. Faraday Soc. 1952, 48 (8), 696-699; (e) Edwards, L. J., The Hydrolysis of Aspirin - a Determination of the Thermodynamic Dissociation Constant and a Study of the Reaction Kinetics by Ultra-Violet Spectrophotometry. Trans. Faraday Soc. 1950, 46 (9), 723-735; (f) Blanch, J.; Finch, A., Student Experiment in Chemical Kinetics Hydrolysis of Aspirin. Am J Pharm Educ 1971, 35 (2), 191-202; (g) Aarons, L.; Clifton, P.; Fleming, G.; Rowland, M., Aspirin Binding and the Effect of Albumin on Spontaneous and Enzyme-Catalyzed Hydrolysis. J. Pharm. Pharmacol. 1980, 32 (8), 537-543.

46. Albert, A.; Serjeant, E. P., The determination of ionization constants : a laboratory manual. 3rd ed.; Chapman and Hall: London ; New York, 1984; p x, 218 p.

47. Schmidt, O. T.; Becher, P.; Hübner, M., Zur Kenntnis der Farbstoffe der Roten Rübe, III. Chem. Ber. 1960, 93 (6), 1296-1304.

48. Piattelli, M.; Minale, L.; Prota, G., Isolation, structure and absolute configuration of indicaxanthin. Tetrahedron 1964, 20 (10), 2325-2329.

49. Novak, M.; Bonham, G. A.; Mulero, J. J.; Pelecanou, M.; Zemis, J. N.; Buccigross, J. M.; Wilson, T. C., Hydrolysis of N-acetyl-p-benzoquinone imines: pH dependence of the partitioning of a tetrahedral intermediate. J. Am. Chem. Soc. 1989, 111 (12), 4447-4456.

50. Nara, S. J.; Valgimigli, L.; Pedulli, G. F.; Pratt, D. A., Tyrosine Analogues for Probing Proton-Coupled Electron Transfer Processes in Peptides and Proteins. J. Am. Chem. Soc. 2009, 132 (2), 863-872. 


\section{ANEXOS}

\subsection{Curvas cinéticas de hidrólise de Bn nos tampões acetato e citrato}
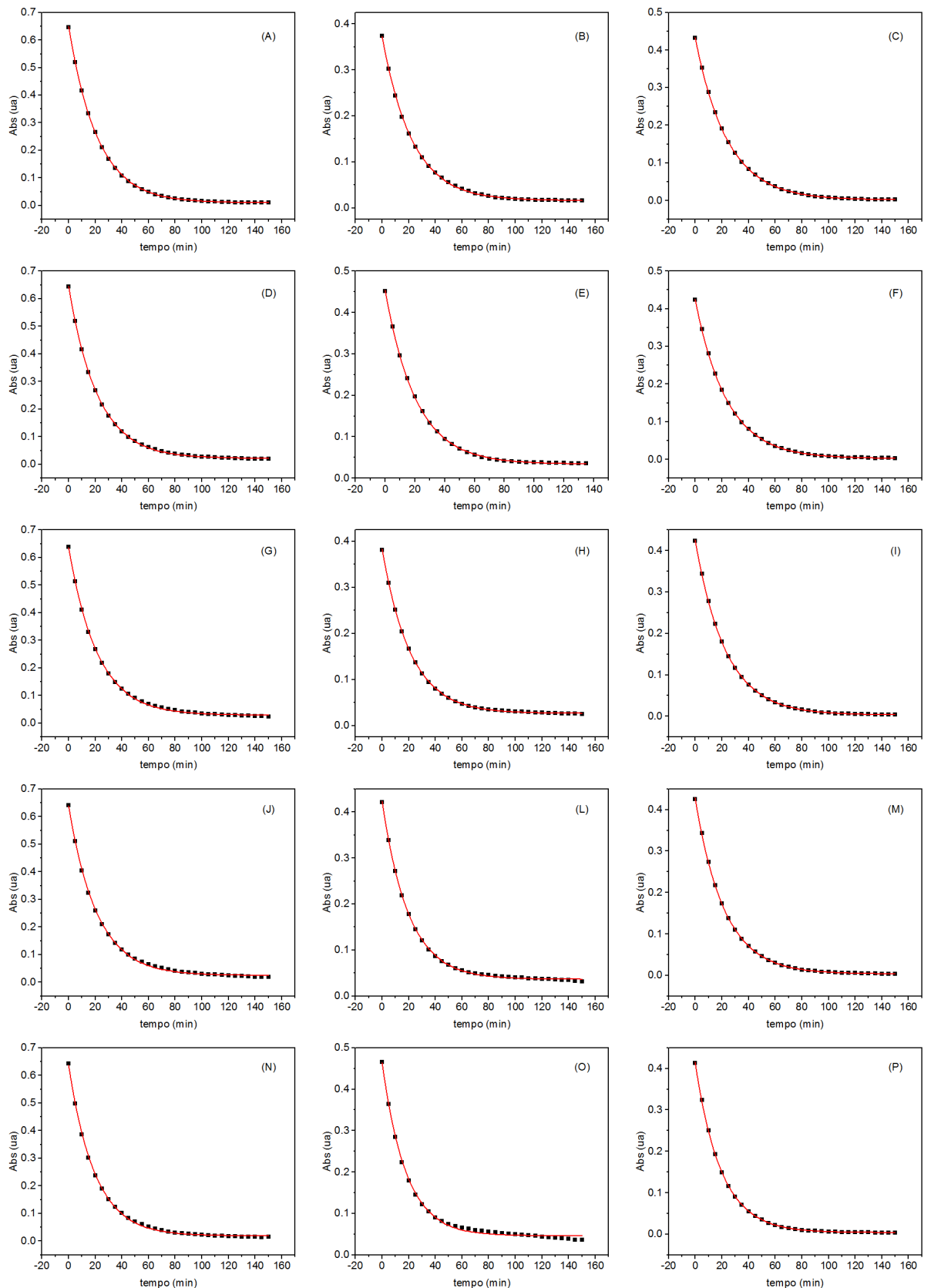

Decaimento de absorção de Bn em função do tempo em tampão acetato e citrato, a $85{ }^{\circ} \mathrm{C}$. Na horizontal, tampão acetato $\mathrm{pH}=4,8$, tampão citrato $\mathrm{pH}=4,8$ e tampão acetato $\mathrm{pH}=5,8$; na vertical, a concentração do tampão é $10,50,100,250,500 \mathrm{mmol} \mathrm{L}^{-1}$. Os espectros foram obtidos a cada 5 min durante $150 \mathrm{~min}$. 

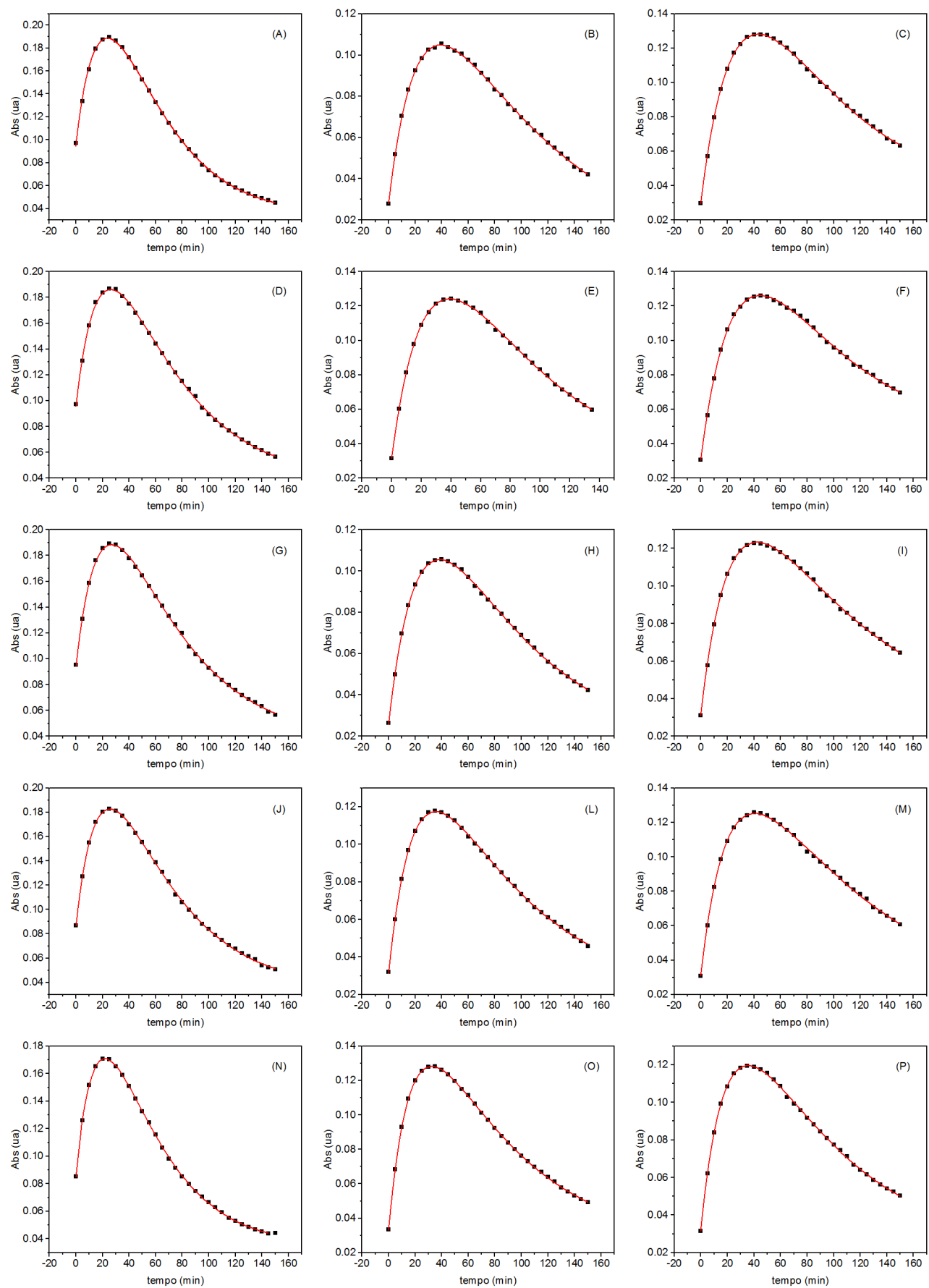

Formação e degradação de $\mathrm{HBt}$ em função do tempo em tampão acetato e citrato, a $85{ }^{\circ} \mathrm{C} . \mathrm{Na}$ horizontal, tampão acetato $\mathrm{pH}=4,8$, tampão citrato $\mathrm{pH}=4,8$, e tampão acetato $\mathrm{pH}=5,8$; na vertical a concentração do tampão é $10,50,100,250,500 \mathrm{mmol} \mathrm{L}^{-1}$. 


\subsection{Curvas cinéticas de hidrólise de Bn em tampão fosfato}
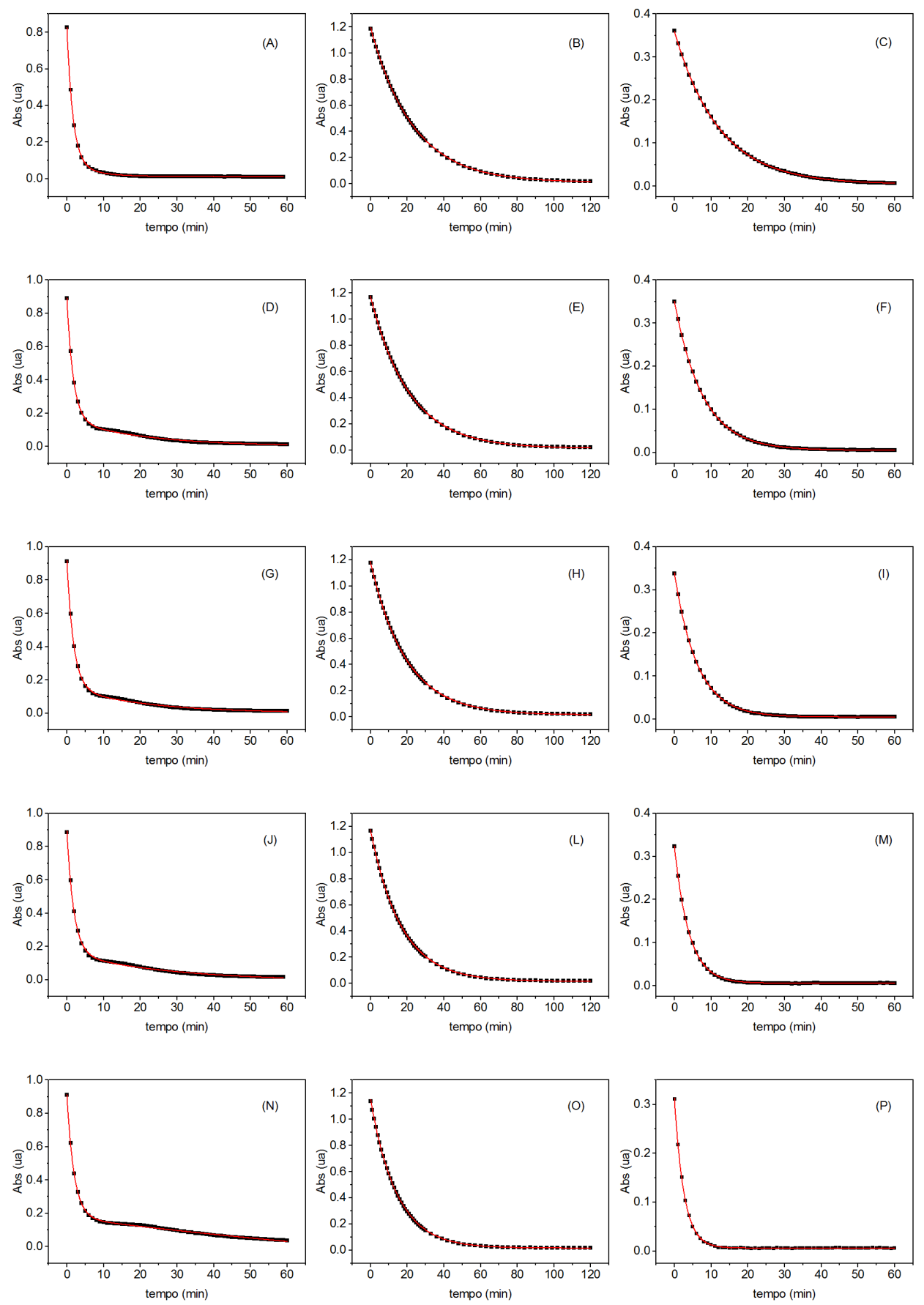

Decaimento de absorção de Bn em função do tempo em tampão fosfato, a $85{ }^{\circ} \mathrm{C}$. Na horizontal o pH é 2,1, 6,2 e 8,2; na vertical, a concentração do tampão é 10, 50, 100, 250, $500 \mathrm{mmol} \mathrm{L}^{-1}$. 

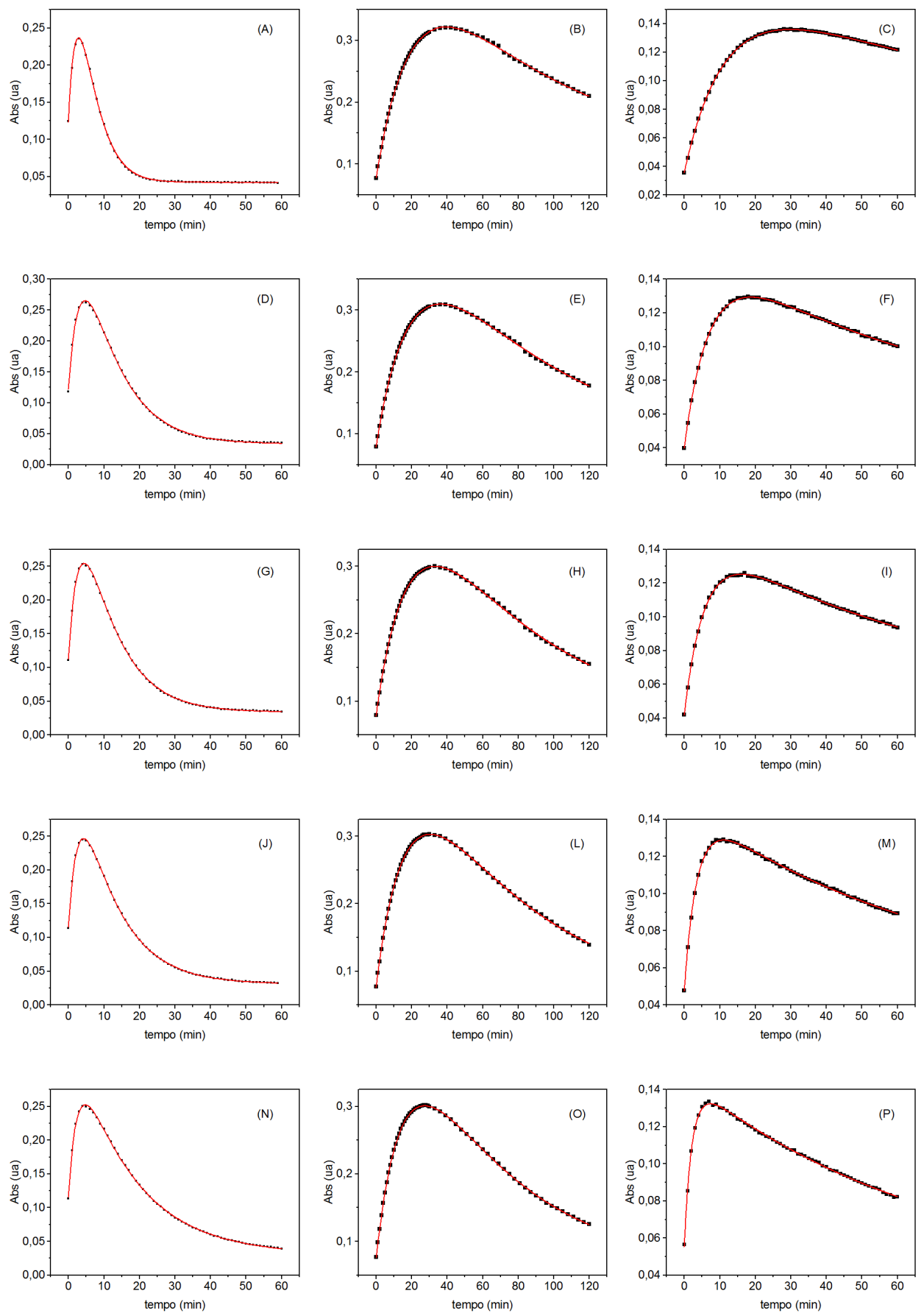

Formação e degradação de $\mathrm{HBt}$ em função do tempo em tampão fosfato, a $85{ }^{\circ} \mathrm{C}$. Na horizontal o pH é 2,1, 6,2 e 8,2; na vertical, a concentração do tampão é 10, 50, 100, 250, $500 \mathrm{mmol} \mathrm{L}^{-1}$. 


\subsection{Curvas cinéticas de hidrólise de Bn em tampão fosfato $100 \mathrm{mmol} \mathrm{L}^{-1}$,}

na presença de sais
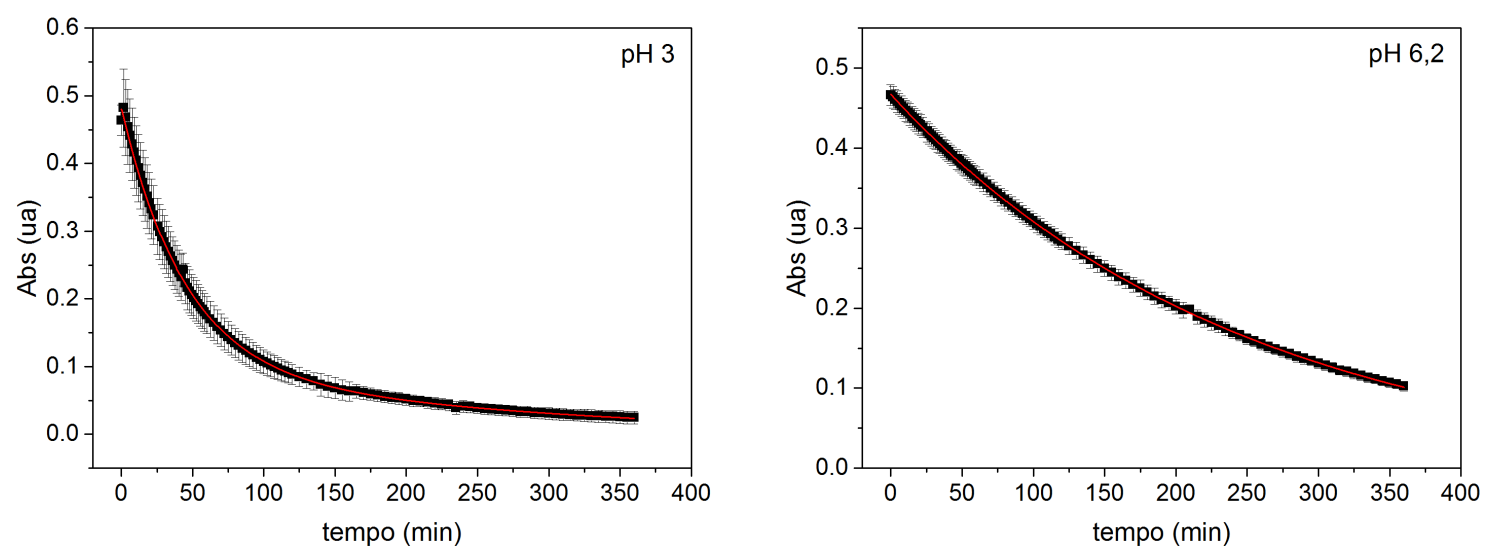

Decaimento de absorção de Bn em função do tempo em tampão fosfato $100 \mathrm{mmol} \mathrm{L}^{-1}$ (A) pH 3 e (B) $\mathrm{pH} 6,2, \mathrm{a} 60^{\circ} \mathrm{C}$.
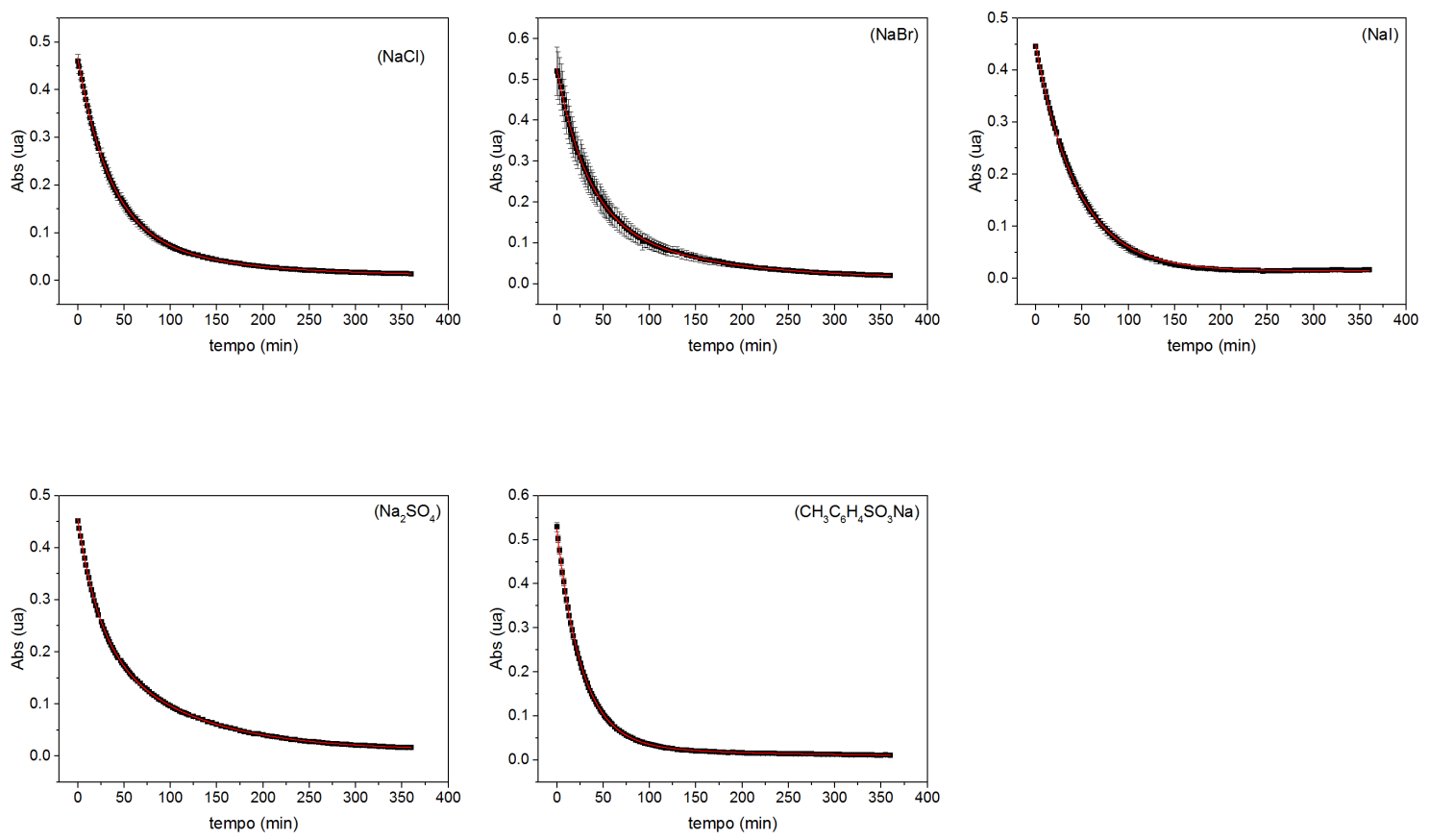

Decaimento de absorção de Bn em função do tempo em tampão fosfato $100 \mathrm{mmol} \mathrm{L}^{-1} \mathrm{pH} 3$, na presença de diferentes sais de sódio, a $60^{\circ} \mathrm{C}$. 

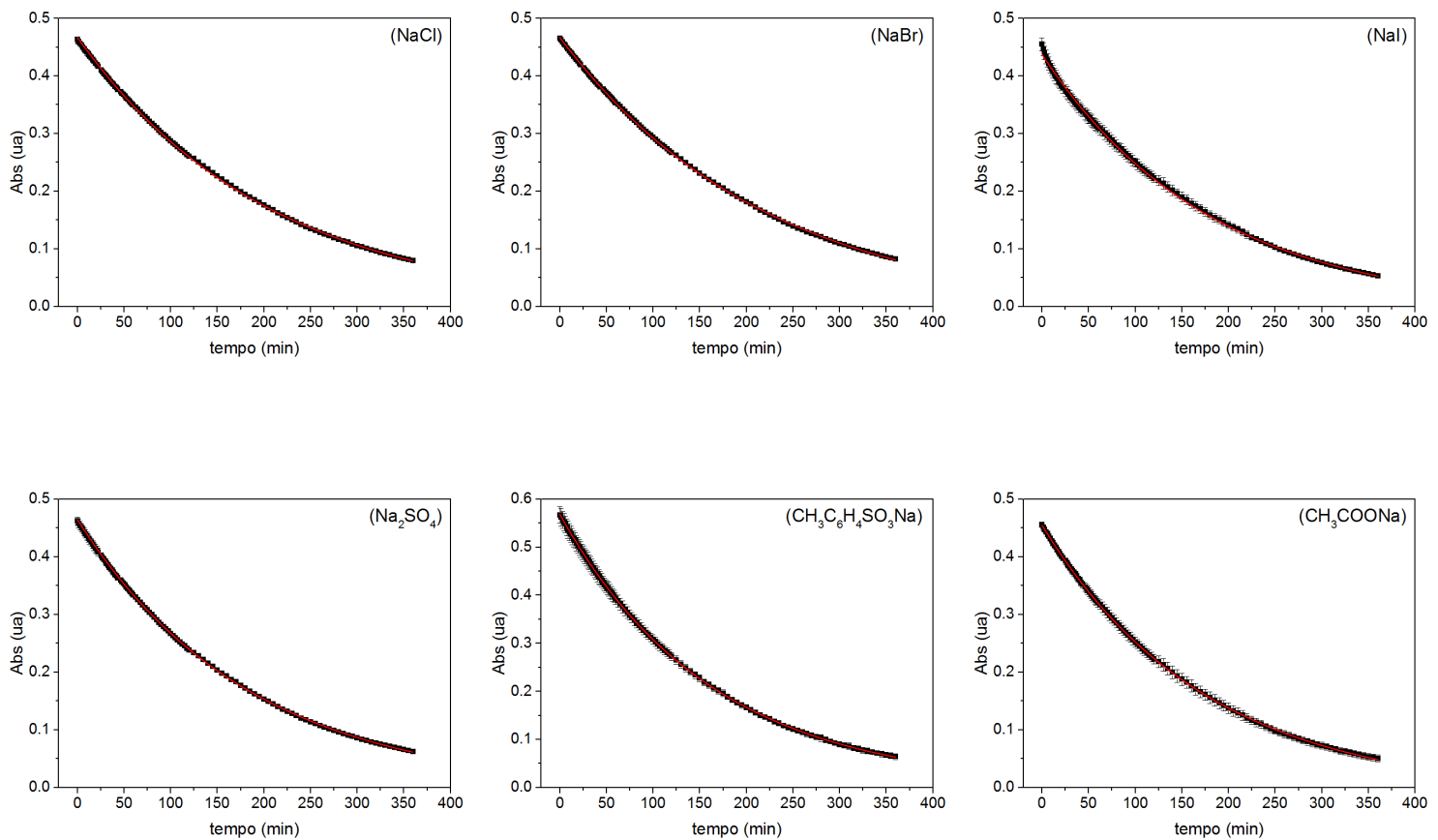

Decaimento de absorção de Bn em função do tempo em tampão fosfato $100 \mathrm{mmol} \mathrm{L}^{-1} \mathrm{pH}=6,2$, na presença de diferentes sais de sódio, $60^{\circ} \mathrm{C}$.
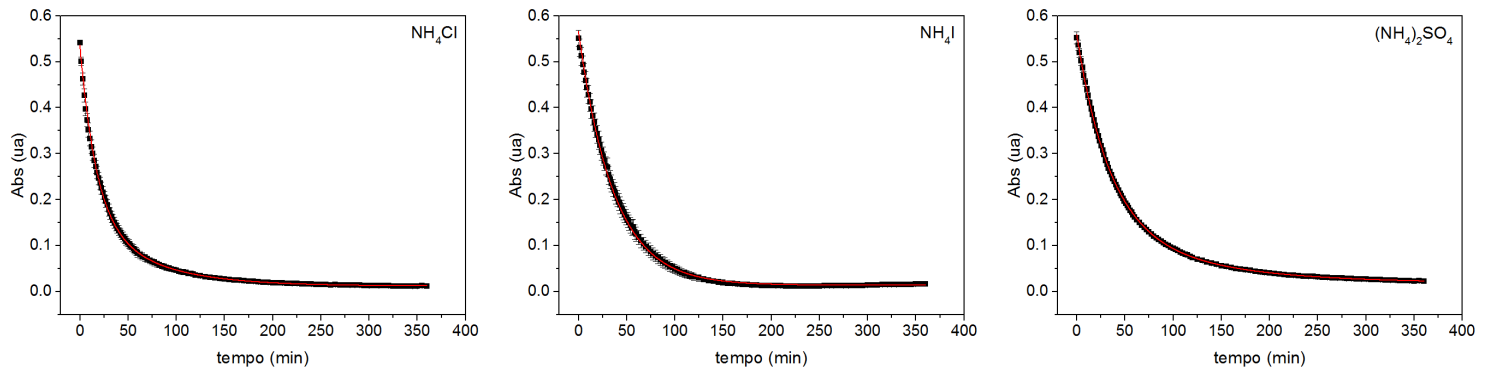

Decaimento de absorção de Bn em função do tempo em tampão fosfato $100 \mathrm{mmol} \mathrm{L} \mathrm{L}^{-1} \mathrm{pH}=3$, na presença de diferentes sais de amônio, a $60^{\circ} \mathrm{C}$. 

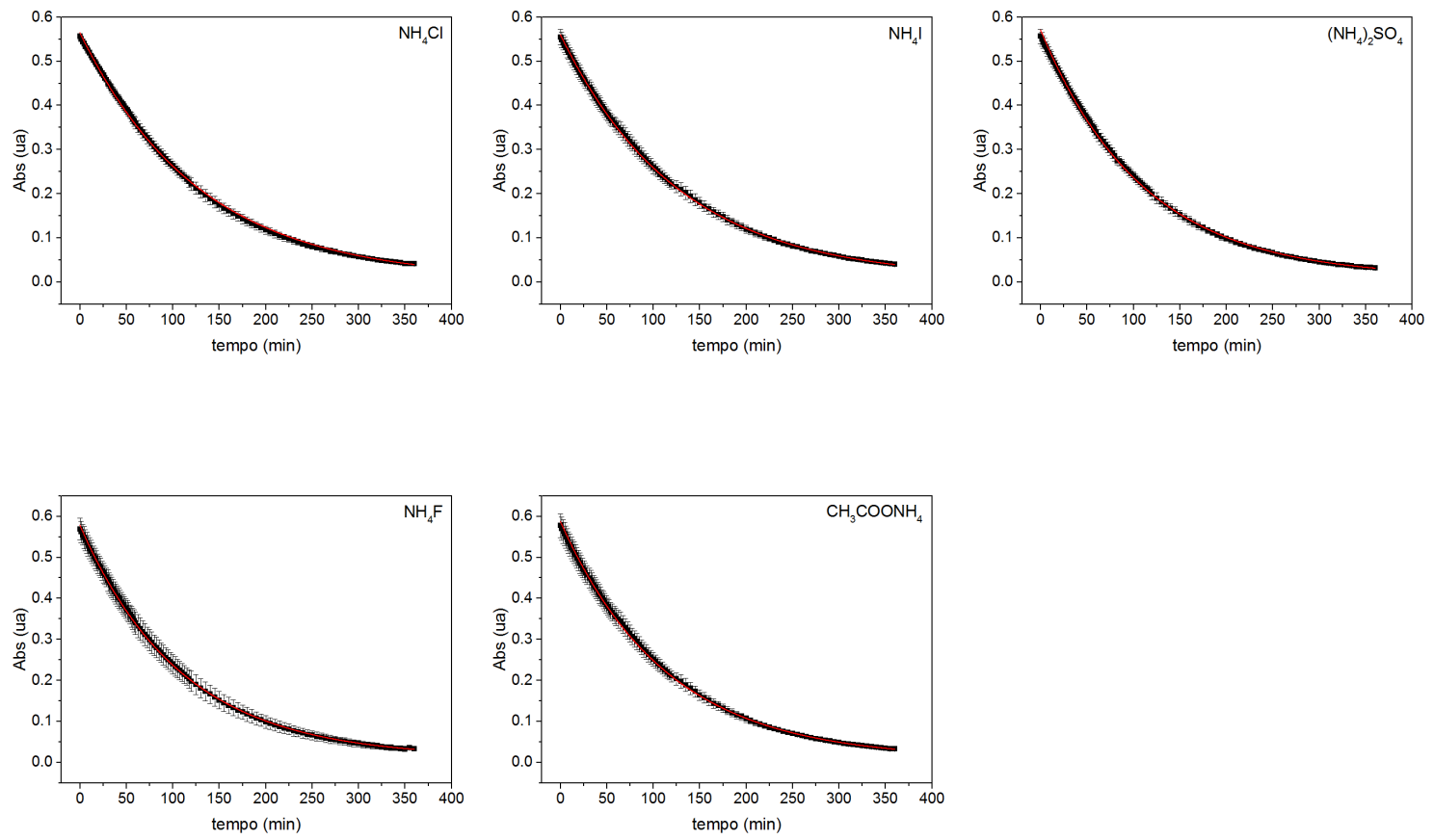

Decaimento de absorção de Bn em função do tempo em tampão fosfato $100 \mathrm{mmol} \mathrm{L}^{-1} \mathrm{pH}=6,2$, na presença de diferentes sais de amônio, a $60^{\circ} \mathrm{C}$.
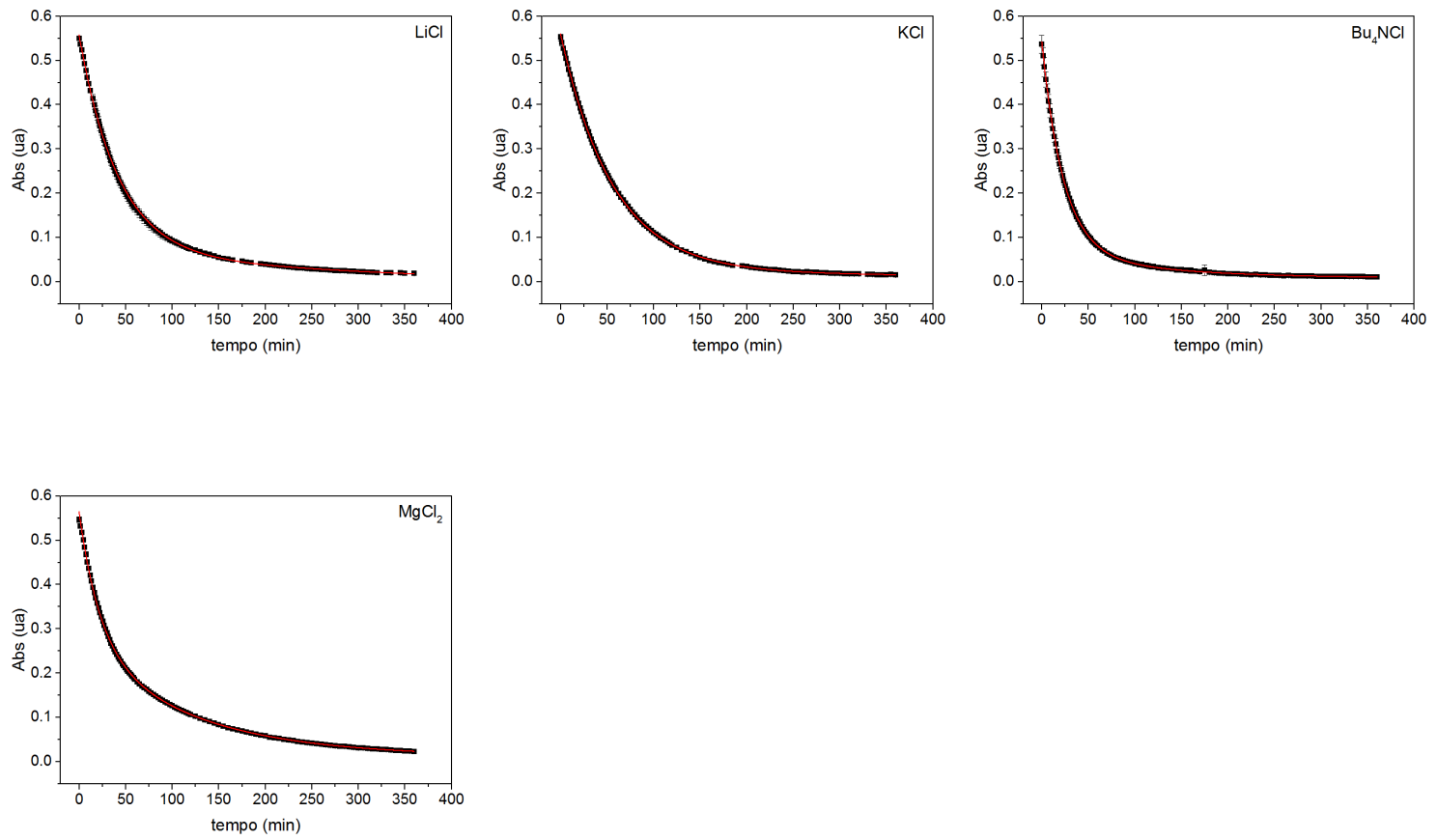

Decaimento de absorção de Bn em função do tempo em tampão fosfato $100 \mathrm{mmol} \mathrm{L}{ }^{-1} \mathrm{pH}=3$, na presença de diferentes sais cloretos, $60^{\circ} \mathrm{C}$. 

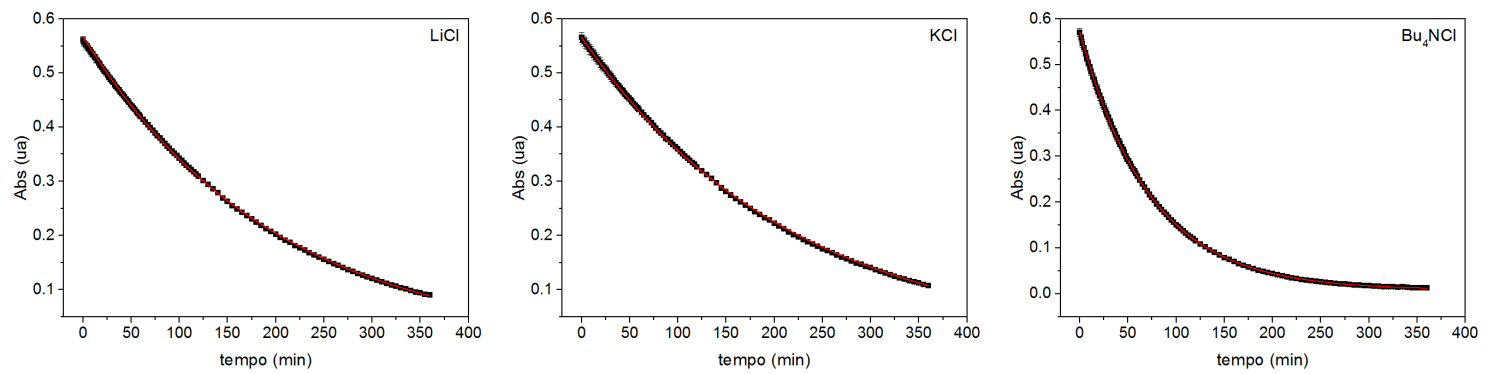

Decaimento de absorção de Bn em função do tempo em tampão fosfato $100 \mathrm{mmol} \mathrm{L}^{-1} \mathrm{pH}=6,2$, na presença de diferentes sais cloretos, a $60{ }^{\circ} \mathrm{C}$. 


\subsection{Curvas cinéticas de hidrólise de $\mathrm{Bn}$ em tampão fosfato $10 \mathrm{mmol} \mathrm{L}^{-1}$,}

em função do $\mathrm{pH}$ e da temperatura
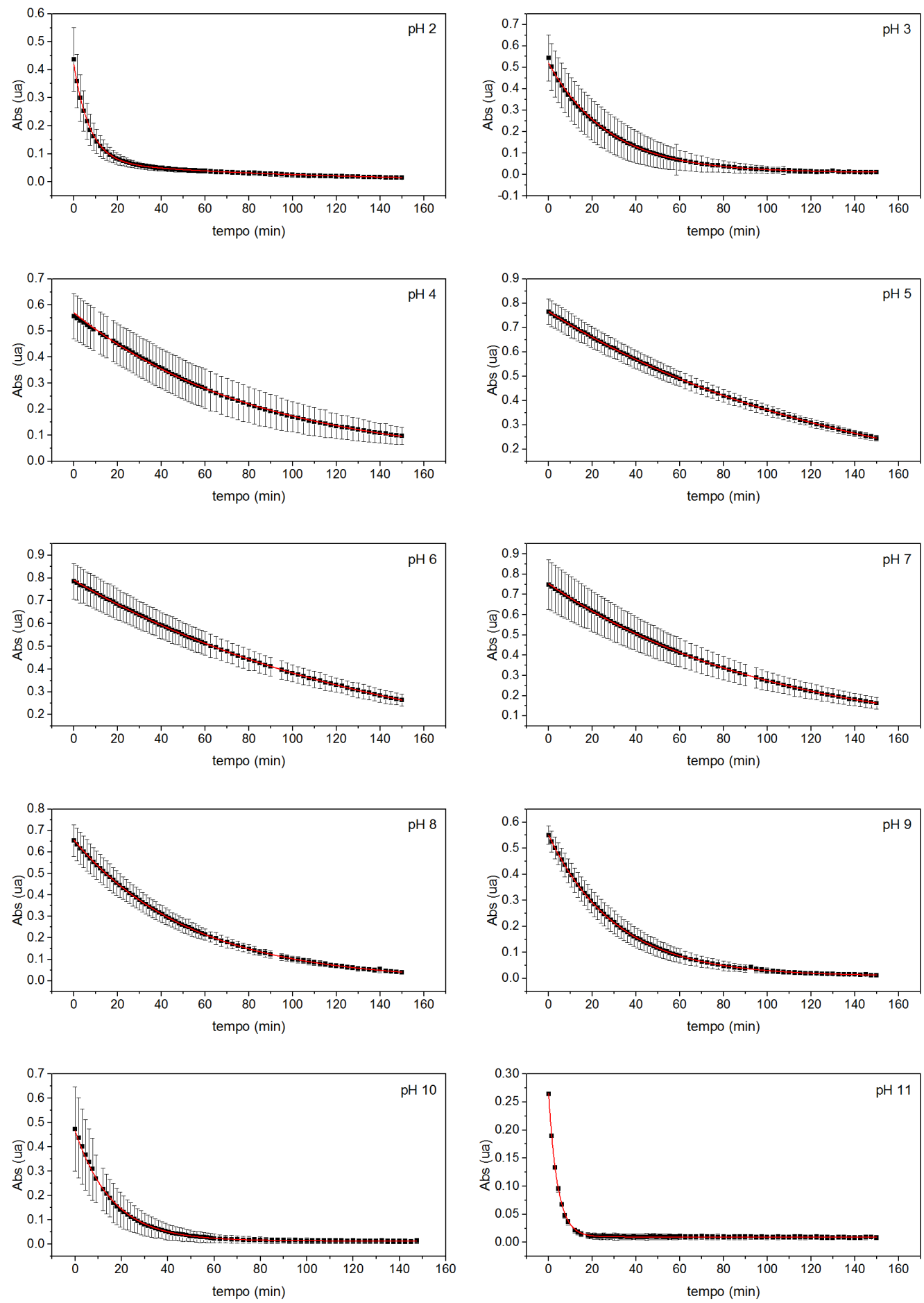

Decaimento de absorção de Bn em função do tempo em tampão fosfato $10 \mathrm{mmol} \mathrm{L}^{-1} \mathrm{em}$ diferentes pHs, a $65^{\circ} \mathrm{C}$. 

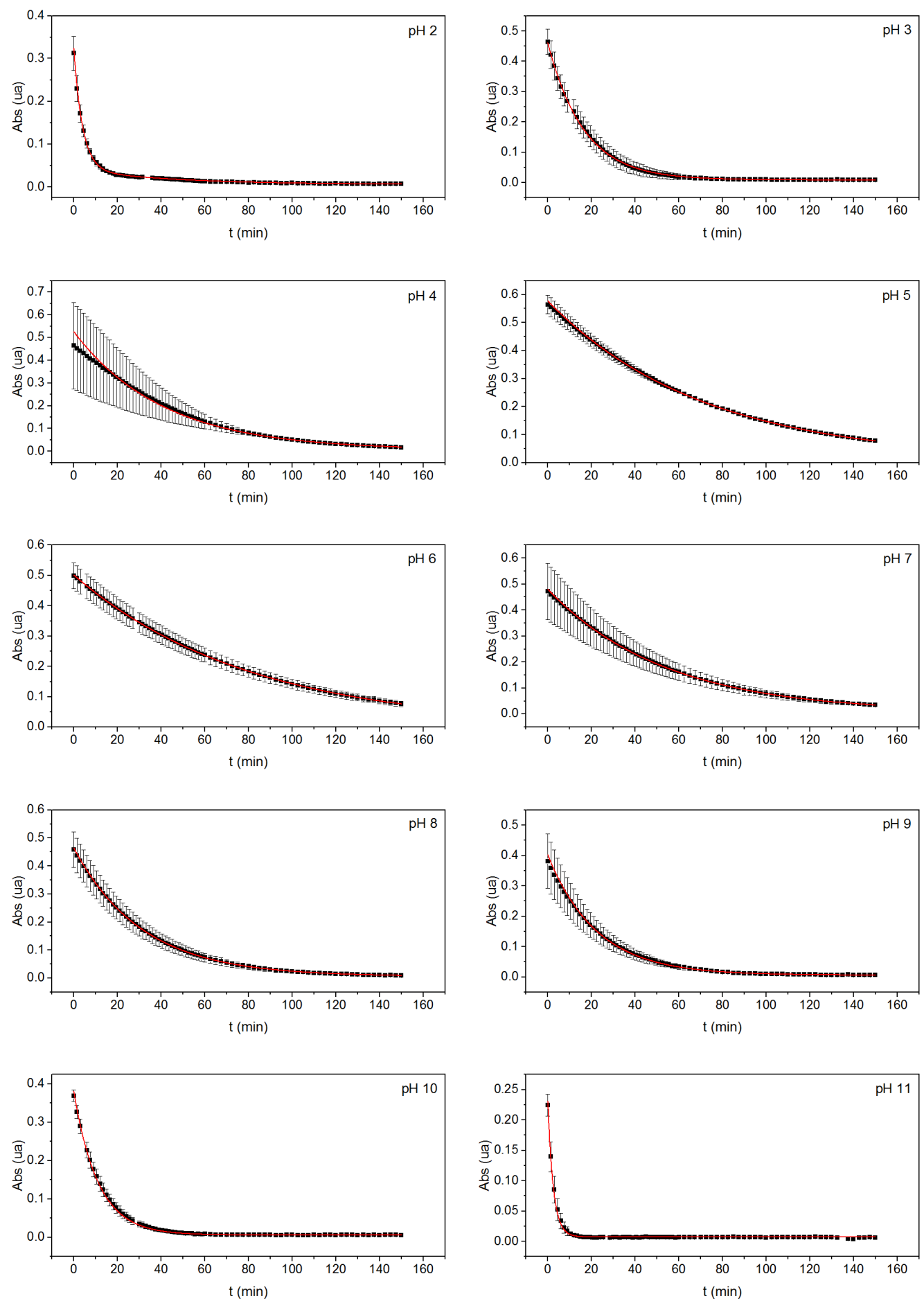

Decaimento de absorção de $\mathrm{Bn}$ em função do tempo em tampão fosfato $10 \mathrm{mmol} \mathrm{L}^{-1} \mathrm{em}$ diferentes pHs, a $70{ }^{\circ} \mathrm{C}$. 

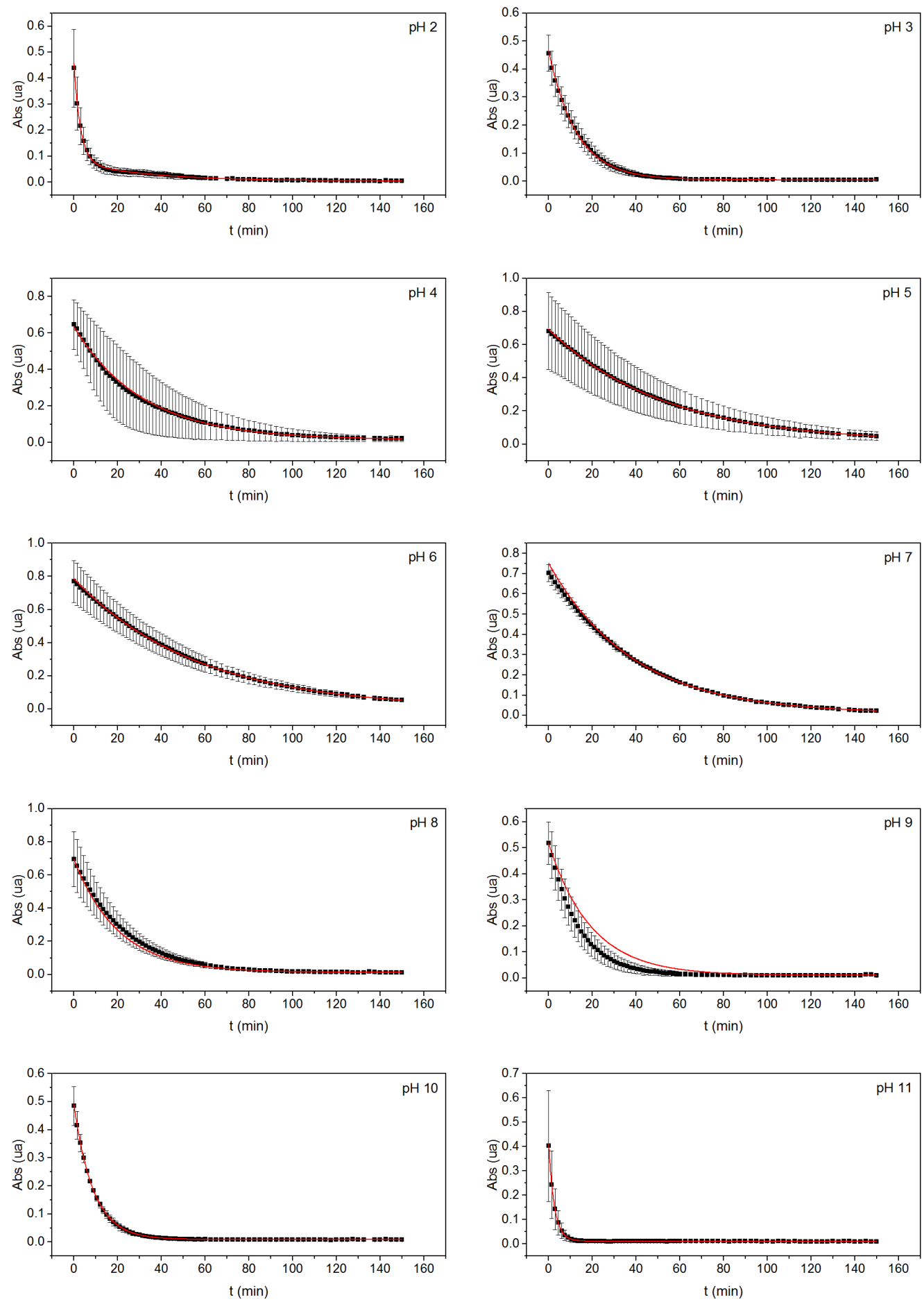

Decaimento de absorção de Bn em função do tempo em tampão fosfato $10 \mathrm{mmol} \mathrm{L}^{-1} \mathrm{em}$ diferentes pHs, a $75^{\circ} \mathrm{C}$. 

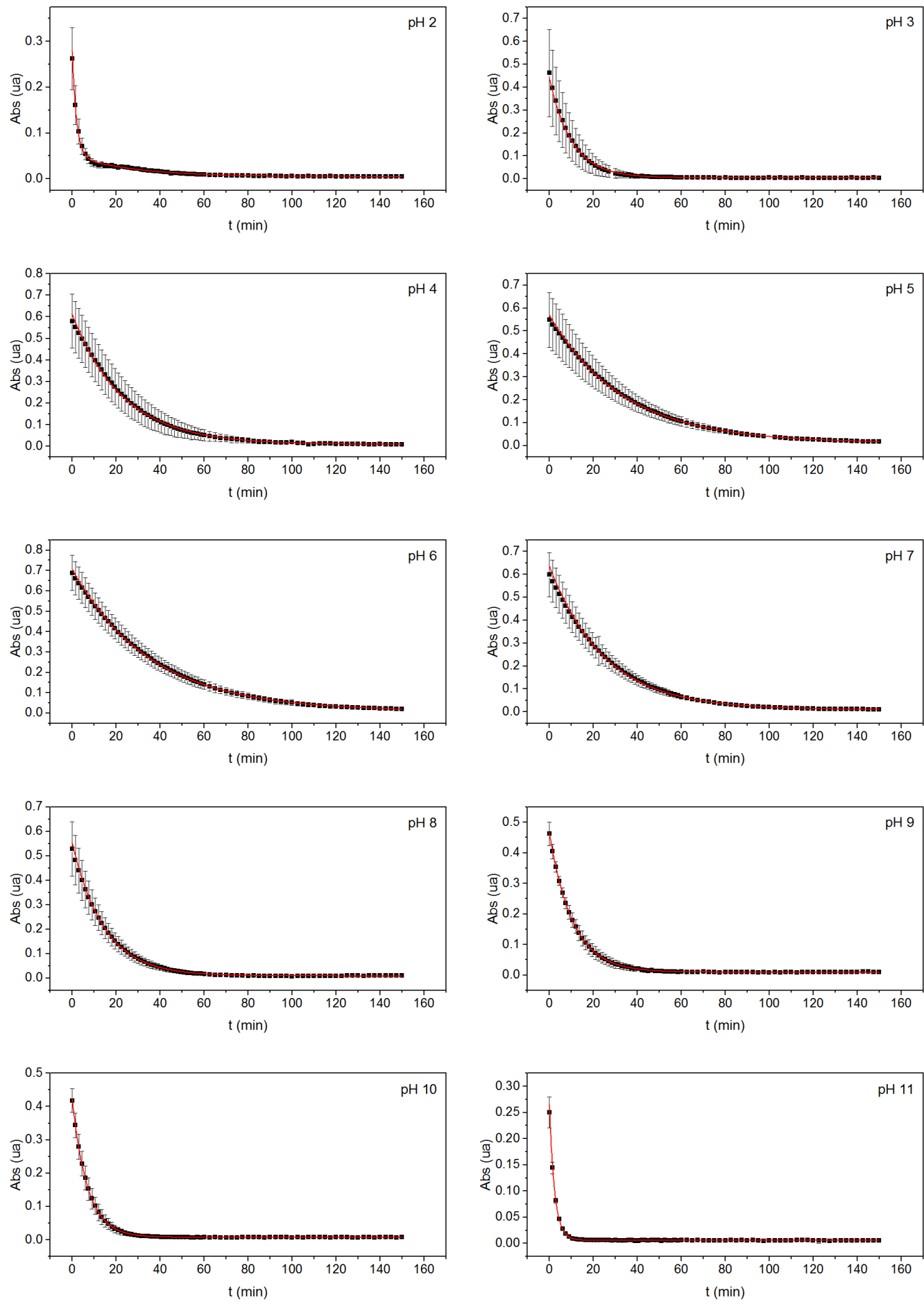

Decaimento de absorção de $\mathrm{Bn}$ em função do tempo em tampão fosfato $10 \mathrm{mmol} \mathrm{L}^{-1} \mathrm{em}$ diferentes pHs, a $80^{\circ} \mathrm{C}$. 

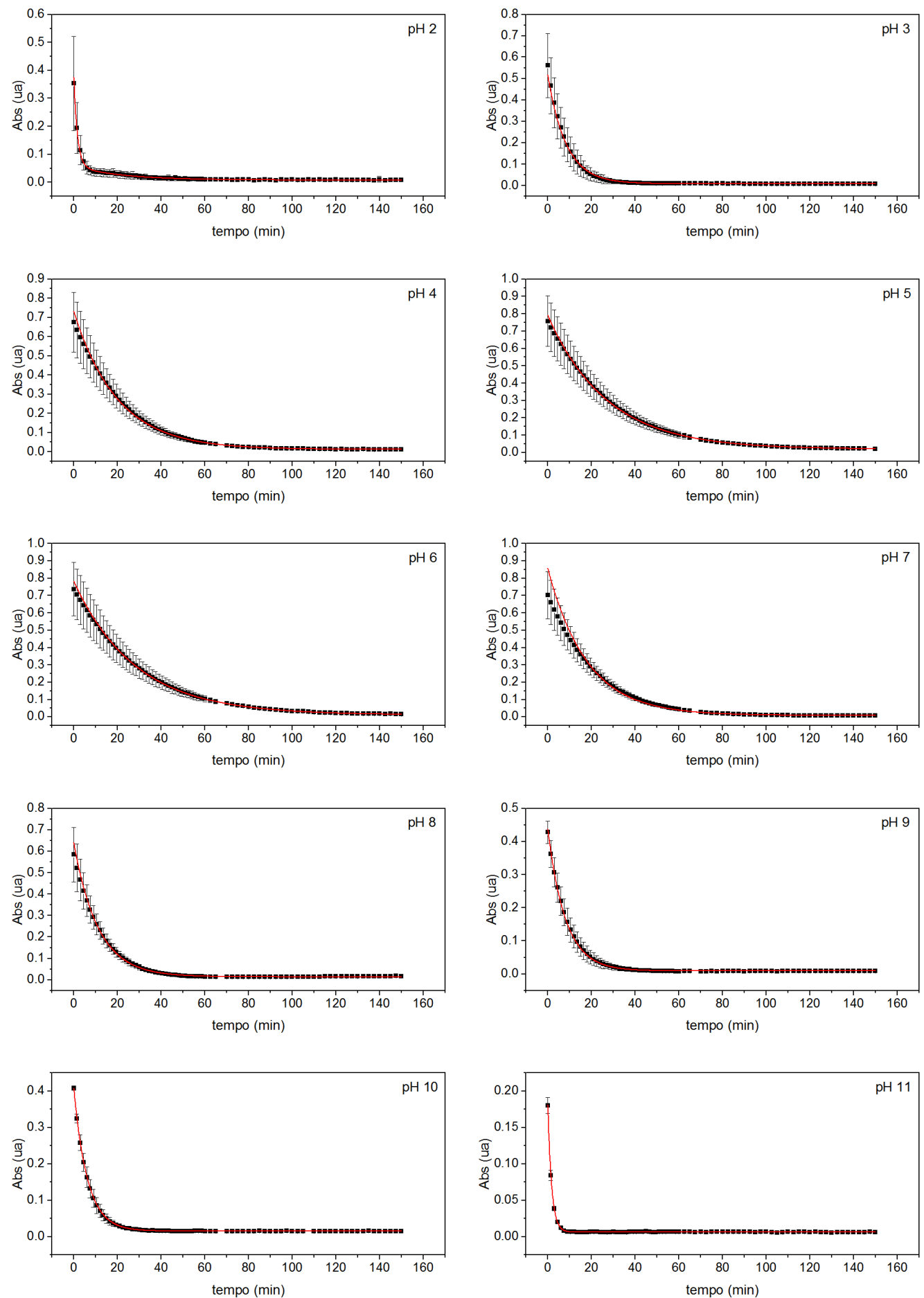

Decaimento de absorção de Bn em função do tempo em tampão fosfato $10 \mathrm{mmol} \mathrm{L}^{-1} \mathrm{em}$ diferentes pHs, a $85^{\circ} \mathrm{C}$. 


\subsection{Gráficos de Arrhenius}
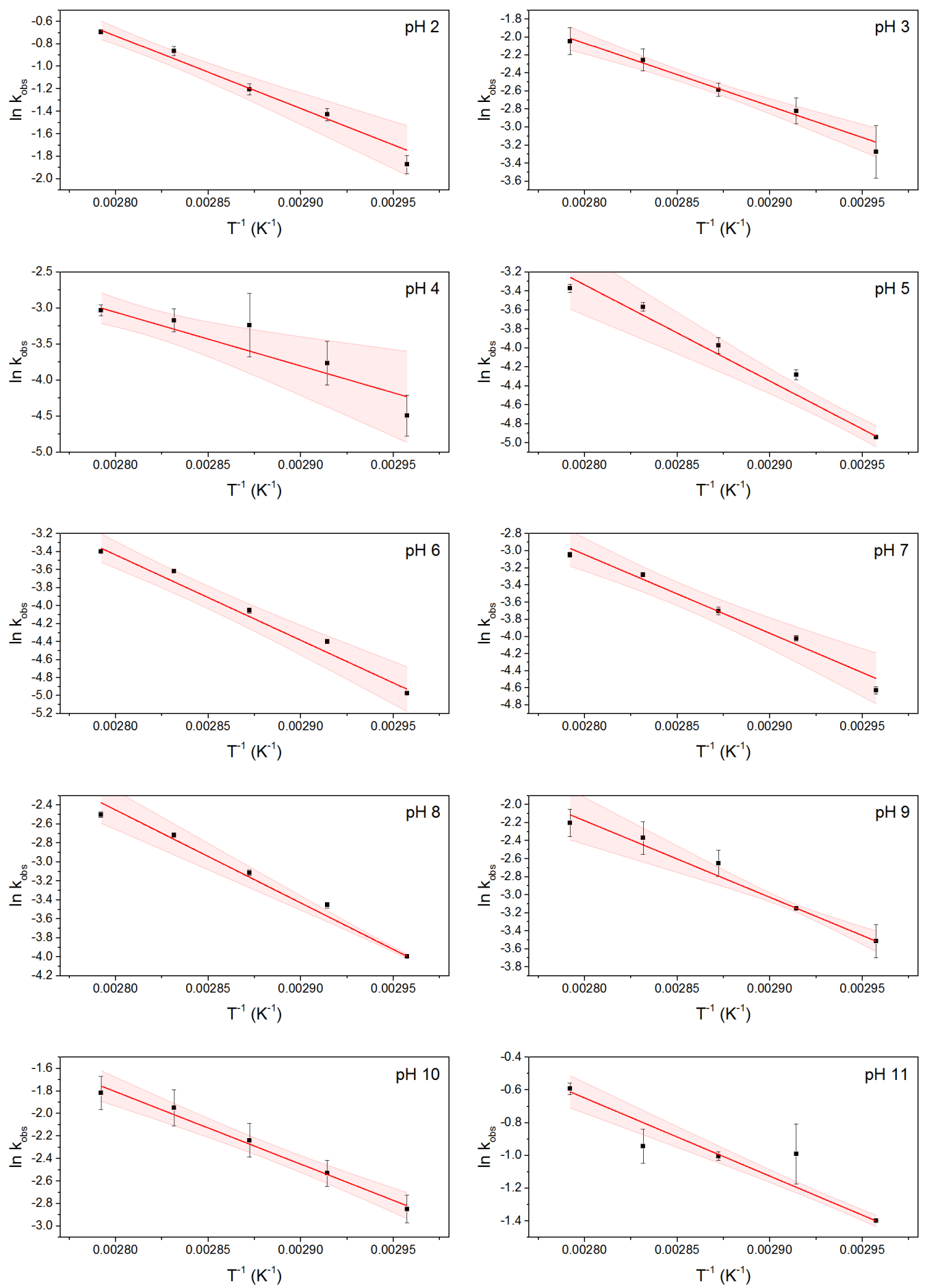

Gráficos de $\ln k_{\mathrm{obs}}$ em função de $\mathrm{T}^{-1}$. $k_{\mathrm{obs}}$ é a constante cinética observada de hidrólise de Bn em tampão fosfato $10 \mathrm{mmol} \mathrm{L}^{-1}$, obtida pelo ajuste exponencial dos dados de decaimento da banda da Bn. 
Coeficiente angular da regressão linear $(\alpha)$, coeficiente linear $(\beta)$ e coeficiente de determinação ajustado (Adj-R ${ }^{2}$ ) das curvas. pH $2\left(\alpha=-6471 ; \beta=17\right.$; Adj- $\left.\mathrm{R}^{2}=0,98\right)$, $\mathrm{pH} 3(\alpha=-6992 ; \beta=17$; Adj- $\left.\mathrm{R}^{2}=0,98\right), \mathrm{pH} 4\left(\alpha=-7454 ; \beta=18 ;\right.$ Adj- $\left.\mathrm{R}^{2}=0,88\right), \mathrm{pH} 5\left(\alpha=-10148 ; \beta=25 ;\right.$ Adj- $\mathrm{R}^{2}=$ 0,98), pH $6\left(\alpha=-9487 ; \beta=23\right.$; Adj- $\left.\mathrm{R}^{2}=0,98\right), \mathrm{pH} 7\left(\alpha=-9181 ; \beta=23\right.$; Adj- $\left.\mathrm{R}^{2}=0,97\right)$, pH 8 $\left(\alpha=-9810 ; \beta=25 ;\right.$ Adj- $\left.\mathrm{R}^{2}=0,99\right)$, pH $9\left(\alpha=-8498 ; \beta=22 ;\right.$ Adj- $\left.\mathrm{R}^{2}=0,97\right), \mathrm{pH} 10(\alpha=-6433$; $\beta=16 ;$ Adj- $\left.\mathrm{R}^{2}=0,98\right)$, pH $11\left(\alpha=-4773 ; \beta=13 ; \operatorname{Adj}-\mathrm{R}^{2}=0,99\right)$. 
8.6. Curvas cinéticas de hidrólise de BtP em tampão fosfato $10 \mathrm{mmol} \mathrm{L}^{-1}$, em função do $\mathrm{pH}$
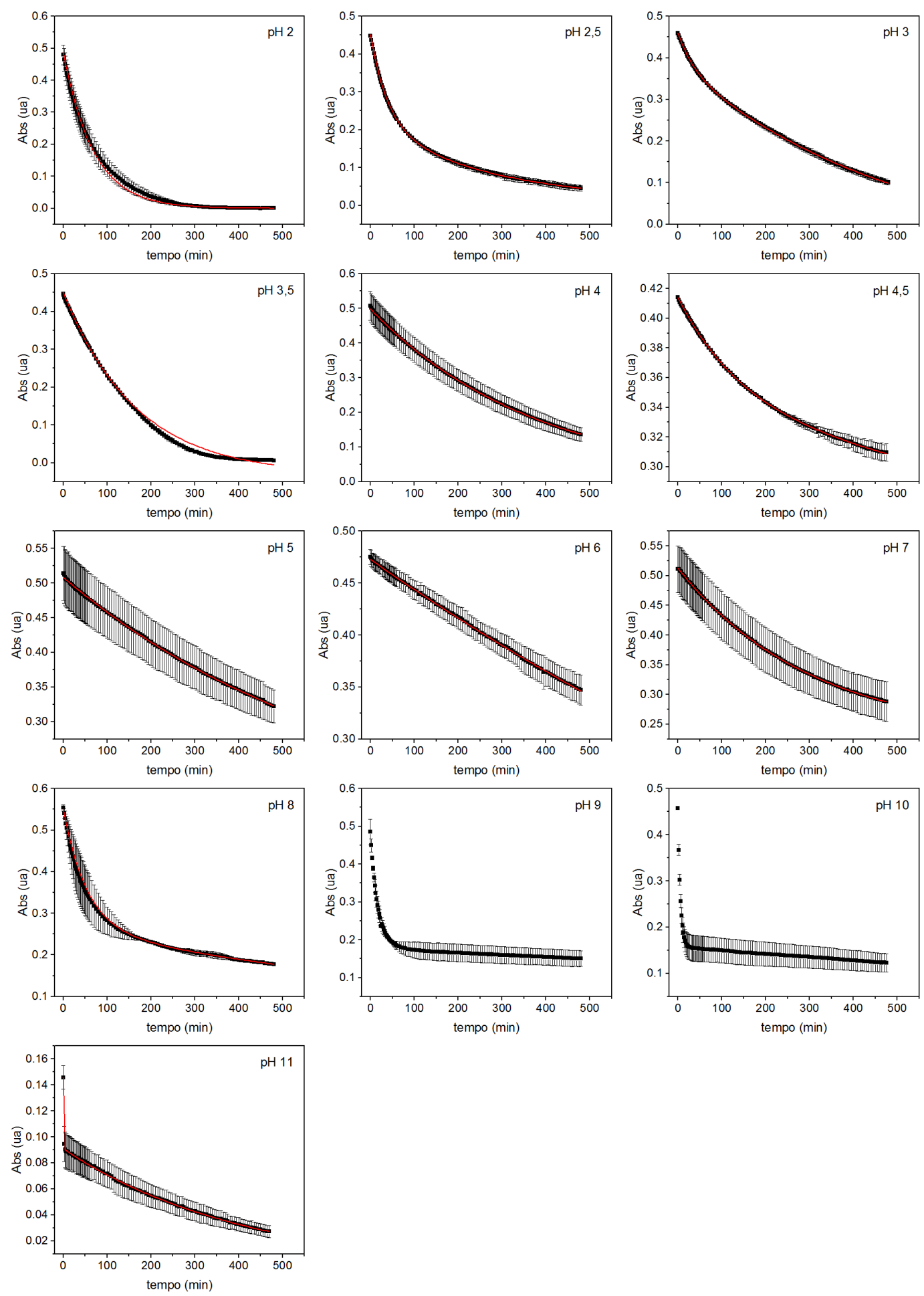

Decaimento de absorção de BtP em função do tempo em tampão fosfato $10 \mathrm{mmol} \mathrm{L}^{-1} \mathrm{em}$ diferentes pHs, a $60^{\circ} \mathrm{C}$. 